\title{
Pobreza monetaria. Crecimiento y redistribución
}

\author{
Monetary Poverty. \\ Growth and Redistribution
}

Alejandra Uribe*

Werner L. Hernani-Limarino**

\section{Resumen:}

El trabajo documenta y explica la evolución de la pobreza monetaria en Bolivia durante el periodo 1999-2011. En primer lugar, hemos encontrado una significativa reducción en ambos tipos de pobreza, extrema y moderada. Durante el periodo de análisis, la incidencia, la brecha y la severidad de la pobreza extrema se han reducido en 55, 67 y 73\%, respectivamente; mientras que la incidencia, la brecha y la severidad de la pobreza moderada se han reducido en 32,50 y 60\%, también respectivamente. La velocidad de la reducción de la pobreza fue mayor en la pobreza extrema que en la pobreza moderada, con diferencias significativas según las medidas de pobreza, áreas y periodos de tiempo. Por un lado, la tasa media de reducción en incidencia en pobreza extrema para el área urbana fue 10.4\% por año en el periodo 2005-2011 y $3.5 \%$ por año en el periodo 1999-2005; mientras que en el área rural fue $7.2 \%$ por año en el periodo $2005-2011$ y 3.9\% por año en el periodo 1999-2005. Por otro lado, la tasa media de reducción en incidencia en pobreza moderada para el área urbana fue de 3.7\% por año en el periodo 2005-2011 y 1.9\% por año en el periodo 1999-2005; mientras en el área rural fue $4.4 \%$ por año en el periodo $2005-2011$ y 2.4\% por año en el periodo 1999-2005.

En segundo lugar, hemos encontrado que el crecimiento y la redistribución del ingreso per cápita de los hogares han jugado roles diferentes en la reducción de la pobreza, por área y periodo de tiempo. Por un lado, cambios en la pobreza en el área urbana durante el periodo

* Fundación ARU. Contacto: auribe@aru.org.bo

** Fundación ARU. Contacto: whl@aru.org.bo 
1999-2005 son mayormente explicados por el crecimiento en el ingreso per cápita, el cual fue suficiente para compensar el aumento de la desigualdad de ingresos; mientras que cambios en la pobreza durante el periodo 2005-2011 fueron resultado de ambos, crecimiento y redistribución del ingreso per cápita. Por otro lado, reducciones de pobreza en el área rural son explicados mayormente por un sostenido crecimiento del ingreso per cápita de los hogares, más intensamente durante el último que durante el primer periodo.

Palabras clave: Pobreza, crecimiento, redistribución.

\section{Abstract:}

This paper documents and explains the evolution of monetary poverty in Bolivia during the period 1999-2011. First, we find a significant reduction in both, extreme and moderate, poverty. During the period under analysis, extreme poverty headcount, gap and severity have reduced in 55,67 and 73\%; while moderate poverty headcount, gap and severity have reduced in 32,50 and $60 \%$, respectively. The speed of poverty reduction was greater in extreme poverty than in moderate poverty, with significant differences by poverty measures, areas, and time periods. On the one hand, the average reduction rate in extreme poverty headcount in urban areas was $10.4 \%$ per year in the 2005-2011 period and 3.5\% per year in the $1999-2005$ period; while in rural areas was $7.2 \%$ per year in the 2005 - 2011 period and $3.9 \%$ per year in the 1999 2005 period. On the other hand, the average reduction rate in moderate poverty headcount in urban areas was $3.7 \%$ per year in the 2005-2011 period and $1.9 \%$ per year in the $1999-2005$ period; while in rural areas was $4.4 \%$ per year in the $2005-2011$ period and $2.4 \%$ per year in the 1999-2005 period.

Second, we find that growth of and redistribution in per capita household income have played different roles in poverty reductions by are and time period. On the one hand, poverty changes in urban areas during the 1999-2005 period are mainly explained by the growth in per capita income -which was enough to compensate for the increase on income inequality; while poverty changes during the 2005-2011 period was the result of both, growth in and redistribution of per capita income. On the other hand, poverty reductions in rural areas are mainly explained by the sustained growth of per capita household income, more intense during the last than during the first period.

Keywords: Poverty, growth, redistribution 


\section{Introducción}

En septiembre de 2000, 189 Estados miembros delas Naciones Unidas (Bolivia entre ellos) acordaron conseguir para el 2015 ocho objetivos que lograrían mejorar las condiciones de vida de las personas más vulnerables y empobrecidas. De los ocho objetivos de desarrollo del milenio, el primero es el más importante para este estudio, pues establece erradicar la pobreza extrema y el hambre. Sin embargo, la reducción de la pobreza también es una preocupación del Estado, pues forma parte de la Constitución Política del Estado Plurinacional de Bolivia ${ }^{1}$, así como de dos decretos supremos ${ }^{2}$. Éstas son razones de sobra para impulsar un estudio sobre la evolución de la pobreza; este estudio puede ser interpretado como una forma de monitoreo, un análisis acerca de la tendencia de la pobreza, que permite además observar si Bolivia se encuentra en camino de llegar al objetivo o si cada vez se aleja más de él.

Surge entonces la primera pregunta relevante: ¿cómo fue la evolución de la pobreza en Bolivia desde el 2000? Es posible responder a esta pregunta haciendo uso de la serie armonizada de encuestas de hogares de la Fundación ARU y las líneas de pobreza desarrolladas por Mena, Jiménez y Hernani (2013). En este aspecto los resultados son alentadores. Partiendo de 1999 y durante los 13 años siguientes, las medidas de pobreza e indigencia presentaron una tendencia decreciente; la pobreza extrema liderizó este cambio, pues cayó a más de la mitad de su valor inicial (de 47.3 a $21.2 \%$ ).

Profundizando más en el análisis y realizando una separación por áreas, se encontró que el área rural tuvo una caída más grande que el área urbana; la pobreza moderada de la primera va de 89.6 a 59.1\%, y la pobreza extrema va de 76.7 a $38.5 \%$, mientras que la segunda va de 60.1 a $42.7 \%$, y de 30 a $12.6 \%$, respectivamente.

En base a las anteriores observaciones surgen nuevas preguntas importantes: ifue constante la tendencia decreciente durante todo el periodo estudiado?, ¿cómo se explican estos cambios en la pobreza?

1 Constitución Política del Estado, 2009, Artículo 316, numeral 7. Tiene como parte de las funciones del Estado en la economía, erradicar la pobreza en sus múltiples dimensiones.

2 Decreto Supremo $N^{\circ} 29246$, de 22 de agosto de 2007, que tiene como objetivo de política de protección social y desarrollo integral comunitario contribuir a erradicar las causas estructurales de la pobreza y extrema pobreza. Por su parte, el Decreto Supremo $N^{\circ}$ 29272, de 12 de septiembre de 2007, establece como uno de los lineamientos estratégicos del Plan Nacional de Desarrollo promover el desarrollo integral a través de la construcción de un nuevo patrón de desarrollo diversificado e integrado y la erradicación de la pobreza, desigualdad social y exclusión. 
Dividiendo el periodo en dos, el primero de siete años partiendo de 1999, y el segundo que también comprende siete años empezando el 2005, se muestra que los datos tomaron rumbos distintos en cada periodo. Durante el primer periodo la pobreza extrema nacional se reduce en $21.6 \%$, mientras que durante el segundo periodo lo hace al doble (42.8\%), situación que se refleja para el resto de las medidas.

Antes de responder la última pregunta se debe tomar en cuenta que los cambios en la pobreza son por un cambio en el crecimiento del ingreso y/o un cambio en la distribución del ingreso. En Bolivia no es posible definir a uno de los componentes como principal actor en la reducción de la pobreza, pues cambian de acuerdo al área y al periodo. Para el área urbana, durante el primer periodo los cambios en pobreza se explicaron por una redistribución del ingreso. Este escenario no se refleja en el segundo periodo, en el que fue el crecimiento del ingreso el componente que predominó. Por otro lado, el área rural presentó una realidad distinta a la urbana; tanto para el primer como para el segundo periodo, los cambios son explicados por el crecimiento del ingreso, dejando de lado a la redistribución.

El documento sigue la siguiente estructura. La sección 2 describe los datos, la sección 3 desarrolla la evolución de la pobreza, la sección 4 presenta las medidas de robustezy la sección 5 hace un análisis de la descomposición de la pobreza. Finalmente, la sección 6 presenta las conclusiones, y para concluir se despliegan los anexos.

\section{Datos}

Los resultados presentados en este documento están basados en dos fuentes de datos: la serie armonizada de encuestas de hogares 1999-2011 y la línea de pobreza desarrollada por Mena, Jiménez y Hernani(2013).

La serie armonizada de encuestas de hogares de la Fundación ARU incluye encuestas realizadas a nivel nacional, para el área urbana y rural. Al inicio del proceso las encuestas eran libres de procesos de imputación, es decir, no fueron trabajadas por ninguna institución con anterioridad. A partir de ello, se aplicaron procesos modernos y homogéneos de limpieza. A continuación, definiciones similares fueron usadas para la construcción de variables e indicadores, lo que permite la comparación de las mismas a través del tiempo.

La variable usada para la elaboración de las medidas es la distribución del ingreso del hogar per cápita, la cual sigue la siguiente estructura (Mena y Hernani, 2013): 


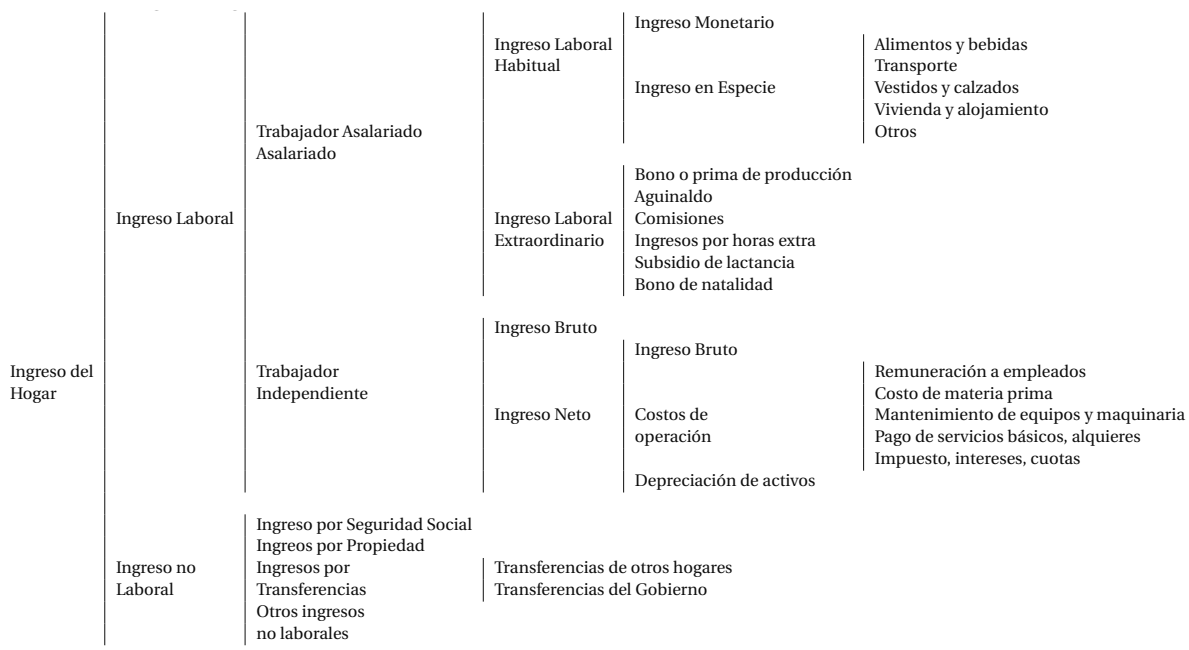

Finalmente, la base utilizada pasa por un último proceso de limpieza en el que se eliminan ceros y outliers. Este proceso de limpieza se encuentra de forma detallada en Eid, Aguirre y Hernani-Limarino (2013).

\section{Pobreza en Bolivia, análisis de su evolución}

Empezamos el análisis de la evolución de la pobreza desarrollando la incidencia de la pobreza, pues da un panorama general del fenómeno de la pobreza. Esta medida hace simplemente un recuento de los hogares que quedan por debajo de la línea de pobreza, es decir, la proporción de la población pobre. 
Figura 1: Incidencia de la pobreza en Bolivia, 1999-201 1

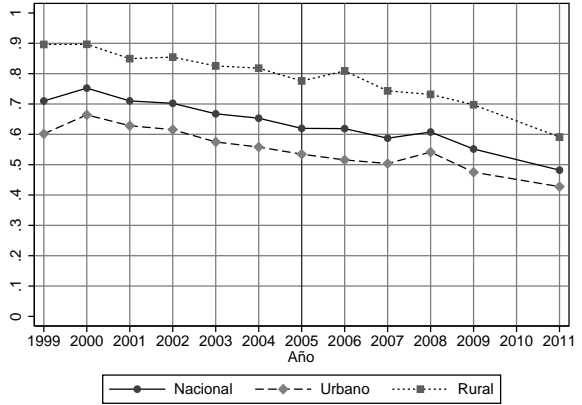

Pobreza Moderada

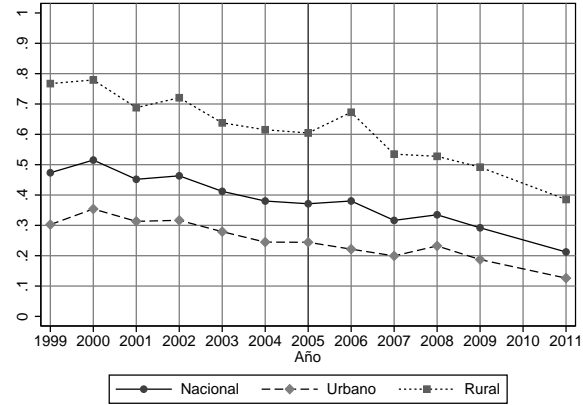

Pobreza Extrema

\begin{abstract}
Fuente: Estimación del autor basada en la serie armonizada de la Fundación ARU de las encuestas de hogares. Ceros y outliers fueron eliminados de la muestra. Los outliers fueron encontrados a través del algoritmo BACON con $\alpha=0.0001$. El ingreso per cápita del hogar es igual al total del ingreso del hogar dividido entre los miembros del mismo. El total del ingreso del hogar es la suma del ingreso por seguridad social y laboral, transferencias del gobierno e inter-hogares, rentas por propiedad y otras fuentes. La incidencia de la pobreza tiene la siguiente fórmula: $P_{0}=\frac{1}{N} \int_{i=0}^{q} d y$ donde $N$ es la cantidad total de hogares, $q$ es la cantidad de hogares pobres y y es el ingreso del hogar.
\end{abstract}

La figura 1 responde a la primera pregunta, formulada en la introducción, y refleja la incidencia de la pobreza en Bolivia para el periodo 1999-2011.

A simple vista se obtiene la primera observación sobre el comportamiento de la evolución de la pobreza. La incidencia de la pobreza es decreciente durante el periodo estudiado. De manera específica se tiene que, para el año 1999, del total de hogares, el $71 \%$ eran considerados pobres, de los cuales el $47.3 \%$ se encontraban en situación de indigencia y el $23.7 \%$ eran pobres no indigentes. Una realidad por demás preocupante, pero la pobreza ha pasado por grandes cambios desde entonces: para el año 2011 la situación mejoró notablemente, ya que, del total de hogares, solamente el $48.1 \%$ fueron considerados pobres, de los cuales el $21.2 \%$ fueron considerados como indigentes y el $26.9 \%$ serían hogares pobres no indigentes, es decir, una caída del 32\% de la pobreza moderada y $55.1 \%$ de la pobreza extrema. La caída de la incidencia de la pobreza es completamente alentadora. Sin embargo, aunque este resultado final es una mejora considerable, no deja de ser preocupante que cerca del 50\% de la población boliviana sea pobre al final del periodo.

Realizando el mismo análisis por áreas, se observa que existe una diferencia en la tendencia del área urbana y la del área rural. Esta diferencia es en magnitud, pues ambas siguen una tendencia decreciente, aunque el área rural presenta una caída más pronunciada que el área 
urbana. Como muestra de eso, la pobreza moderada cae en el área urbana de 60.1 a 42.7\% (una reducción de 17.3 puntos) y en el área rural de 89.6 a 59.1\% (una caída de 30.5 puntos). Tomando en cuenta la pobreza extrema, el área urbana cae de 30.2 a 12.6\% (es decir, 17.6 puntos), mientras en el área rural cae de 76.7 a 38.5\% (reducción de 38.1 puntos).

Contestando a la segunda pregunta propuesta, es posible dividir el periodo en dos, el primero anterior a 2005 y el segundo desde 2005, pues la incidencia muestra magnitudes distintas para cada periodo.

A nivel nacional, para el primer periodo, la pobreza baja $12.7 \%$ y la incidencia cae $21.6 \%$, resultados de por sí alentadores, pero para el segundo periodo la pobreza cae 22.2\% (10\% más que en el primer periodo) y la incidencia cae $42.8 \%$, aproximadamente el doble respecto del primer periodo. Añadiendo nuevamente el análisis por área, la diferencia entre área urbana y rural se hace más notable; mientras que la pobreza moderada en el área urbana se reduce en 5.8 puntos para el primer periodo, y en el área rural cae 16.2 puntos, para el segundo periodo caen 11.8 y 21.9 puntos, respectivamente. Analizando la pobreza extrema, en el área urbana cae 6.7 puntos y en el área rural, 12 puntos. Finalmente, durante el segundo periodo la incidencia cae 10.6 y 18.4 puntos en las áreas urbana y rural, respectivamente. Esto establece la predominancia de los cambios que tiene el segundo periodo sobre el primero y el área rural sobre el área urbana.

Para terminar el análisis de la incidencia de la pobreza, se observan las irregularidades de la evolución. Estas irregularidades se presentan en dos años, la primera durante 2006, cuando la pobreza en el área rural rompe con la tendencia de la serie y presenta un nivel superior al anterior (la pobreza sube 3 puntos y la indigencia sube 7 puntos); la segunda irregularidad es en 2008, cuando nuevamente la incidencia de la pobreza presenta un salto de 4 puntos de indigencia y pobreza (pero este cambio es en el área urbana).

Sin embargo, el vacío que deja el analizar solamente la incidencia de la pobreza ha sido ampliamente criticado en la literatura sobre el tema. Para cubrir esta falta, se han desarrollado otras medidas de pobreza, de entre las cuales la familia de medidas de Foster, Greer y Thorbecke (1984), (FGT), de índices de pobreza, es de gran interés y fácil aplicabilidad, lo cual se demuestra a través de su frecuente uso. Estos índices identifican varias características de los pobres. La familia FGT permite ver además de la incidencia de la pobreza, la brecha de pobreza y la severidad de la pobreza; medidas que sirven para dar un panorama más amplio 
de la evolución de la pobreza. Estas medidas son una función del ingreso per cápita, el ingreso promedio y la línea de pobreza.

Un primer paso hacia el entendimiento de la pobreza consiste en comprender la diferencia entre las medidas de pobreza, las cuales, en lugar de ser sustitutivas, son complementarias, ya que cada una de ellas muestra una característica distinta de la pobreza.

\subsection{Familia de medidas FGT}

Para el estudio de las medidas de pobreza se hace uso de la familia de medidas desarrolladas por Foster, Greer y Thorbecke (1984).

$$
P_{\alpha}=\frac{1}{N} \int_{i=0}^{q}\left(\frac{z-y_{i}}{Z}\right)^{\alpha} d y
$$

Donde $\mathrm{N}$ es el número total de hogares; z, la línea de pobreza; y yi, el ingreso del hogar i. El parámetro que varía es $\alpha$, y determina la medida que se evalúa, es decir, para $\alpha=0$ se obtiene la incidencia en pobreza; para $\alpha=1$, la brecha de pobreza, y por último, para un $\alpha=2$ se tiene la severidad de la pobreza.

\subsubsection{Incidencia de la pobreza $(H)$}

Pese a ser una de las medidas de pobreza más criticadas debido a que no cumple con dos axiomas muy importantes (monotonicidad y transferencia), es también una de las medidas más usadas, por su cálculo sencillo y su fácil interpretación. Además, es una buena primera aproximación a la magnitud del problema, como se vio anteriormente.

Se obtiene cuando el parámetro $\alpha=0$, y tiene la siguiente forma

$$
P_{0}=\frac{1}{N} \int_{i=0}^{q} d y
$$

\subsubsection{Brecha de pobreza (P1)}

La brecha de pobreza mide la distancia entre el ingreso que recibe cada hogar y la línea de pobreza, lo que da como resultado la proporción de la línea de pobreza que se debería otorgar a los hogares pobres para que estos puedan salir de su condición. Esta medida, en comparación con la anterior, mide sobre todo la profundidad de la pobreza que presenta la 
población. Sin embargo, esta medida, que es usada de manera frecuente, también ha recibido varias críticas, pues si bien cumple con el axioma de monotonicidad, no cumple con el axioma de transferencia. ${ }^{3}$

La brecha de pobreza se calcula mediante la siguiente fórmula:

$$
P_{1}=\frac{1}{N} \int_{i=0}^{q} \frac{z-y_{i}}{Z} d y
$$

\subsubsection{Severidad de la pobreza (P2)}

Finalmente, la severidad de la pobreza es un reflejo de la distribución de los ingresos entre los pobres, es decir, si anteriormente se podía calcular cuántos pobres existen (incidencia) y cuán pobres son (brecha de pobreza), ahora también se puede ver cómo es la distribución de sus ingresos. Esto, junto con las dos anteriores medidas, da un panorama más completo sobre el nivel de pobreza de una población.

Esta medida sigue la siguiente fórmula:

$$
P_{2}=\frac{1}{N} \int_{i=0}^{q}\left(\frac{z-y_{i}}{Z}\right)^{2} d y
$$

Teniendo clara la diferencia entre las distintas medidas de pobreza, es posible empezar con el análisis complementario de la evolución de la pobreza.

3 Al tomar en cuenta solamente el promedio de las distancias, no considera la posible transferencia entre hogares, o la desigualdad de los ingresos. 
Figura 2: Brecha de pobreza en Bolivia, 1999-201 1

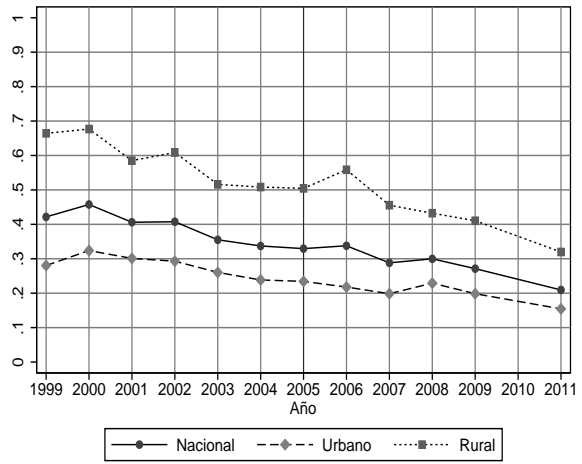

Pobreza Moderada

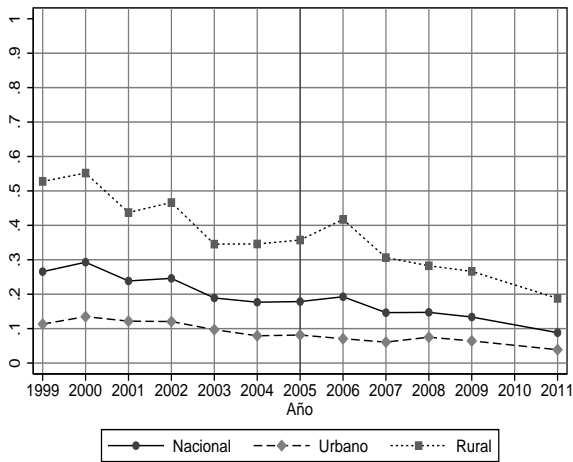

Pobreza Extrema

Fuente: Estimación del autor basada en la serie armonizada de la Fundación ARU de las encuestas de hogares. Ceros y outliers fueron eliminados de la muestra. Los outliers fueron encontrados a través del algoritmo BACON con $\alpha=0.0001$. El ingreso per cápita del hogar es igual al total del ingreso del hogar dividido entre los miembros del mismo. El total del ingreso del hogar es la suma del ingreso por seguridad social y laboral, transferencias del gobierno e inter-hogares, rentas por propiedad y otras fuentes. La brecha de pobreza se calcula mediante $P_{1}=\frac{1}{N} \int_{i=0}^{q} \frac{z-y_{i}}{Z} d y$

\section{Figura 3: Severidad de la pobreza en Bolivia, 1999-2011}

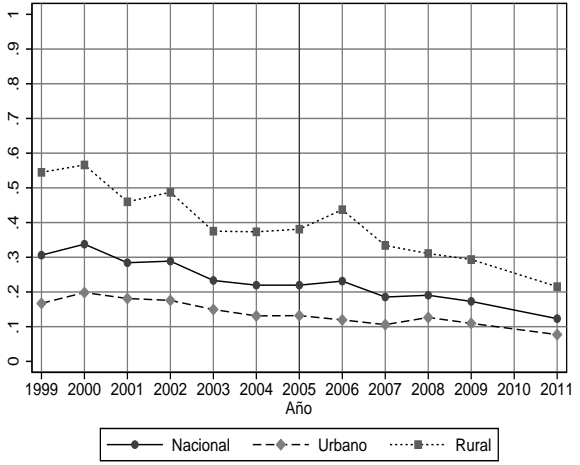

Pobreza Moderada

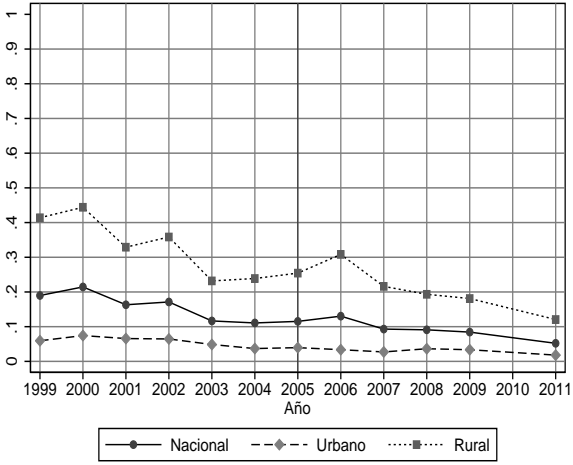

Pobreza Extrema

Fuente: Estimación del autor basada en la serie armonizada de la Fundación ARU de las encuestas de hogares. Ceros y outliers fueron eliminados de la muestra. Los outliers fueron encontrados a través del algoritmo BACON con $\alpha=0.0001$. El ingreso per cápita del hogar es igual al total del ingreso del hogar dividido entre los miembros del mismo. El total del ingreso del hogar es la suma del ingreso por seguridad social y laboral, transferencias del gobierno e inter-hogares, rentas por propiedad y otras fuentes. La severidad de la pobreza se calcula mediante $P_{2}=\frac{1}{N} \int_{i=0}^{q}\left(\frac{z-y_{i}}{Z}\right)^{2} d y$ 


\subsection{Profundidad y gravedad de la pobreza}

\subsubsection{Brecha de pobreza}

Anteriormente se mostró la evolución de la incidencia de la pobreza a nivel nacional, tanto en el área rural como en la urbana, la cual tuvo a lo largo de todo el periodo un comportamiento ejemplar. Como forma complementaria a esta medida se presentan la brecha de pobreza y la severidad de la pobreza, las cuales muestran características similares: tendencia decreciente durante todo el periodo y, dividiendo en dos periodos, mayor intensidad en el segundo.

No obstante, estas medidas presentan algunas características adicionales. La brecha de pobreza de Bolivia muestra que la distancia del ingreso de los hogares indigentes a la línea de indigencia se reduce a una tercera parte, aproximadamente (de 26.5\% en 1999 a $8.8 \%$ en 2011); los hogares pobres no indigentes, por otro lado, también reducen su brecha de pobreza, pero no de forma tan notable, pues se reduce de $15.6 \%$ a $11.2 \%$.

"El nivel de pobreza existente en las principales ciudades no es nada alentador" Con esta frase comienza la caracterización de la pobreza urbana en el trabajo desarrollado por Pereira y Velasco (1993), y para ese entonces la frase era completamente válida. Sin embargo, desde entonces la situación en el área urbana ha cambiado de manera muy notable. El área urbana (aunque en distintas proporciones) sigue las pautas que tiene la evolución a nivel nacional. Es decir, durante todo el periodo muestra una tendencia decreciente.

De forma contraria a la descripción realizada por Pereira-Tito, la evolución de los índices de pobreza durante todo el periodo son alentadores, pues presentan una reducción ejemplar. Muestra de ello es que en 1999 la brecha de pobreza de los indigentes tenía un valor de 11.3\%, el cual se redujo a $0.03 \%$ para finales del periodo, la brecha de los pobres cae de $28 \%$ a $15.4 \%$.

Analizando ahora el área rural, se tiene que, si bien la evolución de la pobreza muestra índices optimistas, su evolución es completamente ejemplificable. Es en ésta área donde se presentan los mayores cambios en la situación de la pobreza, y como ocurre a nivel nacional y a nivel urbano, estos cambios presentan una tendencia decreciente. Como en los anteriores casos, la brecha de pobreza cae, para la pobreza moderada $51.8 \%$ (de $66.4 \%$ a $31.9 \%$ ) y para el caso de la extrema $64.3 \%$ (de $52.7 \%$ a $18.7 \%$ ). 


\subsubsection{Severidad de la pobreza}

La severidad de la pobreza, como se podía esperar, presenta la misma tendencia que la brecha de pobreza en todos los casos.

Partiendo de la severidad de la pobreza a nivel nacional, se observa que la distribución del ingreso de los hogares pobres va igualándose a través del tiempo, en el caso de los hogares indigentes va de una concentración de 18.9\% en 1999 a una de 5.21\% en 2011. Es decir, el ingreso de los hogares indigentes se va emparejando cada año a una tasa promedio de $8 \%$, y los hogares pobres a una tasa de $5.5 \%$ por año.

En las áreas urbana y rural la concentración del ingreso presenta resultados alentadores. En ambas se presenta cada vez una menor concentración. Los pobres del área urbana tienen una disminución del 44.8\%, y dentro de ellos los indigentes muestran una reducción del 65.7\%. En el área rural la concentración va de $54.4 \%$ a $21.5 \%$, para el caso de pobreza moderada, y de $41.3 \%$ a $12.06 \%$, para el caso extremo.

El análisis de la evolución de la pobreza nos permite determinar algunas observaciones importantes. Las medidas de pobreza presentan una tendencia decreciente durante el primer periodo, y de forma más intensa durante el segundo periodo. Los cambios en la pobreza son más grandes en el área rural que en el área urbana.

\subsection{Datos estimados vs. datos oficiales}

A lo largo de la descripción de la evolución de la pobreza se menciona que ésta tiene una tendencia decreciente durante todo el periodo. Esta tendencia es más marcada después de 2005. Sin embargo, este resultado difiere de los datos oficiales, los mismos que muestran una tendencia similar a partir del segundo periodo (iniciado en 2005), pero una tendencia distinta durante el primer periodo (anterior a 2005). A través de la figura 4, que muestra la incidencia de la pobreza a nivel nacional ${ }^{4}$, es posible ver las diferencias entre los datos estimados y los oficiales.

Para el primer periodo existe una subestimación de la incidencia por parte de los datos oficiales. Según éstos, no habría existido cambios relevantes durante el primer periodo, pues los resultados presentados muestran un nivel casi constante para los primeros siete años. Sin

4 Para un detalle de las diferencias existentes entre los datos oficiales y los estimados, ver el Anexo A. 
embargo, es interesante ver cómo ambas medidas (estimadas y oficiales) convergen hacia 2005, y a partir de este año ambos resultados se encuentran cercanos. Esto con excepción de 2007, cuando el resultado oficial sobrestima el nivel de pobreza.

Figura 4: Incidencia de la pobreza en Bolivia, 1999-201 1

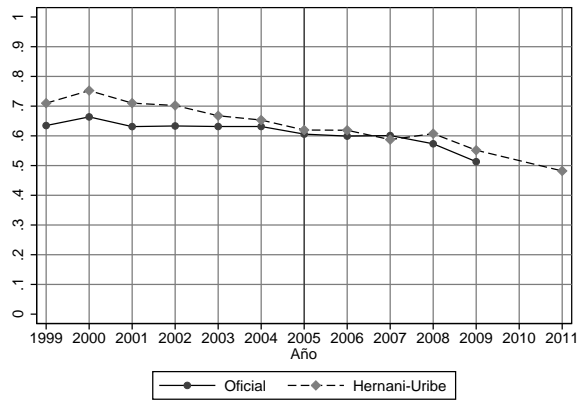

Pobreza Moderada

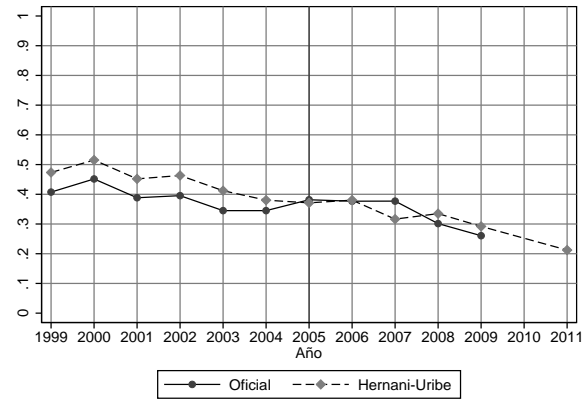

Pobreza Extrema

\begin{abstract}
Fuente: Estimación del autor basada en la serie armonizada de la Fundación ARU de las encuestas de hogares. Ceros y outliers fueron eliminados de la muestra. Los outliers fueron encontrados a través del algoritmo BACON con $\alpha=0.0001$. El ingreso per cápita del hogar es igual al total del ingreso del hogar dividido entre los miembros del mismo. El total del ingreso del hogar es la suma del ingreso por seguridad social y laboral, transferencias del Gobierno e inter-hogares, rentas por propiedad y otras fuentes. Los datos oficiales fueron extraídos del Dossier de la Unidad de Análisis de Políticas Públicas y Económicas (UDAPE) 2011.
\end{abstract}

Las implicaciones que se generan a través de esta diferencia son importantes, pues presentan realidades distintas. Siguiendo los resultados oficiales, durante el primer periodo 1999-2005 la incidencia de la pobreza y la indigencia tuvo un comportamiento casi constante, llegando al final del primer periodo con una ligera reducción de la pobreza. Los cambios solamente son percibidos en el segundo periodo, cuando la tendencia comienza a ser decreciente. Esta observación difiere en mucho de la observación hallada en el documento, donde la pobreza tiene una tendencia decreciente desde el inicio del primer periodo.

La diferencia que existe entre los resultados estimados y los oficiales para las áreas urbana y rural se muestran en las figuras 5 y 6 , las cuales muestran el mismo patrón que a nivel nacional, solo que en distinta magnitud. Las figuras 5 y 6 ponen en evidencia la diferencia que existe entre el primero y el segundo periodo, pues para el primer caso el valor oficial subestima la medida en todos las situaciones, dando como resultado una tendencia por debajo de la estimada, pero a partir del segundo periodo las medidas se encuentran o se distancian por 
muy poco una de la otra, llegando al final a una diferencia que es nula en algunos casos, y baja en el resto 5 .

Figura 5: Incidencia de la pobreza, área urbana, 1999-201 1
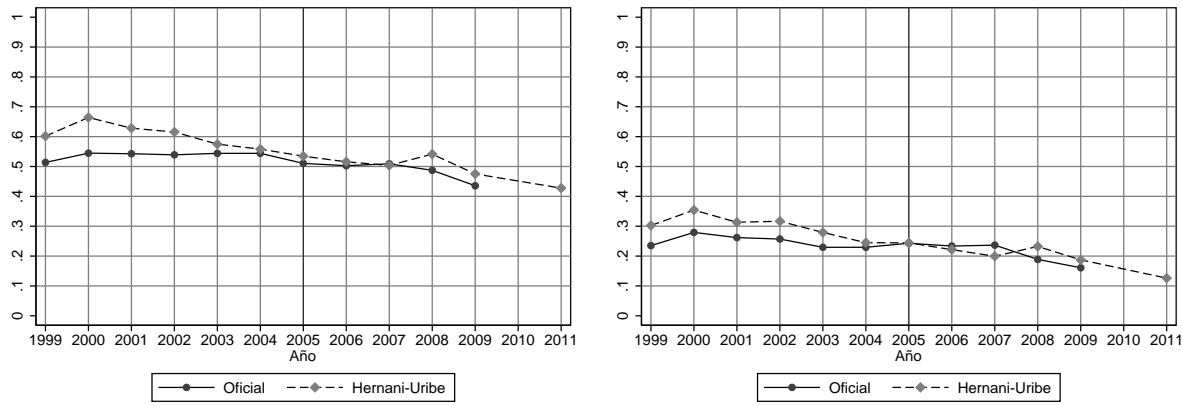

Pobreza Moderada

Pobreza Extrema

Fuente: Estimación del autor basada en la serie armonizada de la Fundación ARU de las encuestas de hogares. Ceros y outliers fueron eliminados de la muestra. Los outliers fueron encontrados a través del algoritmo BACON con $\alpha=0.0001$. El ingreso per cápita del hogar es igual al total del ingreso del hogar dividido entre los miembros del mismo. El total del ingreso del hogar es la suma del ingreso por seguridad social y laboral, transferencias del Gobierno e inter-hogares, rentas por propiedad y otras fuentes. Los datos oficiales fueron extraídos del Dossier de la Unidad de Análisis de Políticas Públicas y Económicas (UDAPE) 2011.

\section{Figura 6: Incidencia de la pobreza, área rural, 1999-2011}

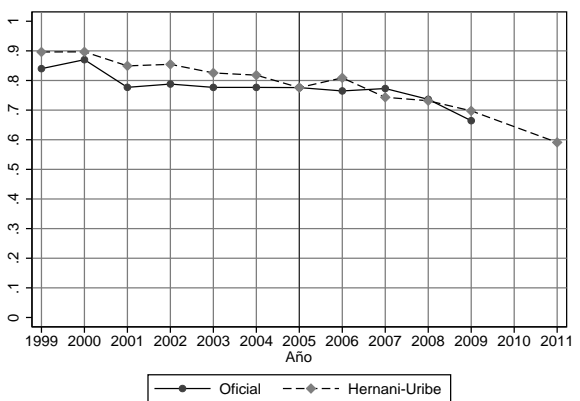

Pobreza Moderada

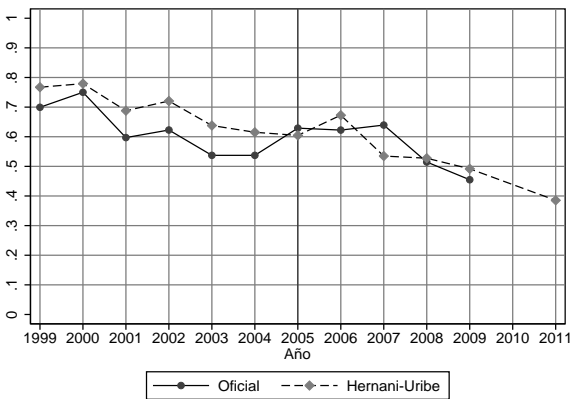

Pobreza Extrema

Fuente: Estimación del autor basada en la serie armonizada de la Fundación ARU de las encuestas de hogares. Ceros y outliers fueron eliminados de la muestra. Los outliers fueron encontrados a través del algoritmo BACON con $\alpha=0.0001$. El ingreso per cápita del hogar es igual al total del ingreso del hogar dividido entre los miembros del mismo. El total del ingreso del hogar es la suma del ingreso por seguridad social y laboral, transferencias del Gobierno e inter-hogares, rentas por propiedad y otras fuentes. Los datos oficiales fueron extraídos del Dossier de la Unidad de Análisis de Políticas Públicas y Económicas (UDAPE) 2011.

5 Para esta comparación se excluye el año 2011, pues no existen datos oficiales para este año. 
En particular, la diferencia de los resultados de la incidencia de la pobreza en el área urbana durante el primer periodo muestra una mayor variabilidad para los primeros años de la pobreza extrema. Esta diferencia se va atenuando hasta coincidir en 2004. Los resultados de la incidencia en la indigencia se mueven con la misma tendencia, pero los datos oficiales tienen la característica de una tendencia más constante.

Aunque el área rural presenta los mismos patrones generales que los anteriores casos, tiene sus peculiaridades. Los datos oficiales subestiman los niveles de incidencia de la pobreza y la indigencia, pero esta diferencia se hace menor al tratarse de la incidencia de la pobreza, mientras que la diferencia en la indigencia llega más de un par de veces a 10 puntos. Sin embargo, como sucede en los anteriores casos, ambos resultados se encuentran en 2005, para luego tener una tendencia decreciente. Esta tendencia conjunta se hace más notable para la pobreza moderada, pues en la pobreza extrema aun existen diferencias para un par de años entre los resultados oficiales y los estimados.

\section{Medidas de robustez}

Los cambios en los niveles de pobreza para el periodo de estudio son bastante alentadores en términos de reducción de la pobreza. No obstante, los perfiles de pobreza desarrollados dependen de las líneas de pobreza y de los datos usados. Ello implica que ante diferentes líneas de pobreza se obtienen diferentes tendencias y se necesita una metodología para asegurar la robustez de los resultados.

En Ravallion (1992) se expone cómo la teoría de la dominancia estocástica ayuda a establecer si los perfiles de pobreza son robustos, y lo usaremos como base para nuestro análisis. El primer paso es estimar la función de distribución acumulada del indicador de bienestar, en este caso el ingreso per cápita. Una vez que se cuenta con esta estimación, se debe tener alguna idea del valor máximo que pueda tomar la línea de pobreza, sin embargo, ello no implica conocer el verdadero valor de la línea. Entonces, a través de la condición de dominancia de primer orden se puede mostrar que la pobreza caerá entre dos periodos $a$ y $b$ si la función de distribución acumulada en $b$ se encuentra por debajo de la función de $a$ hasta el valor máximo de la línea de pobreza.

El análisis de las curvas de la función de distribución acumulada (curva de incidencia) es simple en el caso en el que las curvas no se intersectan. No obstante, también puede darse el caso contrario y las curvas pueden intersectarse no solo una sino varias veces. En este caso se 
recurre a los criterios de segundo, tercer orden, e incluso órdenes más altos de dominancia estocástica, los cuales se explican en mayor detalle en Atkinson, (1970) y Ravallion (1992).

En las figuras 7 a 9 mostramos las estimaciones de la función de distribución acumulada (curva de incidencia) del ingreso expresada en términos del valor de la línea de pobreza de cada año ${ }^{6}$ para Bolivia, el área urbana y el área rural, respectivamente. La línea a la izquierda de 1 representa el valor promedio de la línea de pobreza oficial ${ }^{7}$ y nos da una idea de la diferencia entre la línea oficial y la usada en nuestro análisis.

Figura 7: Curvas de incidencia de pobreza. Bolivia

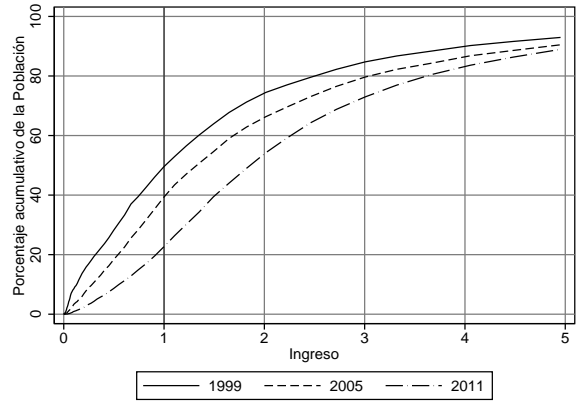

Deflactor: línea de pobreza extrema

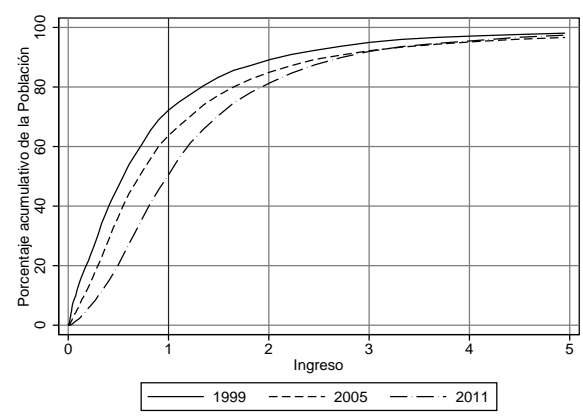

Deflactor: línea de pobreza moderada

La figura 7 nos muestra las estimaciones de las curvas de incidencia para los años 1999, 2005 y 2011 . El primer detalle a notarse es que las curvas no se intersectan y que 1999 fue el año con la mayor cantidad de personas en condición de pobreza, tanto extrema como moderada. La estimación para 2005 muestra que hubo una reducción de la pobreza. Sin embargo, es la estimación para 2011 la que muestra las diferencias más grandes en la reducción de la pobreza.

Si lo observamos desde otra perspectiva, en dos periodos de tiempo iguales ( 7 años) entre 1999 y 2011, han sido los últimos siete años en los cuales se registraron los mayores cambios en la pobreza a nivel nacional. Las estimaciones reafirman nuestros resultados y la conclusión se muestra bastante robusta en relación a los insumos usados en el cálculo de la pobreza.

6 Esto implica que las funciones de distribución acumulada se calculan como función de ingreso $\frac{y_{t}}{z_{t}}$ donde $y_{t}$ es el ingreso de cada año y $z_{t}$ es la línea de pobreza promedio de cada año.

7 Para mayores detalles entre la línea de pobreza oficial y su estimación, véase Mena et al. (2013). 
Figura 8: Curvas de incidencia de pobreza. Área urbana

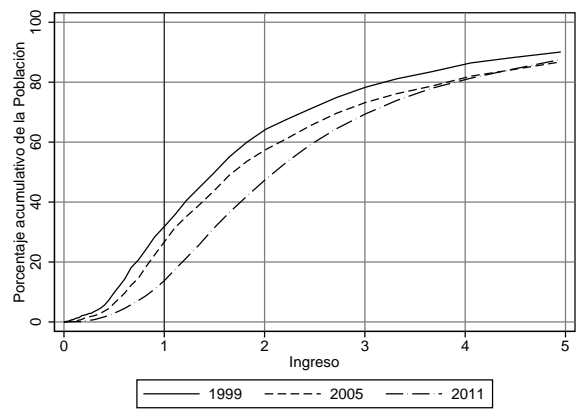

Deflactor: línea de pobreza extrema

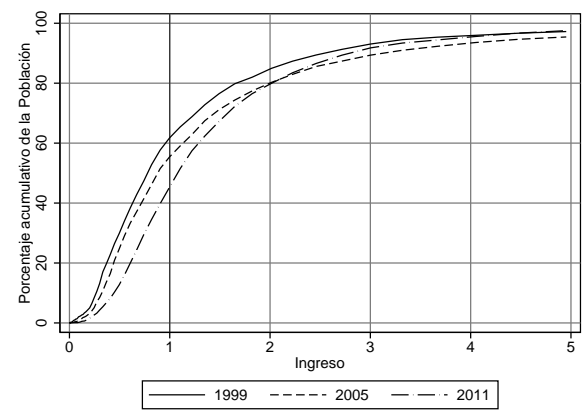

Deflactor: línea de pobreza moderada

Para continuar con nuestro análisis, presentamos en la figura 8 las estimaciones de las curvas de incidencia para el área urbana. La pobreza moderada y extrema son menores en relación a las estimaciones a nivel nacional. El segundo aspecto relevante es que hay una mayor brecha entre la línea de pobreza usada en el análisis y la oficial. Teniendo en cuenta estos detalles, observamos que ha habido una reducción de la pobreza durante el periodo, el cual es más pronunciado después de 2005.

Si usamos la línea de pobreza moderada para deflactar los ingresos (panel b), encontramos que existe una intersección entre las curvas. Sin embargo, este cambio se da en la parte ubicada a la derecha de la línea de pobreza moderada, por lo que no compromete nuestros resultados.

Otro detalle interesante es el cambio en la distribución de la parte superior de ingresos. En el periodo 1999-2005 se observa una diferencia entre ambas distribuciones, mientras que en el segundo periodo el cambio es prácticamente nulo y se observa una intersección a partir de las cuatro líneas de pobreza. 
Figura 9: Curvas de incidencia de pobreza. Área rural

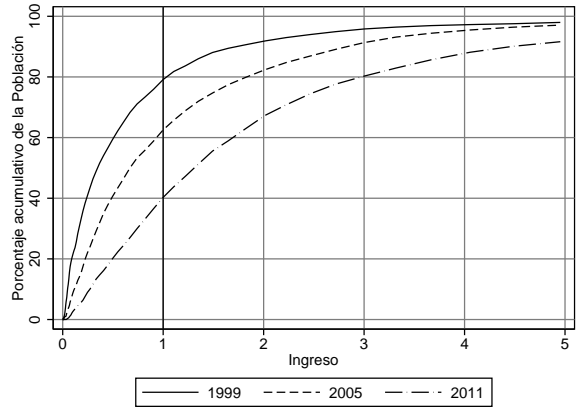

Deflactor: línea de pobreza extrema

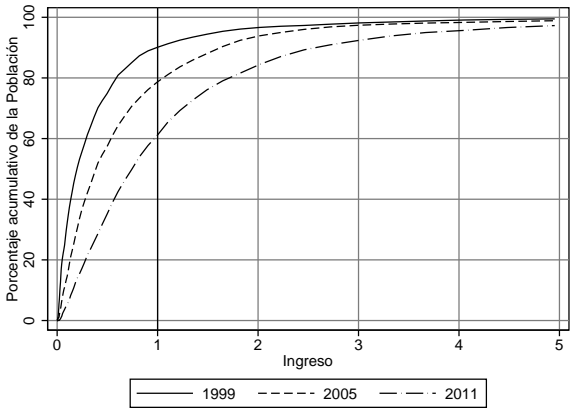

Deflactor: línea de pobreza moderada

Por último, en nuestro análisis de robustez presentamos en la figura 9 las estimaciones para el área rural. A primera vista se observa una gran diferencia en comparación con las estimaciones del área urbana, pues la pobreza es un fenómeno que caracteriza al área rural. Por otra parte, las líneas de pobreza usadas y las oficiales tienen una brecha menor en relación al área urbana; por lo tanto, a priori no son un factor que comprometa los resultados del análisis en el área rural.

El panel (a) de la figura 9 muestra las estimaciones de la curva de incidencia usando la línea de pobreza extrema como deflactor del ingreso per cápita. El punto de intersección de la línea de pobreza extrema con la curva de incidencia se encuentra en 80 en 1999, aproximadamente 60 en 2005 y 40 en 2011. Éste es un hecho que llama la atención, pues implica un fuerte cambio en la disminución de la pobreza extrema en el área rural. Si observamos la parte superior de la distribución, apreciamos que en el periodo 2005-2011 ha habido una mejora en la distribución. O sea, no solamente los pobres mejoraron su situación, sino también los sectores rurales con mayores ingresos, en términos de pobreza extrema.

Las estimaciones de la curva de incidencia usando la línea de pobreza moderada se muestran en el panel (b) de la figura 9. Destaca el hecho de que la pobreza monetaria se reduce, pero en este caso también llama la atención que las mejoras en pobreza no muestran marcadas diferencias entre los periodos 1999-2005 y 2005-2011.

Los hechos que se mostraron en el análisis de robustez nos permiten concluir que la reducción en la pobreza es robusta a los errores que podrían haber en la medición de los ingresos a través de la encuesta, y también las líneas de pobreza usadas. Los interesados pueden 
remitirse a los anexos para encontrar las pruebas de dominancia estocástica de segundo y tercer orden, los cuales apoyan aun más nuestros resultados.

\section{Descomponiendo los cambios en la situación de la pobreza}

A la luz de los resultados encontrados, es válido preguntarse: quién tuvo un mayor impacto en los cambios de pobreza: ¿el crecimiento del ingreso o su redistribución? El inclinarse por cualquiera de estas respuestas conlleva diferentes implicaciones de política. S los cambios en la pobreza se hubieran debido al crecimiento de los ingresos, entonces posiblemente serían las políticas redistributivas (i.e. bonos) las que ayudarían a reducir en una mayor proporción la pobreza. Por otra parte, si el cambio en la pobreza se debe mayormente a un efecto redistribución, habría que focalizar las políticas en sectores que fomenten el crecimiento económico.

\subsection{Descomposición de los cambios en la pobreza: efecto crecimiento y redistribución}

Usualmente se usa el coeficiente de Gini para medir la desigualdad (y por lo tanto los cambios distribución), mas en este caso su uso es inapropiado ${ }^{8}$, pues una reducción en los niveles de desigualdad no implica necesariamente que se reduzca la pobreza.

Ante esta dificultad, Datt y Ravallion (1991) proponen una metodología que permite descomponer los cambios de la pobreza como la suma de un componente de crecimiento (el cambio en la pobreza que se hubiera observado si la curva de Lorenz no se hubiera movido), un componente de redistribución (cambio observado si la media de la distribución no hubiera cambiado) y un residuo (la interacción entre el efecto crecimiento y el efecto redistribución).

La metodología establece una relación formal entre los parámetros de la curva de Lorenz y la familia de indicadores FGT 9 . La curva de Lorenz presenta la relación entre la proporción acumulada de la población $P$ y la proporción acumulada del ingreso $L(P)$. Si asumimos que $P$ es el porcentaje de hogares con ingresos menores a un umbral $X$ y que $L(P)$ es la fracción o proporción del total del ingreso que perciben estos hogares, entonces:

8 Este resultado se debe a que el coeficiente de Gini no cumple con la propiedad de aditividad.

9 Recordando, matemáticamente los indicadores FGT tienen la forma $P_{\alpha}=\frac{1}{n} \int_{0}^{x}\left(\frac{z-y}{z}\right)^{\alpha}$, donde $y$ es el ingreso per cápita del hogar, $(z)$ la línea de pobreza, $\alpha$ es un parámetro no negativo que representa la aversión a la desigualdad; y $n$, el tamaño de la población. 


$$
P=\int_{0}^{x} f(y) d y
$$

y

$$
L(p)=\int_{0}^{x} y f(y) d y
$$

Diferenciando la primera de estas ecuaciones con respecto a la segunda, se obtiene:

$$
\begin{gathered}
\frac{d p}{d x}=f(x) \\
\frac{d L(p)}{d x}=\frac{x}{\mu f(x)}
\end{gathered}
$$

En consecuencia, la pendiente de la curva de Lorenz es:

$$
L^{\prime}(p)=\frac{d L(p)}{d p}=\frac{x}{\mu}
$$

Si asumimos que $p=P_{0}$, o sea que $p$ es la incidencia, tenemos:

$$
L^{\prime}(H)=\frac{z}{\mu} \rightarrow \mu * L^{\prime}(H)=z
$$

La medida $P_{1}$ o brecha de la pobreza se mide como

$$
P_{1}=\left(1-\frac{\mu^{P}}{z} H\right)
$$

donde $\mu^{P}=\frac{\mu L\left(P_{0}\right)}{P_{0}}$ representa la media del ingreso de los pobres. Para la medida $P_{2}$ se debe integrar $\left[1-\left(\frac{\mu}{z} L^{\prime}(p)\right)\right]^{2}$ en el intervalo $\left[0, P_{0}\right]$. La forma funcional de la curva de Lorenz usada en la investigación es la propuesta por Kakwani (1980), y los detalles se encuentran en los anexos. 
Adicionalmente a esta metodología, planteamos realizar simulaciones contrafactuales para enfatizar la importancia del crecimiento y la redistribución en la evolución de la pobreza. Sea $P$ $(\mu, \Omega)$ cualquiera de las medidas de pobreza pertenecientes a la familia FGT una función del ingreso promedio $\mu$ y de los parámetros de la curva de Lorenz $(\Omega=\theta, \delta, \tau)$; la descomposición del cambio en las medidas de pobreza para el período 2000-2011 que se analiza en el trabajo es:

$$
P_{11}-P_{99}=\text { Componente de crecimiento }+ \text { Componente de concentración }+ \text { Residual }
$$

Donde el componente de crecimiento es:

$$
P\left(\mu_{11}, \Omega_{99}\right)-P\left(\mu_{99}, \Omega_{99}\right)
$$

y el componente de concentración es:

$$
P\left(\mu_{99}, \Omega_{11}\right)-P\left(\mu_{99}, \Omega_{99}\right)
$$

En otras palabras, el componente de crecimiento es el cambio en la medida de pobreza que se debe a cambios en el ingreso promedio, manteniendo la distribución del ingreso constante, mientras que el componente de concentración es el cambio en la medida de pobreza que se debe a cambios en los parámetros de la curva de Lorenz manteniendo constante el ingreso promedio.

\subsection{Resultados}

Las figuras 10 a la 19 muestran los resultados encontrados a partir de las estimaciones y las simulaciones. 


\section{Figura 10: Incidencia de la pobreza en Bolivia, 1999-2011}
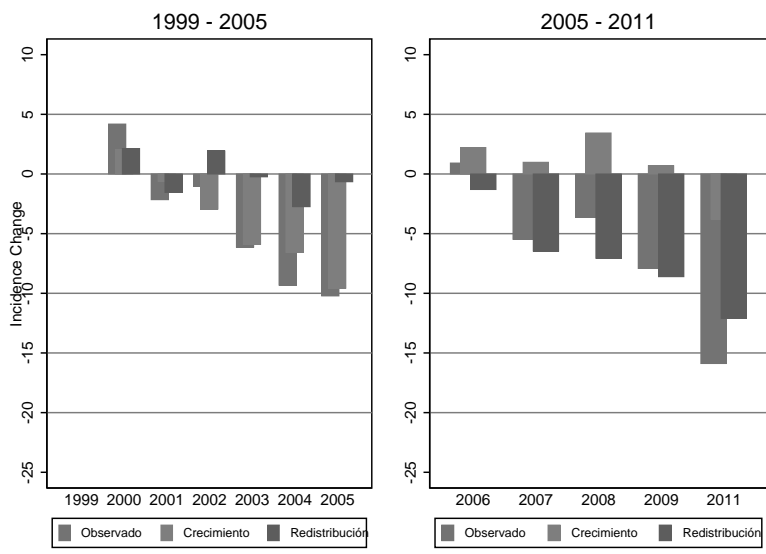

Pobreza Extrema
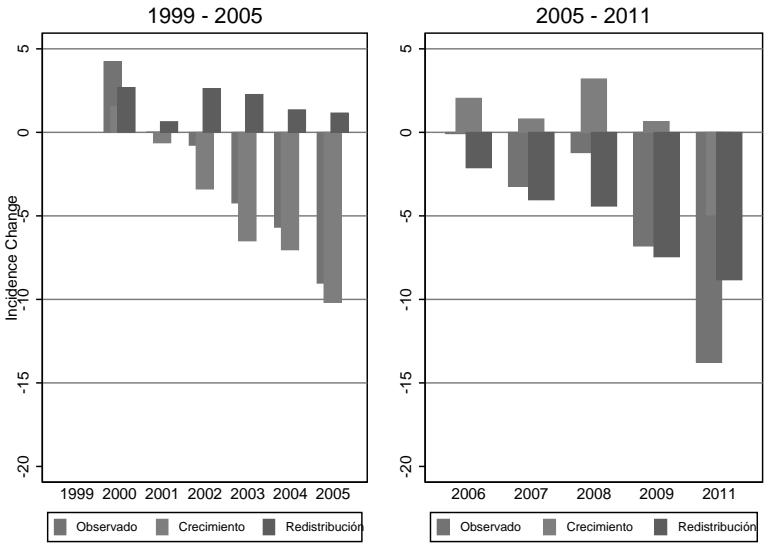

Pobreza Moderada

Fuente: Elaboración de los autores en base a la serie armonizada de encuestas de hogares realizada por la Fundación ARU.

En la figura 10 observamos la evolución de la tasa de crecimiento de la incidencia de la pobreza. Como puede apreciarse en el panel (a), el mayor cambio en la tasa de crecimiento observada se da en 2011, con un 15\% de reducción en este indicador. Al dividir el periodo de estudio en dos, se muestra claramente que en el primer periodo (1999-2005) la reducción de 
la pobreza se debió principalmente al efecto crecimiento, llegando a tener un efecto máximo de aproximadamente $10 \%$ en 2005. El segundo periodo (2006-2011) se caracteriza por mostrar al efecto redistribución como el que mayor impacto tuvo para reducir la pobreza monetaria, con un efecto máximo de más del 10\% en 2011 . Otro detalle importante es que el crecimiento no solamente no contribuyó a reducir la pobreza, sino que tuvo un ligero efecto contrario.

Por el lado de la pobreza moderada las reducciones en la pobreza no fueron de la misma magnitud en relación a la pobreza extrema, pues el efecto máximo se dio en 2011, el cual se aproximó al 15\% de reducción. A diferencia de la pobreza extrema, sin embargo, el efecto crecimiento no aportó a la reducción de la pobreza durante el primer periodo.

Figura 11: Simulación contrafactual: incidencia de la pobreza en Bolivia, 1999-2011

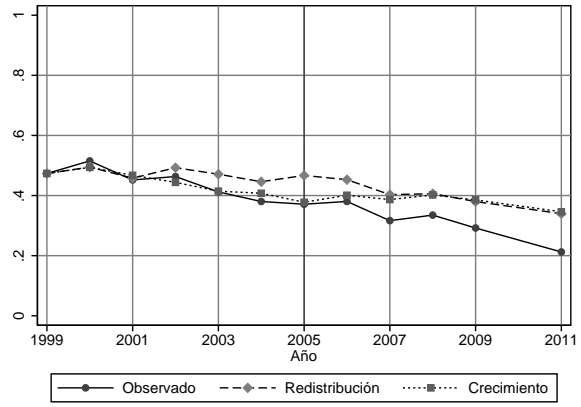

Pobreza extrema

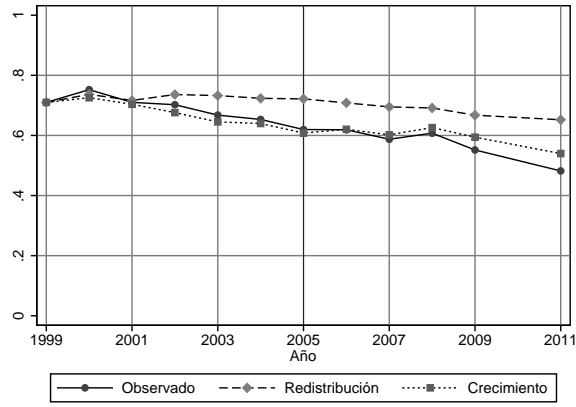

Pobreza moderada

Fuente: Elaboración de los autores en base a la serie armonizada de encuestas de hogares realizada por la Fundación ARU.

El análisis contrafactual que se muestra en el panel (a) de la figura 11 implica que si se hubiera mantenido el crecimiento constante en los niveles de 1999, entonces la caída de la incidencia de la pobreza hubiera sido prácticamente la misma en relación al valor observado hasta 2005. La simulación, manteniendo constante la redistribución, muestra caídas importantes después de 2005, el cual pierde su efecto en 2008, para posteriormente equiparar a la caída en el contrafactual del crecimiento.

Por el lado de la pobreza moderada (panel b), las caídas del contrafactual del crecimiento son bastante similares a la caída observada de la incidencia. Es interesante en este caso 
observar que la brecha en 2011 entre los contrafactuales muestren al indicador contrafactual de la redistribución con el valor más alto.

Figura 12: Brecha de pobreza en Bolivia, 1999-201 1
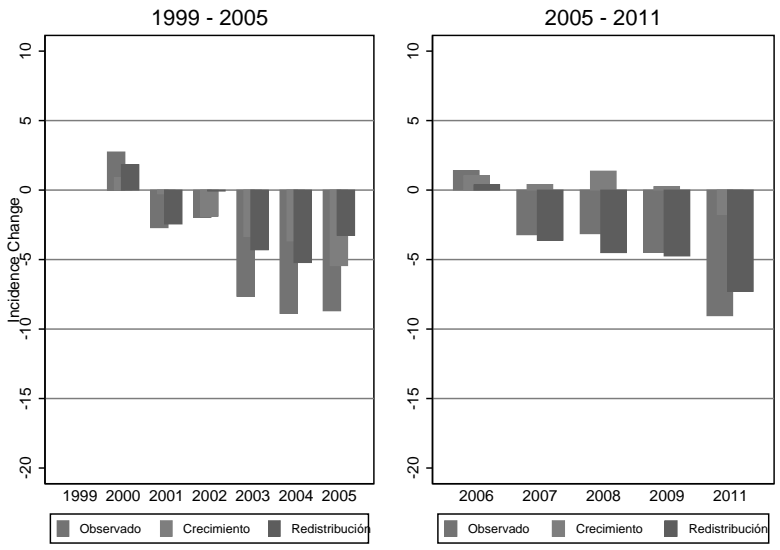

Pobreza Extrema
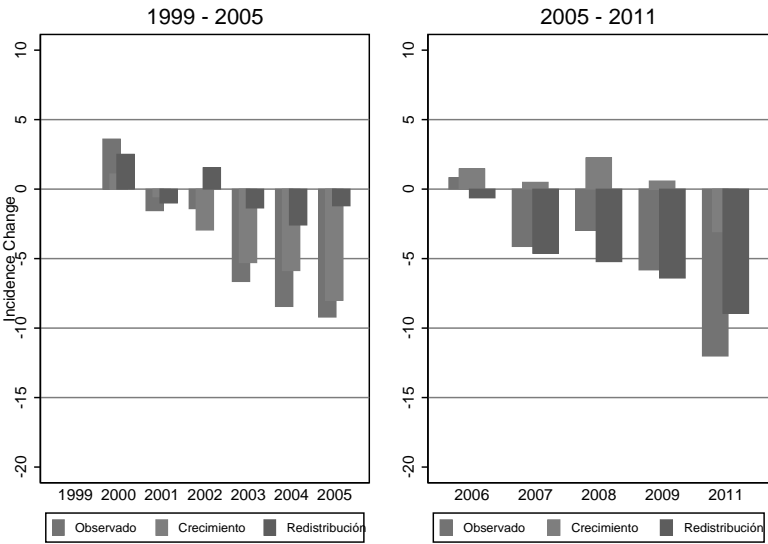

Pobreza Moderada

Fuente: Elaboración de los autores en base a la serie armonizada de encuestas de hogares realizada por la Fundación ARU. 
En la figura 12 se muestra la evolución de la tasa de crecimiento de la brecha de pobreza. Este indicador es importante, ya que nos muestra la evolución de los recursos necesaria para sacar a los pobres de esta condición. Bajo esta perspectiva, tenemos que el nivel observado de la tasa de crecimiento de la brecha de pobreza es mejor durante el primer periodo. Si bien hubo mejoras en este indicador durante el segundo periodo, éstas fueron menores en relación al primer periodo, y solamente en 2011 se alcanzaría un nivel de reducción similar al de 19992005.

El panel (b) no nos permite derivar la misma conclusión para la pobreza moderada, porque el nivel de reducción de la brecha de pobreza es del orden del 10\% en 2011 . Este nivel de reducción es mayor a cualquier año del primer periodo.

Figura 13: Simulación contrafactual: brecha de pobreza en Bolivia, 1999-201 1

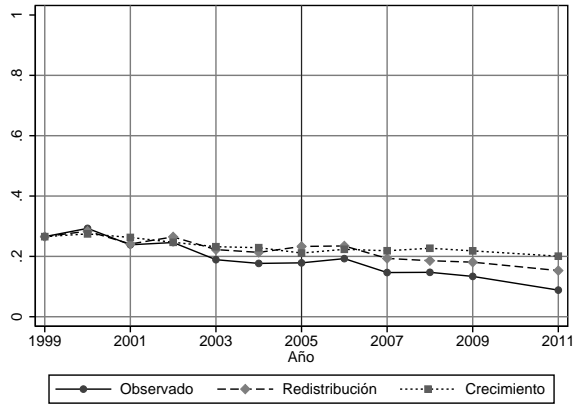

Pobreza extrema

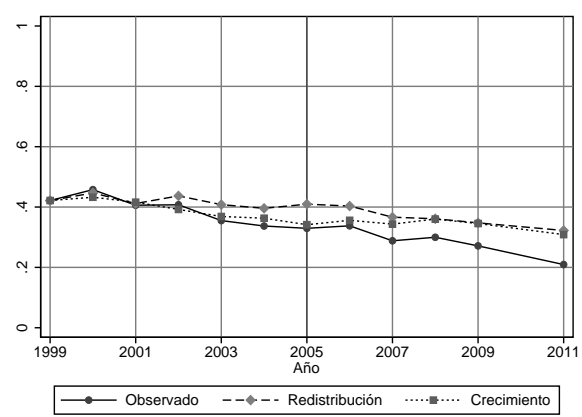

Pobreza moderada

Fuente: Elaboración de los autores en base a la serie armonizada de encuestas de hogares realizada por la Fundación ARU.

El análisis contrafactual en la figura 13 muestra que la diferencia entre el contrafactual de la redistribución y del crecimiento no tiene grandes diferencias antes de 2005 en la evolución de la brecha en la pobreza extrema. Después de 2005 la redistribución tiene un mayor efecto para reducir la brecha de pobreza en relación al crecimiento. Por el lado de la pobreza moderada (panel b) se tiene que ni el crecimiento ni la redistribución tienen un efecto mayor en relación al otro para reducir la brecha de pobreza. 
Figura 14: Severidad de la pobreza en Bolivia, 1999-201 1
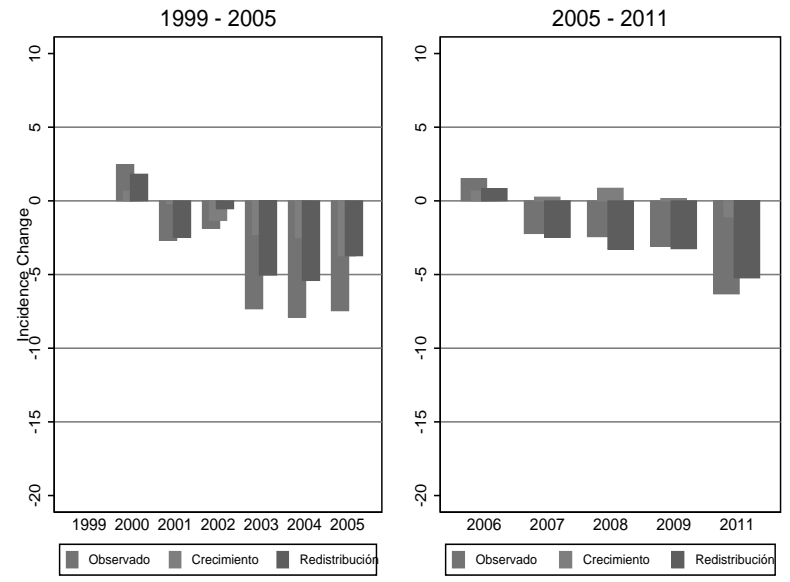

Pobreza Extrema
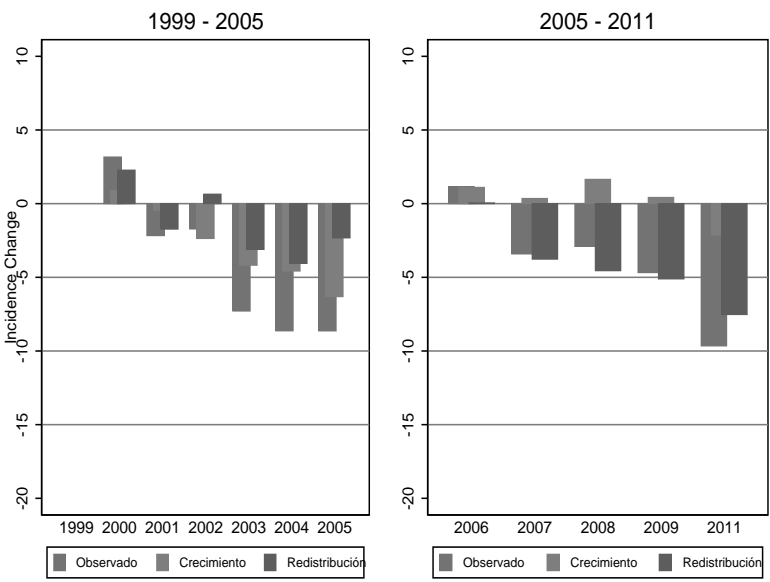

Fuente: Elaboración de los autores en base a la serie armonizada de encuestas de hogares realizada por la Fundación ARU.

En la figura 14 se analiza la tasa de crecimiento de la severidad de la pobreza. A diferencia de los anteriores indicadores (incidencia y brecha), aquí se aprecia claramente el buen desempeño en la reducción de la desigualdad entre los pobres. Un detalle a tomar en cuenta es que la redistribución y el crecimiento tuvieron un efecto positivo en la reducción de este 
indicador durante el primer periodo. En el periodo posterior a 2005 el crecimiento pierde peso en la reducción de la severidad.

Si analizamos la tasa de crecimiento de la severidad de pobreza moderada (panel b), se aprecia una diferencia importante en relación a la severidad de la pobreza extrema, y es que el crecimiento tiene un mayor efecto para reducir este indicador durante el primer periodo.

Figura 15: Simulación contrafactual: severidad de la pobreza en Bolivia, 1999-201 1

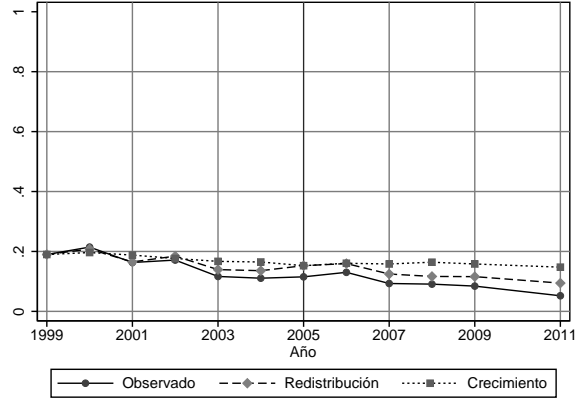

Pobreza extrema

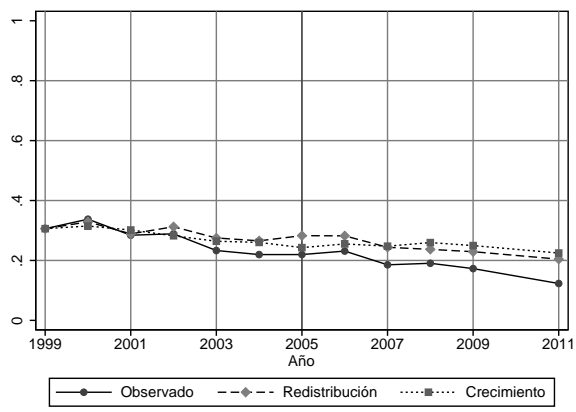

Pobreza moderada

Fuente: Elaboración de los autores en base a la serie armonizada de encuestas de hogares realizada por la Fundación ARU.

De la simulación contractual de la severidad de la pobreza extrema sobresale el hecho de que la redistribución es el componente que más efecto tendría en la reducción de la severidad. En la severidad de la pobreza moderada, sin embargo, el resultado no es tan claro. Hasta 2007 fue el efecto crecimiento el que tuvo un mayor impacto sobre el cambio observado en la severidad de la pobreza moderada, pero posteriormente a este año es el efecto redistribución el que ayuda a explicar mejor la reducción en la severidad.

Los hechos anteriormente mostrados nos llevan a concluir que las reducciones en la pobreza se caracterizan principalmente por tener dos periodos marcados: el primero (19992005), en el cual las reducciones de pobreza se explican en una mayor proporción por el efecto crecimiento del ingreso, y el segundo (2006-2011), en el cual las reducciones en la pobreza son mayormente lideradas por el efecto de la redistribución en el ingreso. Sin embargo, hay que enfatizar que esta característica tan marcada de los periodos cambia si se toman otros indicadores diferentes a la incidencia de pobreza, i.e., la brecha y la severidad de la pobreza. 


\subsubsection{Pobreza urbana-rural}

Para completar nuestro análisis y en virtud del resultado tan marcado sobre la incidencia de pobreza del efecto crecimiento y redistribución por periodos, procedemos a analizar si el comportamiento se repite a nivel urbano-rural. Este análisis es importante en la medida en que en Bolivia hay diferencias marcadas entre ambas áreas, y por lo tanto cada área puede demandar diferentes acciones de política.

En la figura 16 se grafican los valores observados de la incidencia de pobreza para el área urbana, así como los contrafactuales del crecimiento y la redistribución. A primera vista los resultados son interesantes, pues el contrafactual del crecimiento hasta 2005 y posteriormente no ayuda a reducir la pobreza sino que es un factor que provoca aumentos en la incidencia de pobreza. El contrafactual de la redistribución también tiene un comportamiento interesante, en la medida en que durante el primer periodo prácticamente no tiene efecto en la reducción de la pobreza, mientras que en el segundo periodo es un factor de suma importancia para explicar las reducciones de la incidencia de pobreza.

La tendencia del contrafactual de la redistribución en el panel (b), pobreza moderada, nos provee evidencia de que el crecimiento, si bien es un factor que ayuda a disminuir la pobreza, durante algunos periodos puede provocar su incremento (2005-2008). Por el contrario, los efectos en el área urbana de la redistribución causan aumentos en los niveles de pobreza hasta 2005; sin embargo, este resultado no es constante, y posteriormente es la redistribución la que tiene un efecto en la reducción de la pobreza. La pregunta es: ¿cuánto?

Figura 16: Incidencia de la pobreza 1999-2011, área urbana

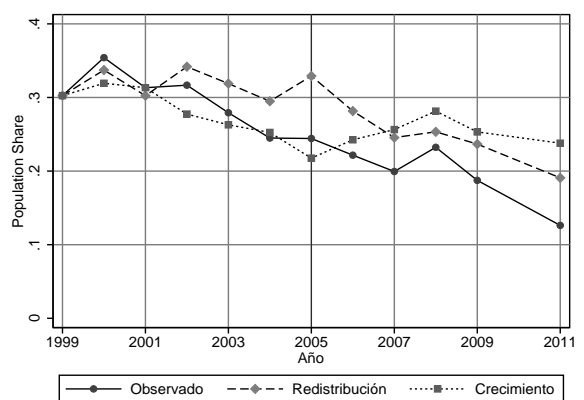

Pobreza extrema

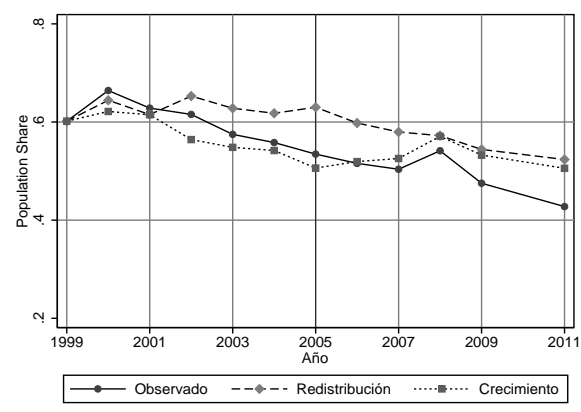

Pobreza moderada

Fuente: Elaboración de los autores en base a la serie armonizada de encuestas de hogares realizada por la Fundación ARU. 
Si inspeccionamos la figura 17, notamos a primera vista que la evolución del efecto crecimiento y redistribución es similar al reportado en el análisis para todo el país. No obstante, las magnitudes difieren, pues durante el primer periodo es el efecto crecimiento el que tuvo mayor relevancia sobre la caída en los niveles tanto de pobreza extrema como de moderada. Como se observa, en 2005 el crecimiento aporta con aproximadamente un 10\% en la reducción y sin embargo la reducción de la pobreza es solo de aproximadamente 5\%, hecho que se debería a que la redistribución jugó un rol negativo al combatir la pobreza.

En el periodo posterior a 2005 tenemos que es el efecto redistribución el que cambia su rol y lidera las reducciones de los niveles de desigualdad. Otro hecho sumamente importante es que el efecto crecimiento se "come" parte de la reducción de la pobreza que se hubiera alcanzado si solamente el efecto redistribución estuviera presente. Asimismo, el año 2008 se caracteriza por mostrar una tasa de crecimiento positiva en la pobreza urbana. Este hecho en particular posiblemente se deba a la inflación registrada en este año.

A primera vista, lo que uno nota en la figura 17 es que la tendencia del contrafactual de la redistribución es prácticamente constante, ya sea en la pobreza extrema (panel a) o en la pobreza moderada (panel b). El contrafactual del crecimiento, por otra parte, muestra una evolución cercana al valor observado de la caída en la incidencia de pobreza. Este hecho es más evidente en el caso de la pobreza moderada.

Otro detalle a tomar en cuenta es que no todo el periodo de análisis se caracteriza por una caída constante en los indicadores de pobreza. Particularmente en 2002 y 2006 estos indicadores muestran incrementos; sin embargo, estos son más bien casos particulares. La mayor caída en la incidencia de la pobreza, tanto extrema como moderada, se da en el periodo 2006-2011.

La figura 19 muestra uno de los resultados más interesantes de todo nuestro análisis del efecto del crecimiento y la redistribución sobre los cambios en la pobreza. Primero, en los años 2001 a 2005 es el crecimiento el que tiene el mayor efecto sobre los cambios en la pobreza, llegando a un máximo de aproximadamente 15\% en 2005 y un mínimo de 5\% en 2002. Durante este lapso de tiempo el efecto redistribución prácticamente no tiene ningún efecto sobre los cambios registrados en la pobreza.

En el periodo 2007-2011, al contrario de lo observado a nivel nacional y urbano, es el efecto crecimiento el que tuvo un mayor efecto sobre los cambios en la pobreza, ya sea pobreza extrema o pobreza moderada. Asimismo, es llamativa la caída (superior al 20\%) 
en la incidencia de la pobreza en 2011. Si analizamos el panel (b), observamos que el efecto redistribución posee un efecto pequeño en los cambios en la pobreza del área rural. Este efecto incluso ayudaría a aumentar la pobreza en 2007 y 2008.

Figura 17: Incidencia de la pobreza 1999 - 2011 . Área urbana
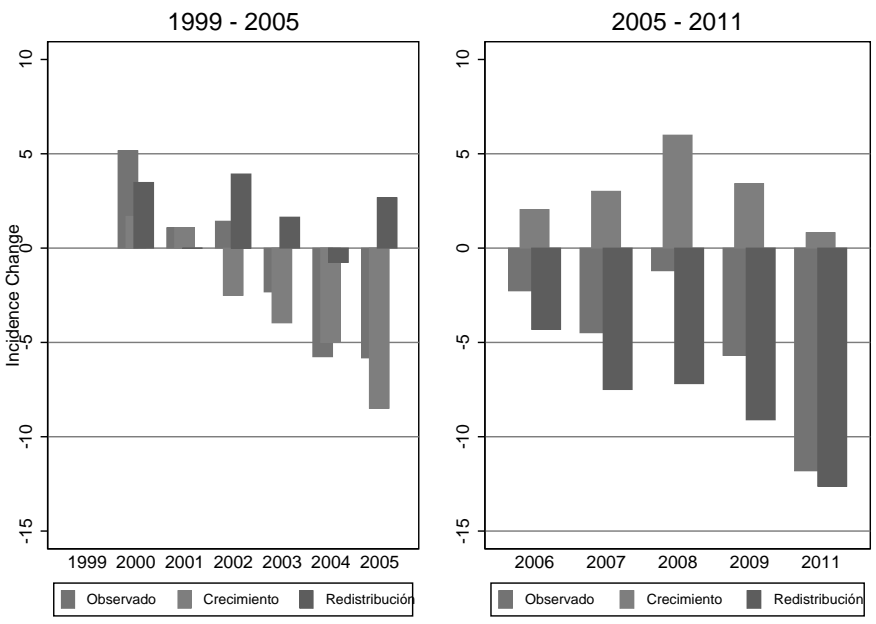

Pobreza Extrema
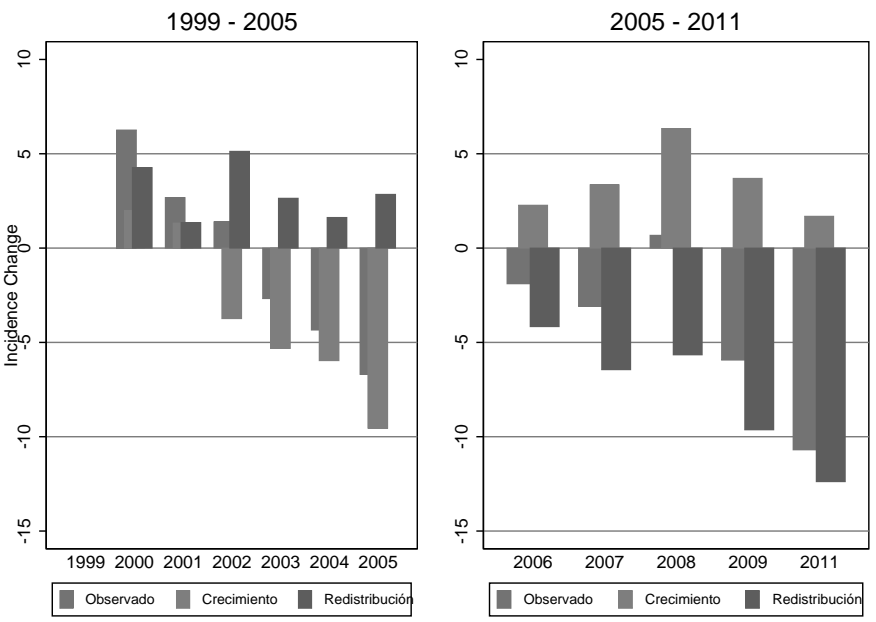

Pobreza Moderada 
Estos resultados son importantes, pues dan los lineamientos para caracterizar la pobreza no solamente a nivel nacional, sino también a nivel urbano y rural. Como se observó, hay una diferencia en los factores que influyen en los cambios en la pobreza en ambas áreas, lo que lleva a considerar diferentes tipos de políticas según corresponda. Aun más importante es investigar a qué se deben estas diferencias entre las áreas, pues un mayor conocimiento de este fenómeno nos llevará a una mejor focalización de los recursos, y por lo tanto a un uso más eficiente de ellos; sin embargo, dicha investigación quedará pendiente para futuros trabajos.

Figura 18: Incidencia de la pobreza 1999 - 2011 . Área rural

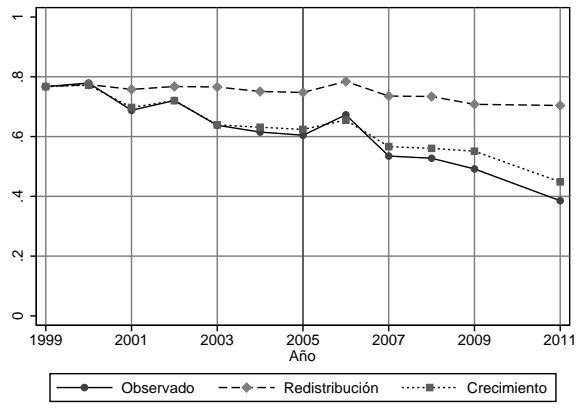

Pobreza extrema

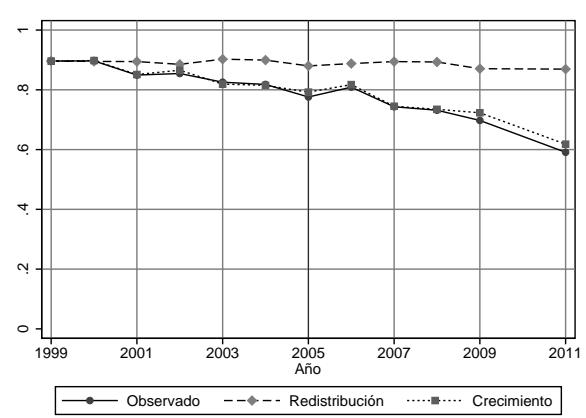

Pobreza moderada

Fuente: Elaboración de los autores en base a la serie armonizada de encuestas de hogares por la Fundación ARU.

\section{Conclusiones}

El documento realizado provee información sobre tres medidas de pobreza: la incidencia de la pobreza (H), la brecha de pobreza (P1) y la severidad de la pobreza (P2), ya que tomar solo la incidencia de la pobreza es insuficiente para explicar todas las características de ésta. El trabajo se enfoca en la evolución desde 1999 hasta el 2011, y explica el comportamiento de la familia de medidas a nivel nacional, urbano y rural.

A través de la descomposición de la pobreza en los componentes crecimiento y distribución del ingreso, el documento realizó un análisis de los cambios y sus respectivos componentes.

El desempeño que tuvieron las medidas de pobreza a lo largo del periodo fue ejemplar, llegando al final de los 13 años con niveles menores que los iniciales de pobreza. Aunque los 
resultados son alentadores (una reducción de más del 30\% de la pobreza moderada y más del 50\% de la pobreza extrema a nivel nacional), aún queda un camino largo por recorrer para alcanzar el primer objetivo del milenio, pues para 2011 aproximadamente 50\% de la población es pobre. Con todo, la situación es alentadora al compararla con el inicio de todo el periodo, aunque aún preocupante.

Las tres medidas de pobreza tuvieron una tendencia decreciente a lo largo del periodo 1999-2011, de las cuales resalta entre todas los cambios en la incidencia de la pobreza, en especial en el área rural, pues presenta la caída más relevante (aproximadamente reducciones por encima del $30 \%$ para todas sus medidas).

Una vez que se dividió el periodo en dos, se encontró que durante el segundo periodo la magnitud de los cambios aumenta, llegando en algunos casos a duplicar el cambio del primer periodo.

Existe una diferencia entre los datos oficiales y los estimados, esta diferencia se hace sustancial durante el primer periodo, en el que los datos oficiales subestiman los niveles de pobreza. Durante el segundo periodo, la diferencia entre los datos oficiales y los datos estimados se hace mínima comparando con la diferencia que existe en el primer periodo. 
Figura 19: Incidencia de la pobreza 1999-201, área urbana
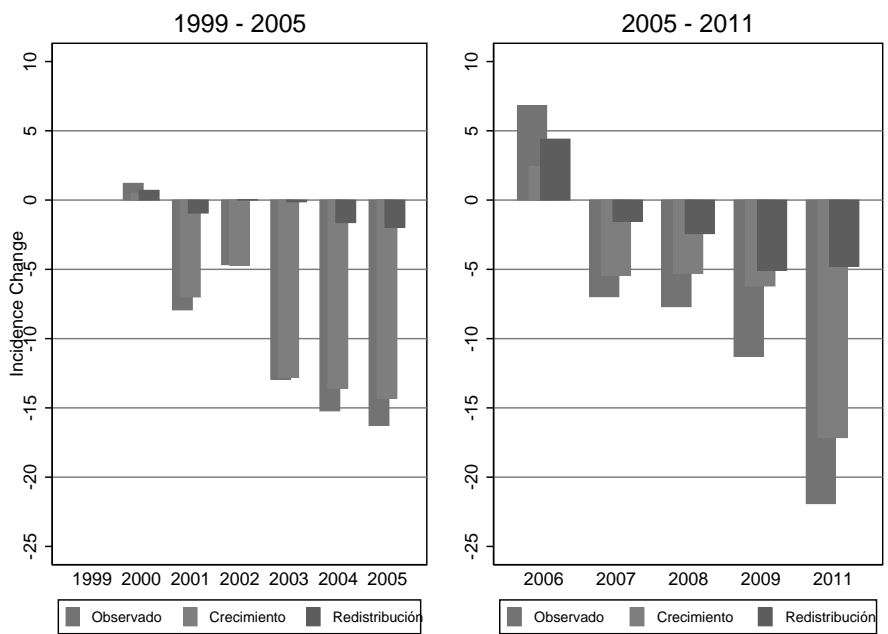

Pobreza Extrema
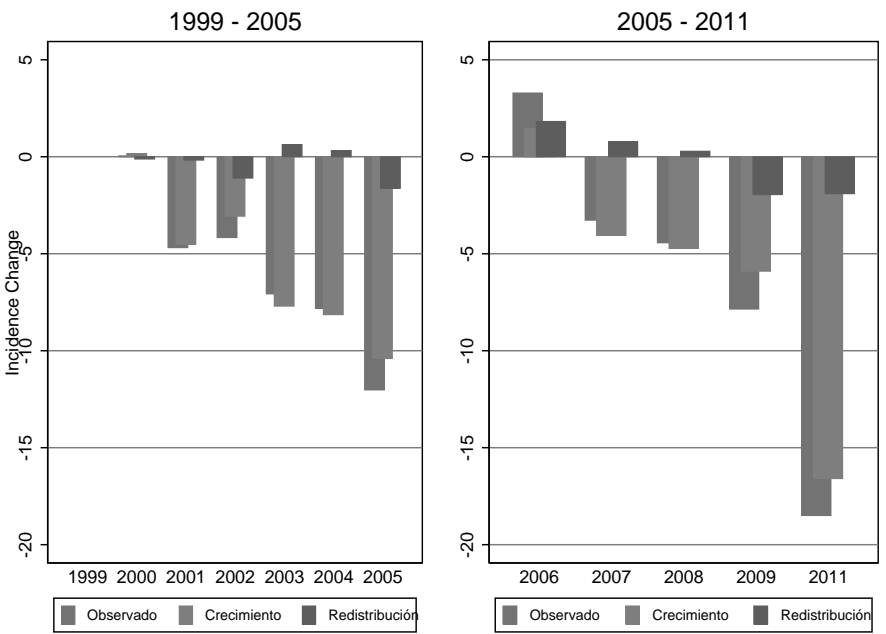

Pobreza Moderada

El análisis de robustez nos permite concluir que existe una brecha mayor entre la línea de pobreza usada y la oficial. Los hallazgos de la descomposición se muestran a continuación: 
Tanto el efecto crecimiento como el efecto redistribución trabajan en conjunto para el descenso de las medidas de pobreza. Pero el primero tiene un impacto aún mayor que el segundo, ya que explica en mayor proporción los cambios existentes.

En particular, durante el segundo periodo la redistribución es un factor positivo en el alivio de la pobreza, de manera más significativa en el área urbana, donde muestra su mayor contribución. Por otro lado, el crecimiento es el factor explicativo de los cambios en el área rural, en el primer y segundo periodo.

Por último las reducciones en la pobreza a nivel nacional no fueron de la misma magnitud en relación a la pobreza extrema, pues el efecto máximo se dio en 2011, el cual se aproximó a $15 \%$ de reducción.

Artículo recibido: 26 de junio de 2013 Aceptado: 7 de septiembre de 2013 


\section{Referencias}

1. Altimir, O. (1979). "La dimensión de la pobreza en América Latina”. Cuadernos de la CEPAL, vol. 27.

2. Apablaza, M., Ocampo, J. P.y Yalonetzky, G. (2010). Descomposición de cambios en la pobreza multidimensional en diez países.

3. Arauco, V. P., Molina, G. G., Pozo, W. J. y Alguilar, E. Y. (2013). Explaining Low Redistributive Impact in Bolivia. CEQ, Working Paper No6.

4. Atkinson, A. B. (1970). "On the Measurement of Inequality. Journal of Economic Theory, 2,244263.

5. Bruno, M., Ravallion, M. y Squire, L. (1998). "Equity and Growth in Developing Countries: Old and New Perspectives on the Policy Issues". En: En: V. Tanzi y K. Chu: Income Distribution and High-quality Growth, 117-146. MIT Press, Cambridge, MA

6. Eid, A., Hernani-Limarino, W. y Aguirre, R. (2013). "Trends in income and consumption inequality in Bolivia: A fairy tale of growing dwarfs and shrinking giants" Draft.

7. Foster, J. Greer, J. y Thorbecke, E. (1984). "A class of decomposable poverty measures". Econometrica, Journal of the Econometric Society, 52 (3), 761-766.

8. $\quad$----(2010)."The Foster-Greer-Thorbecke (FGT) Poverty Measures: 25 yearslater". The Journal of Economic Inequality, 8 (4), 491-524.

9. Grosse,M., Klasen, S.ySpatz, J.(2005). Creating N ational Poverty Profiles and Growth Incidence Curves with Incomplete Income or Consumption Expenditure Data: An Application to B olivia. Tech. rep., Discussion papers//Ibero America Institute for Economic Research.

10. Jiménez, W. y Lizárraga, S. (2003). “Ingresos y desigualdad en el área rural de Bolivia”. UDAPE, La Paz, Bolivia.

11. Kakwani, N. (1980). “On a class of poverty measures". Econometrica, 48 (2): 437-446.

12. Landa, F.(2004). "Las dotaciones de la población ocupada son la fuente que explica la desigualdad de ingresos en Bolivia”. Revista de Análisis Económico, No 19.

13. Meier, G. M. (1964).Leading Issues in Development Economics. New York: Oxford Univ. Press. 
14. Mena, G. yHernani, W.(2013). Construcción del agregado de ingreso y consumo en Bolivia.

15. ------ (2013). Trends in Income and Consumption Inequality in Bolivia. A fairy tale of growing dwarfs and shrinking giants.

16. Mena, G., Jiménez, W.y Hernani, W. (2013). “La canasta básica de alimentos y líneas de pobreza en Bolivia para el periodo 1999-2012”.

17. Myles, J. y Picot, G. (2000). "Poverty Indices and Policy Analysis". Review of Income and Wealth, 46(2), 161-179.

18. Pereira, R. y Velasco, T.A. (1993) “Estimación de la pobreza urbana en Bolivia”, Serie Documentos de trabajo, No/93, UDAPSO, La Paz, Bolivia.

19. Ravallion, M. (1992). "Poverty Comparisons. A Guide to Concepts and Methods". World Bank. Living Standards Measurement Study Working Paper (88).

20. ------ (2004). Pro-poor Growth: A primer. World Bank Policy Research. Working Paper (3242).

21. 21. Ravallion, M. y Chen, S. (2003). "Measuring pro-poor growth". Economics letters, 78 (1), 93-99.

22. Sastre, M.y Trannoy, A. (2002). "Shapley inequality decomposition by factor components: Some methodological issues”. Journal of Economics, 9 (1), 51-89.

23. Sen, A. (1976). "Poverty: an Ordinal Approach to Measurement." Econometrica: Journal of the Econometric Society, 44(2),219-231.

24. Sucujayo, L. Dinámica de la pobreza y el crecimiento económico en Bolivia.

25. White, H.y Anderson, E. (2001). Growth versus Distribution: does the pattern of growth matter?" Development Policy Review, 19 (3),267-289. 


\section{Apéndices}

\section{Apéndice A. Robustez de las medidas}

El análisis de robustez de las medidas desarrollado por Ravallion (1992) permite la comparación de la distribución de ingresos de distintas sociedades, o en este caso de la misma sociedad en distintos tiempos.

Partiendo de la función acumulada de la distribución con la incidencia de la pobreza en el eje y, y la línea de pobreza en el eje x, esta curva puede ser vista como la "curva de incidencia en pobreza”, donde cada punto en la curva da la proporción de la población que tiene como ingreso menos que el monto dado en el eje horizontal (panel a). Si se calcula el área debajo de la curva a cada punto, entonces se traza la "Curva de déficit de pobreza" (panel b). Denotando la brecha de pobreza como PG, por sus siglas en inglés, cada punto de esta curva es simplemente el valor de PG veces la línea de pobreza. Si nuevamente se calcula el área debajo de la curva de déficit a cada punto, entonces se obtiene la "Curva de la severidad de la pobreza" (panel c). 


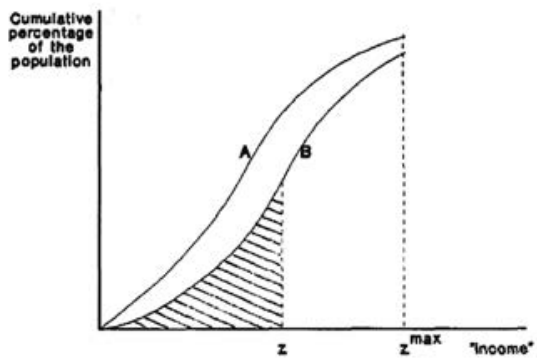

(a) Poverty Incidence Curves for two Distributions A and B

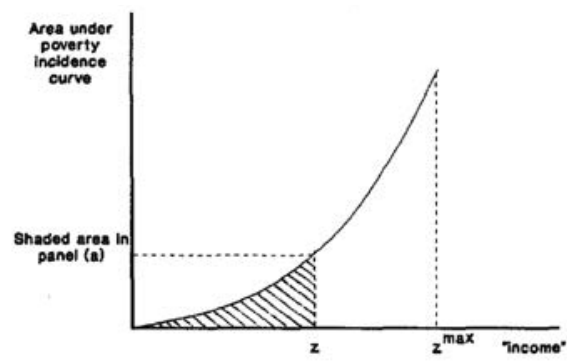

(b) Poverty Deflolt Curve for Distribution B

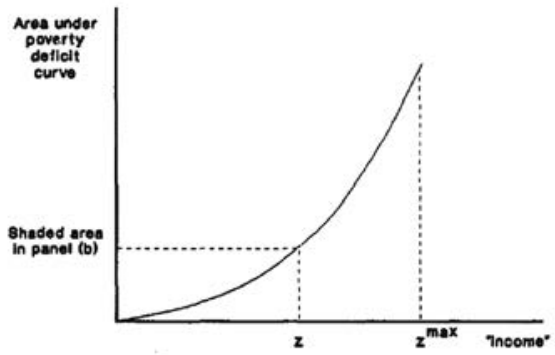

(c) Poverty Severity Curve for Distribution B

Severidad

Fuente: Ravallion (1992) 


\section{Apéndice B. Estimación de la Curva de Lorenz}

Como se detalló anteriormente, la estimación de la medida de pobreza requiere de la estimación de la Curva de Lorenz, que se realiza en base ala siguiente forma funcional:

$$
L(P)=P-\theta P^{\tau}(1-P)^{\beta}
$$

De la que se obtiene:

$$
P-L(P)=\theta P^{\tau}(1-P)^{\beta}
$$

Tomando los logaritmos de esta expresión se obtiene la ecuación que permite la estimación de los tres parámetros:

$$
\log [P-L(P)]=\log \theta+\tau \log P+\beta \log (1-P)
$$

La estimación (que se realizó por el método OLS o mínimos cuadrados ordinarios) se implementó utilizando observaciones agrupadas por percentiles. A pesar de que esto causa una pérdida de información, se justifica por la siguiente razón:

- Mientras la reducción en el número de observaciones puede resultar en que la estimación de la Curva de Lorenz sea menos precisa, el procedimiento permitirá mayor exactitud en la estimación de medidas de pobreza, que es el objetivo final de este trabajo.

Disponiendo de los parámetros de la Curva de Lorenz, $\theta, \tau$ y $\delta$, el ingreso promedio de cada grupo, $\mu$, y la línea de pobreza, $z$, se tiene toda la información necesaria para la aplicación de las fórmulas desarrolladas en el anterior apartado.

Por otra parte, con la misma información se puede estimar el Coeficiente de Gini. Recordando que:

$$
G=2 \int_{0}^{1}[P-L(P)] d P=2 \int_{0}^{1} \theta P^{\tau}(1-P)^{\beta} d P
$$


Por lo que se tiene que:

$$
G=2 \theta B(1+\tau, 1+\delta)
$$

Donde

$$
B(1+\tau, 1+\delta)=\frac{\Gamma(1+\tau) \Gamma(1+\delta)}{\Gamma(2+\tau+\delta)}
$$

$B$ es la función Beta incompleta y $\Gamma$ es la distribución Gamma. 


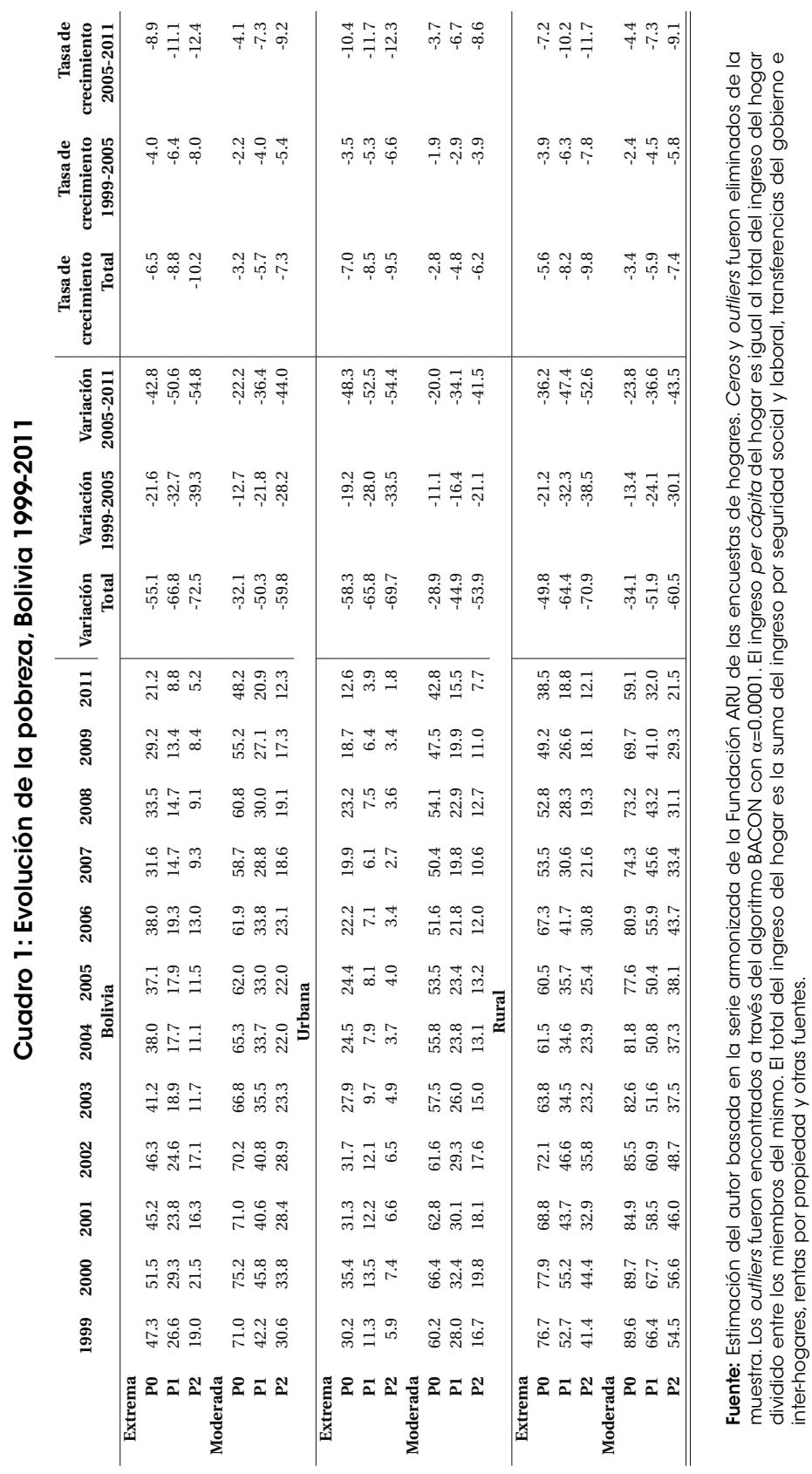




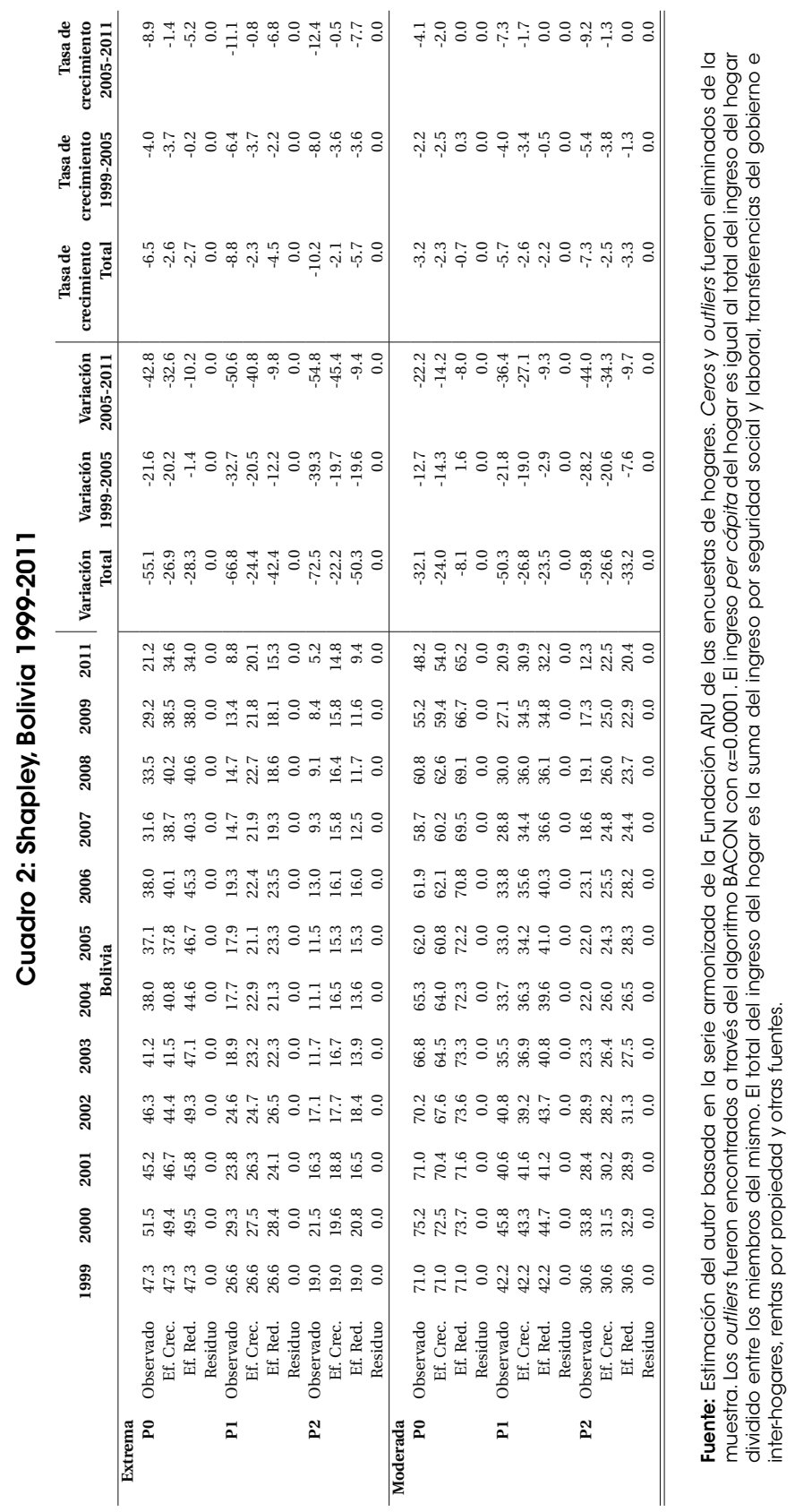




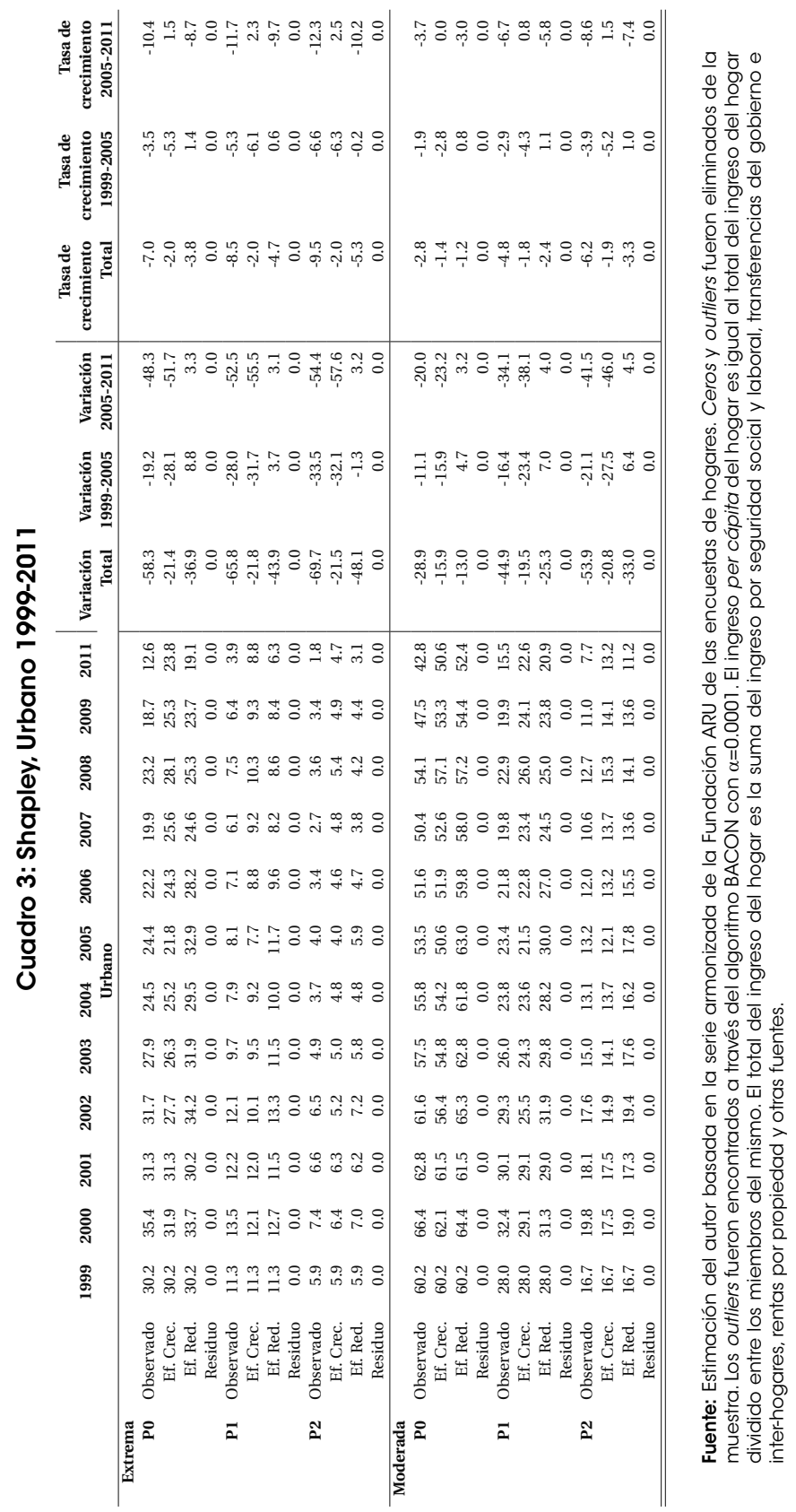




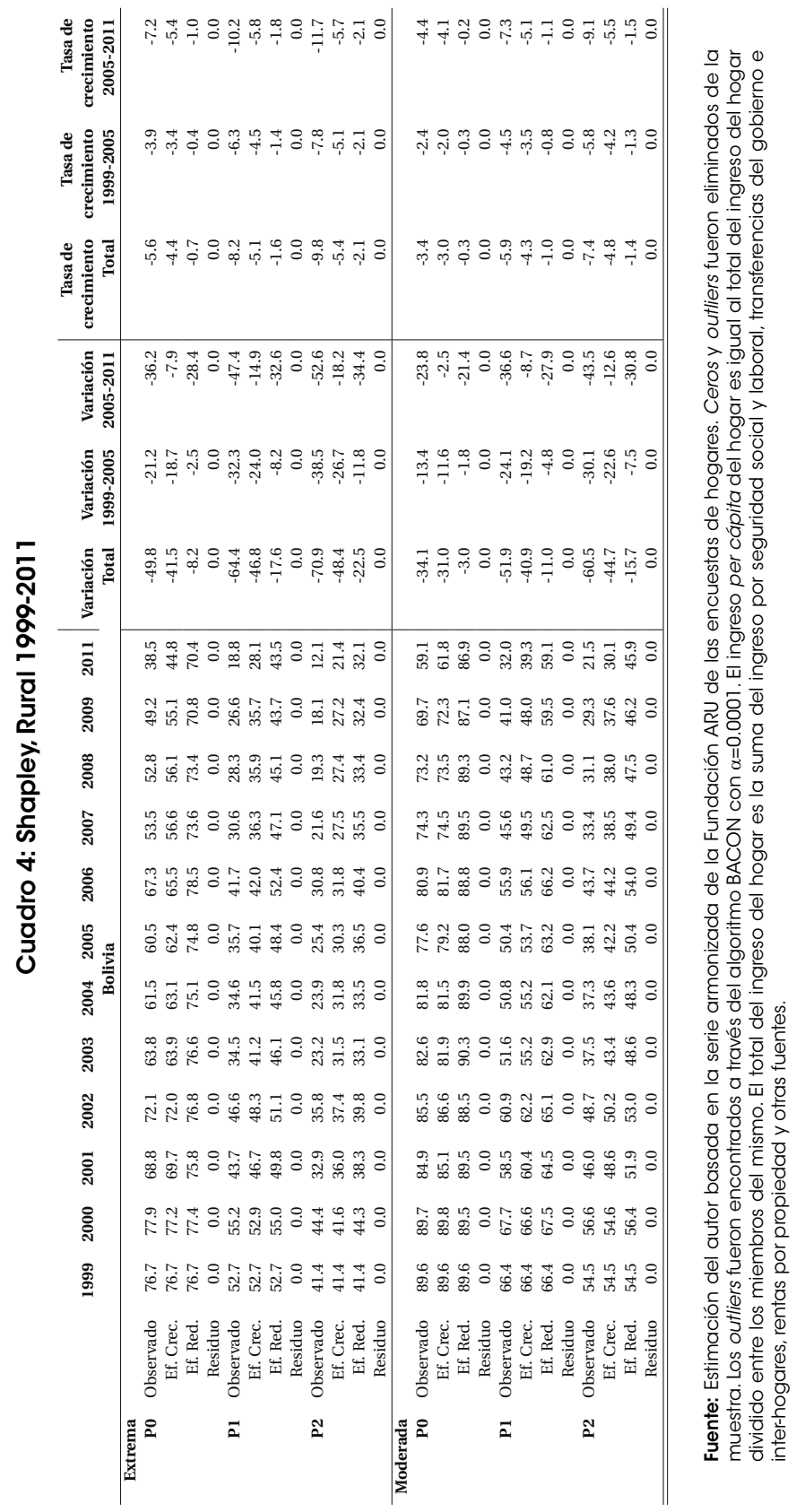




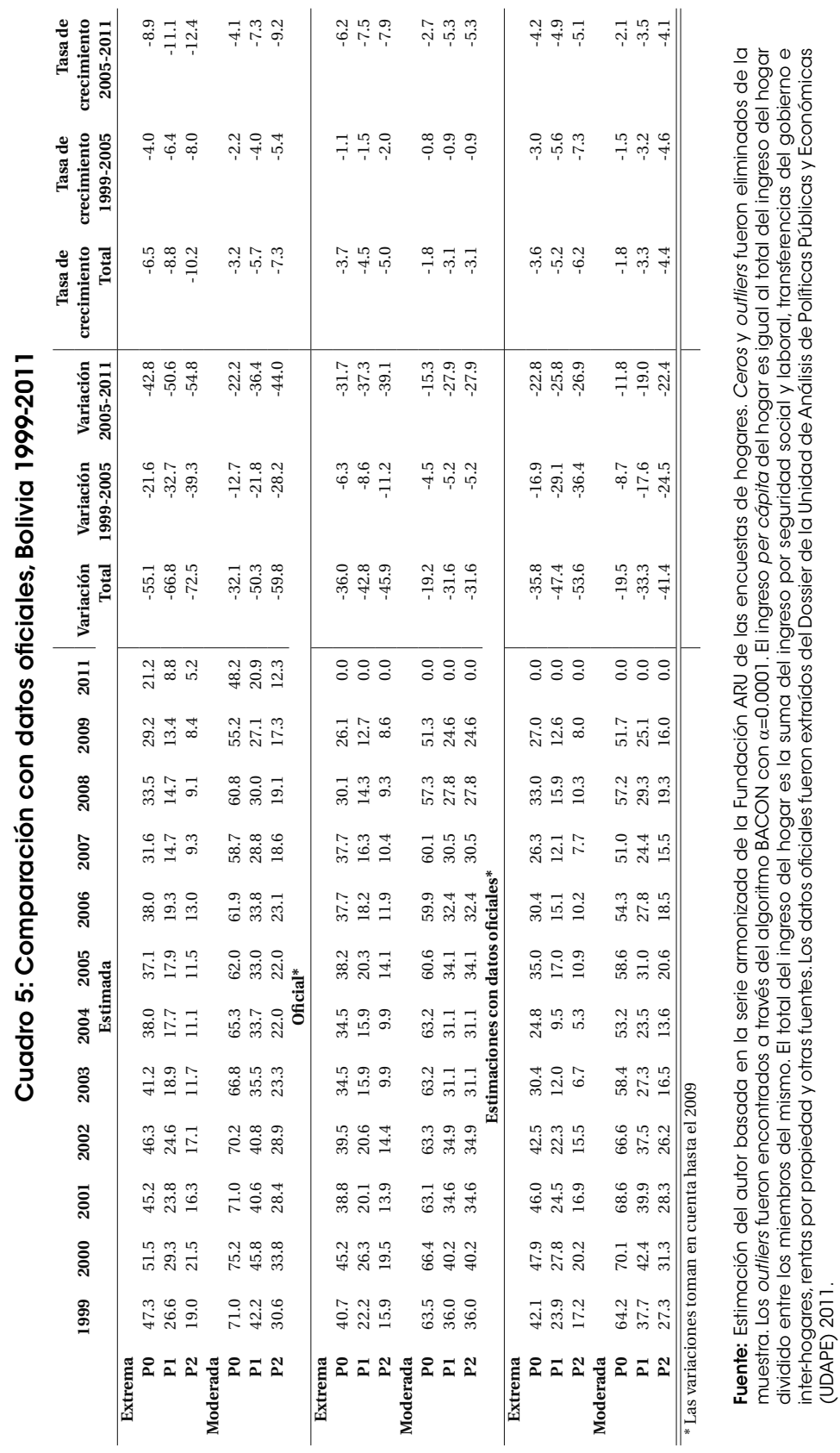




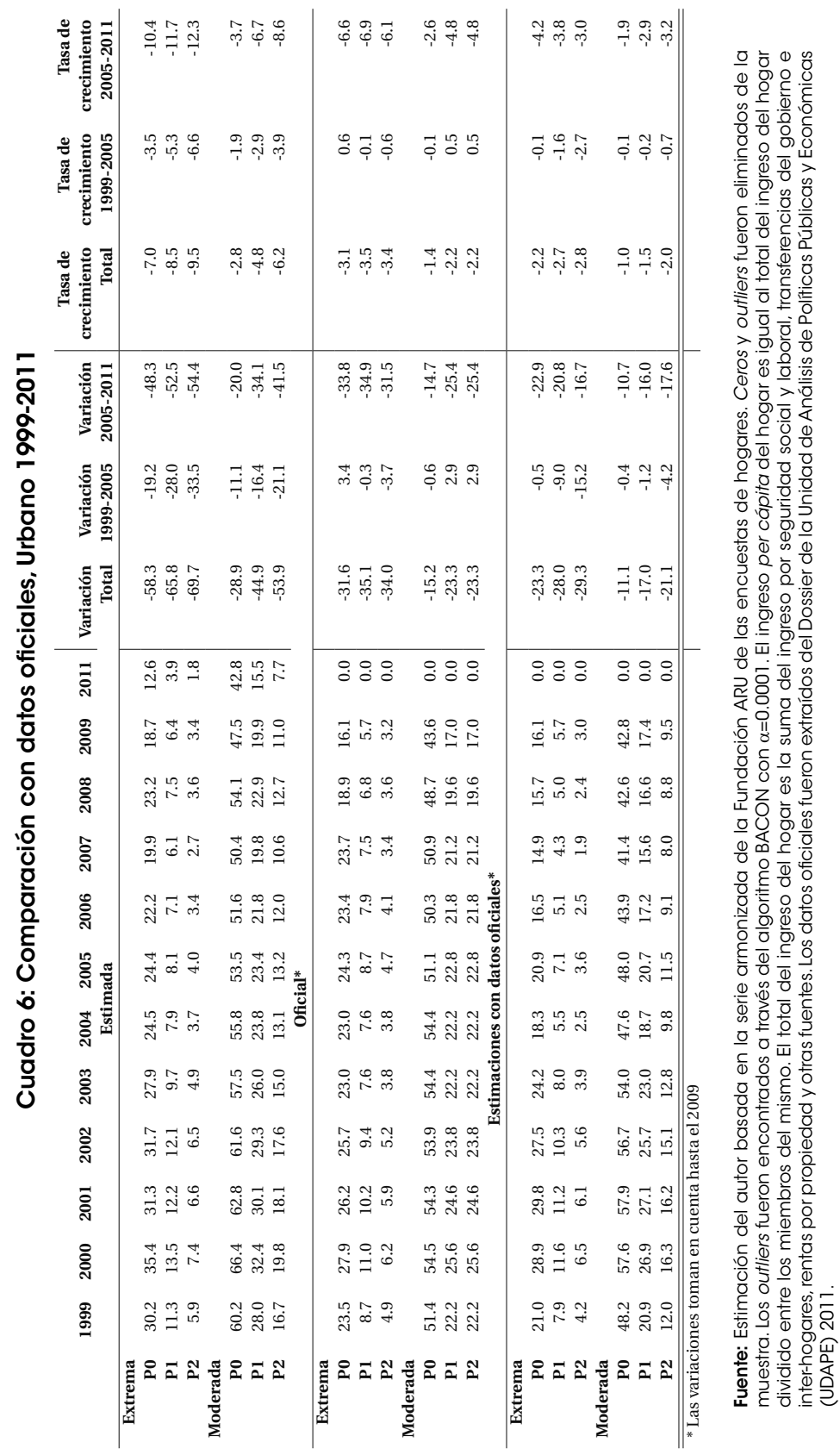




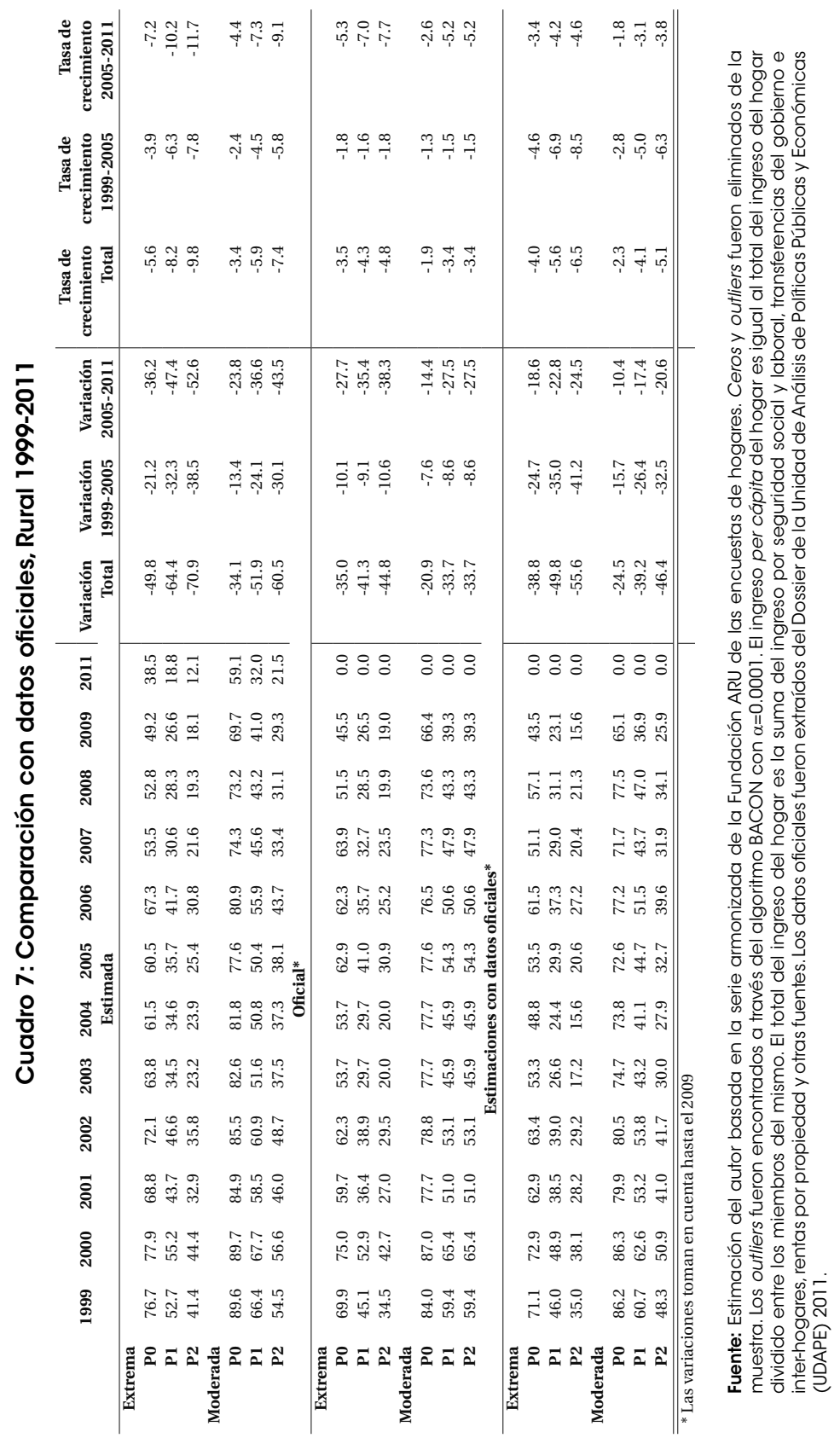




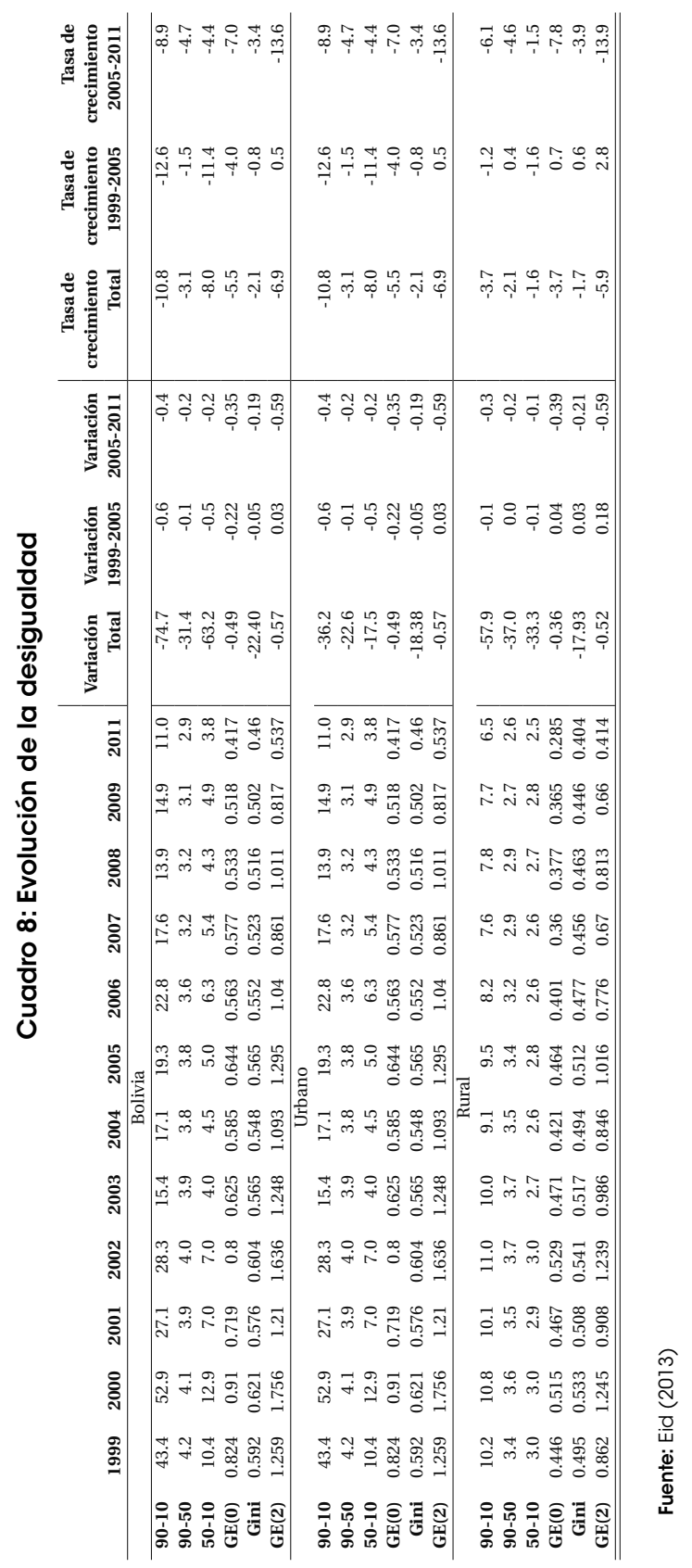




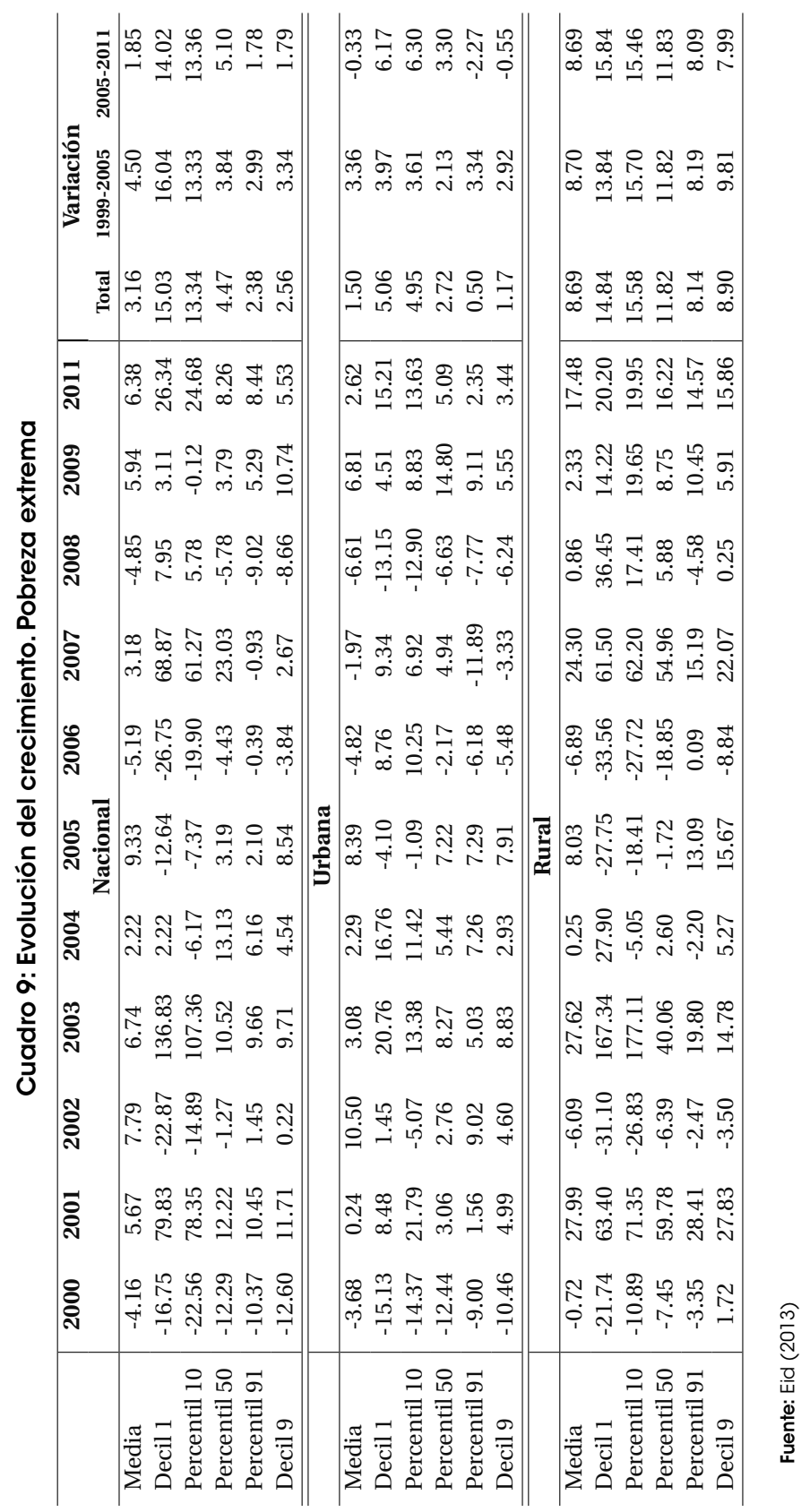




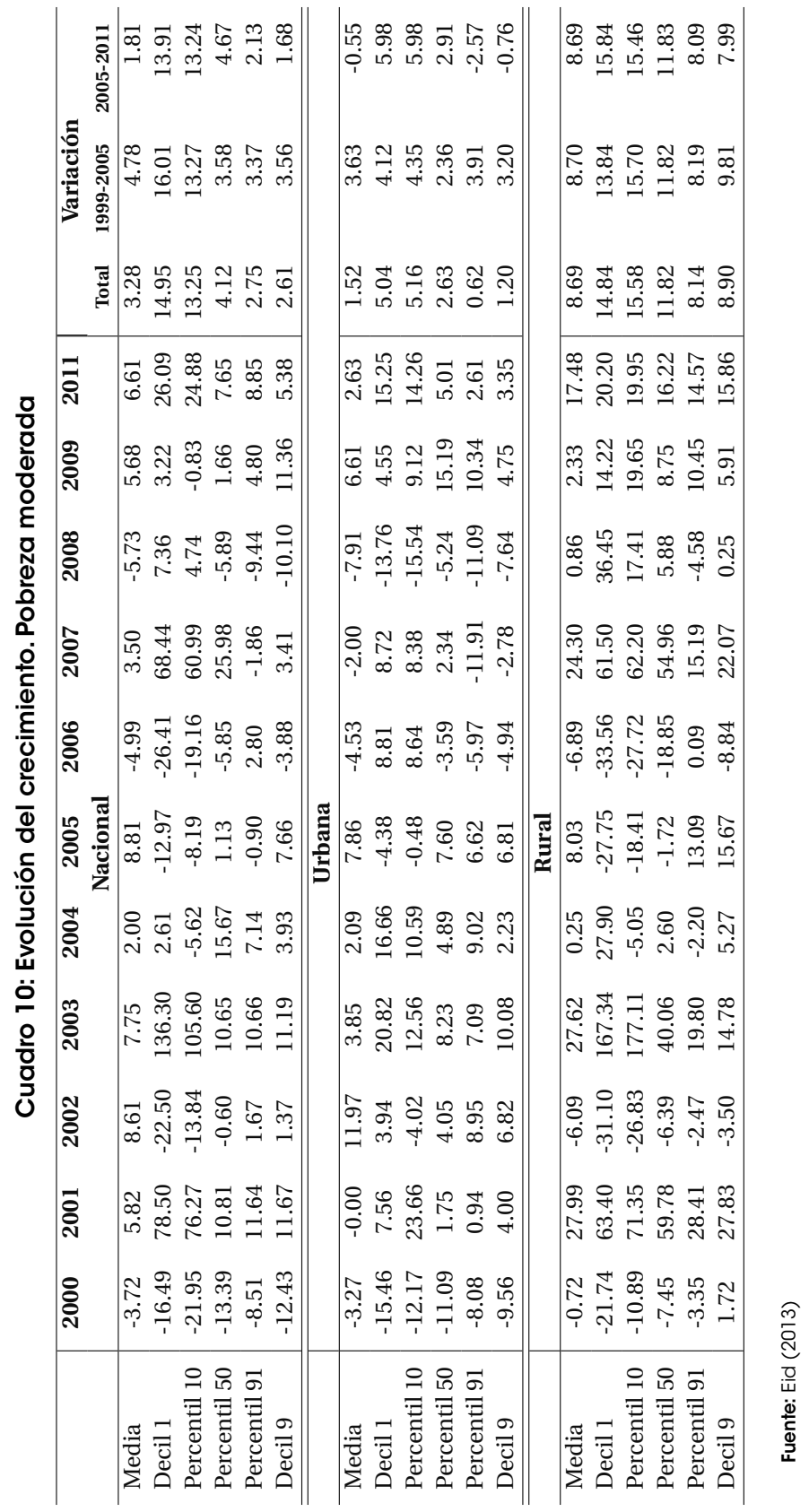




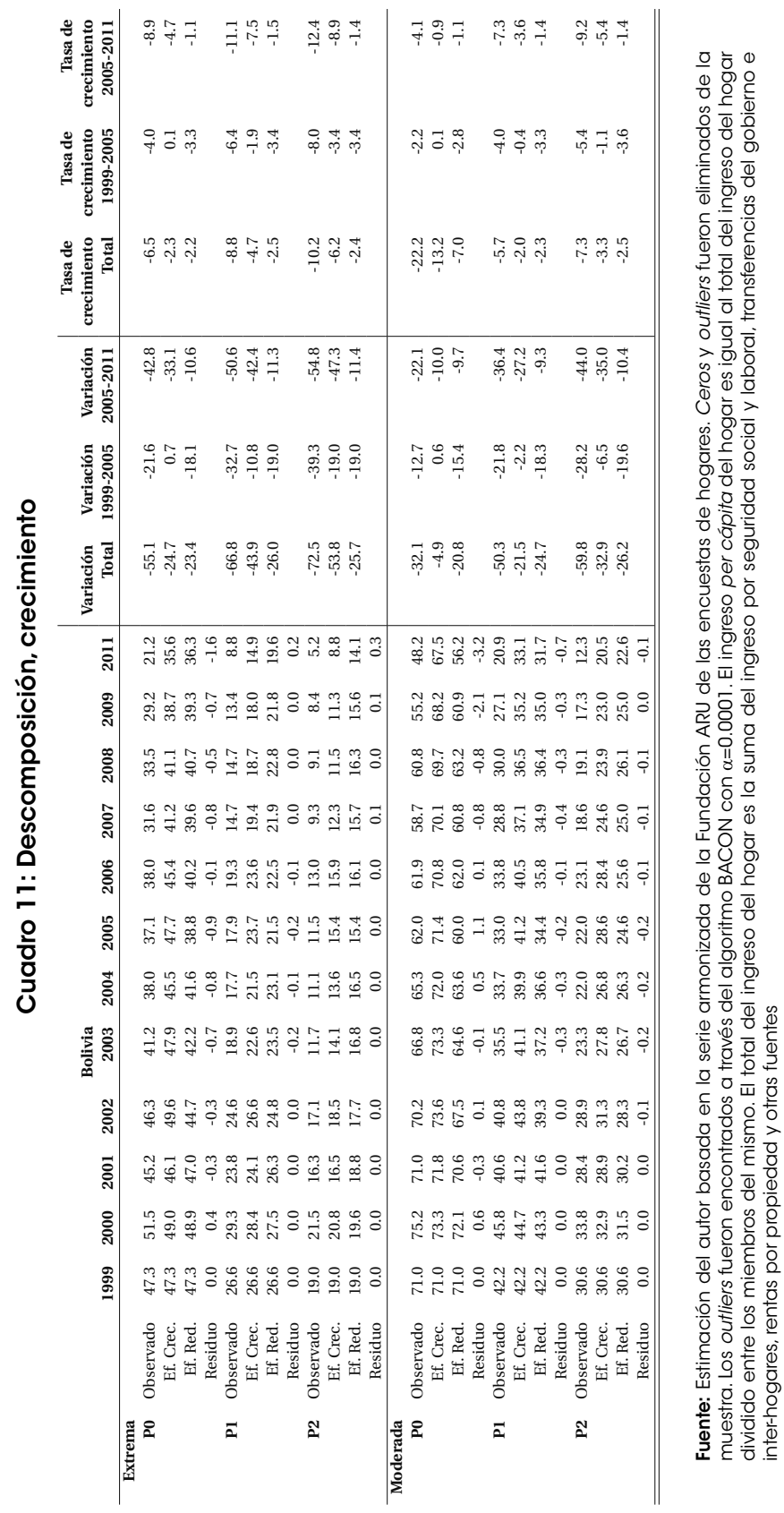




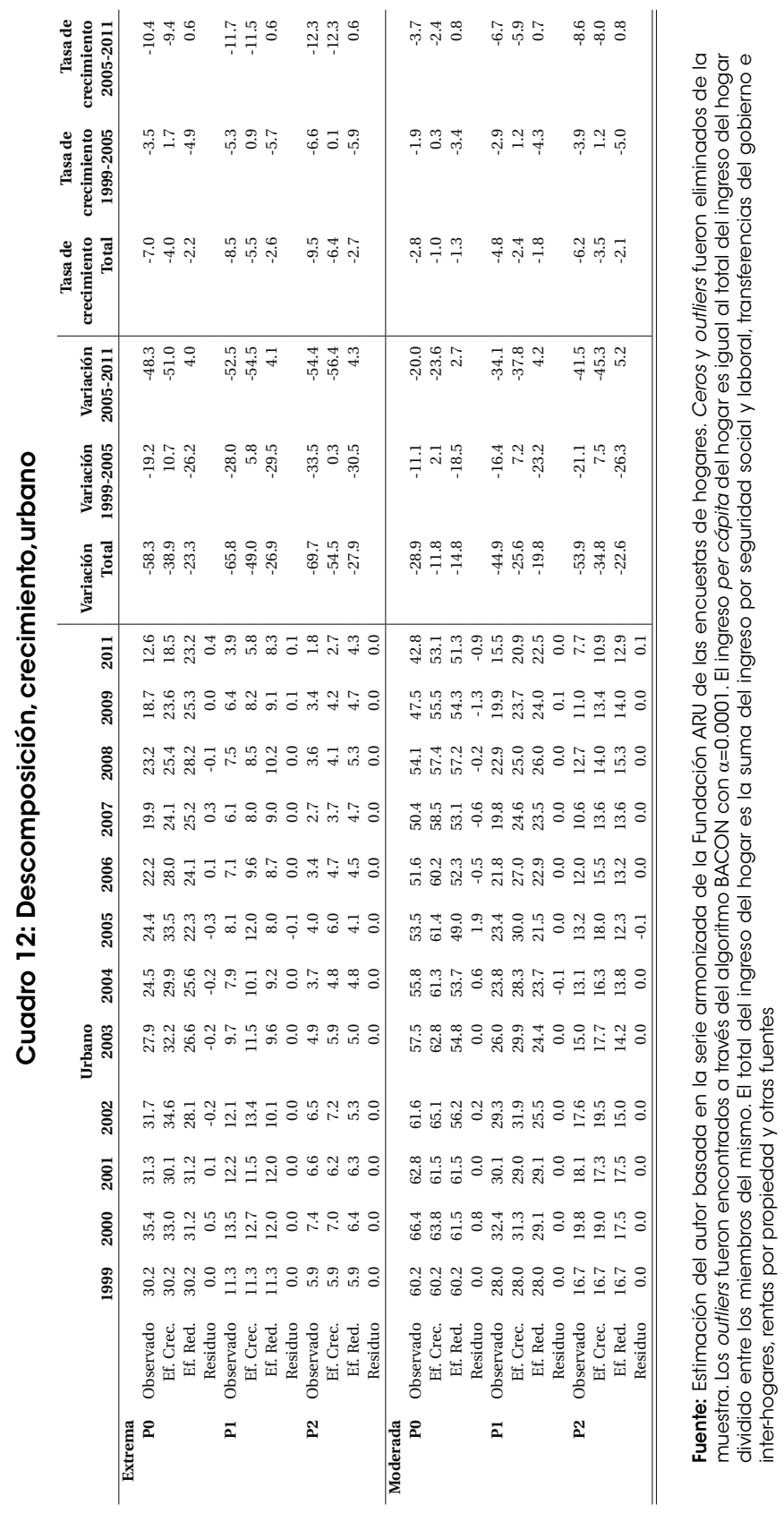




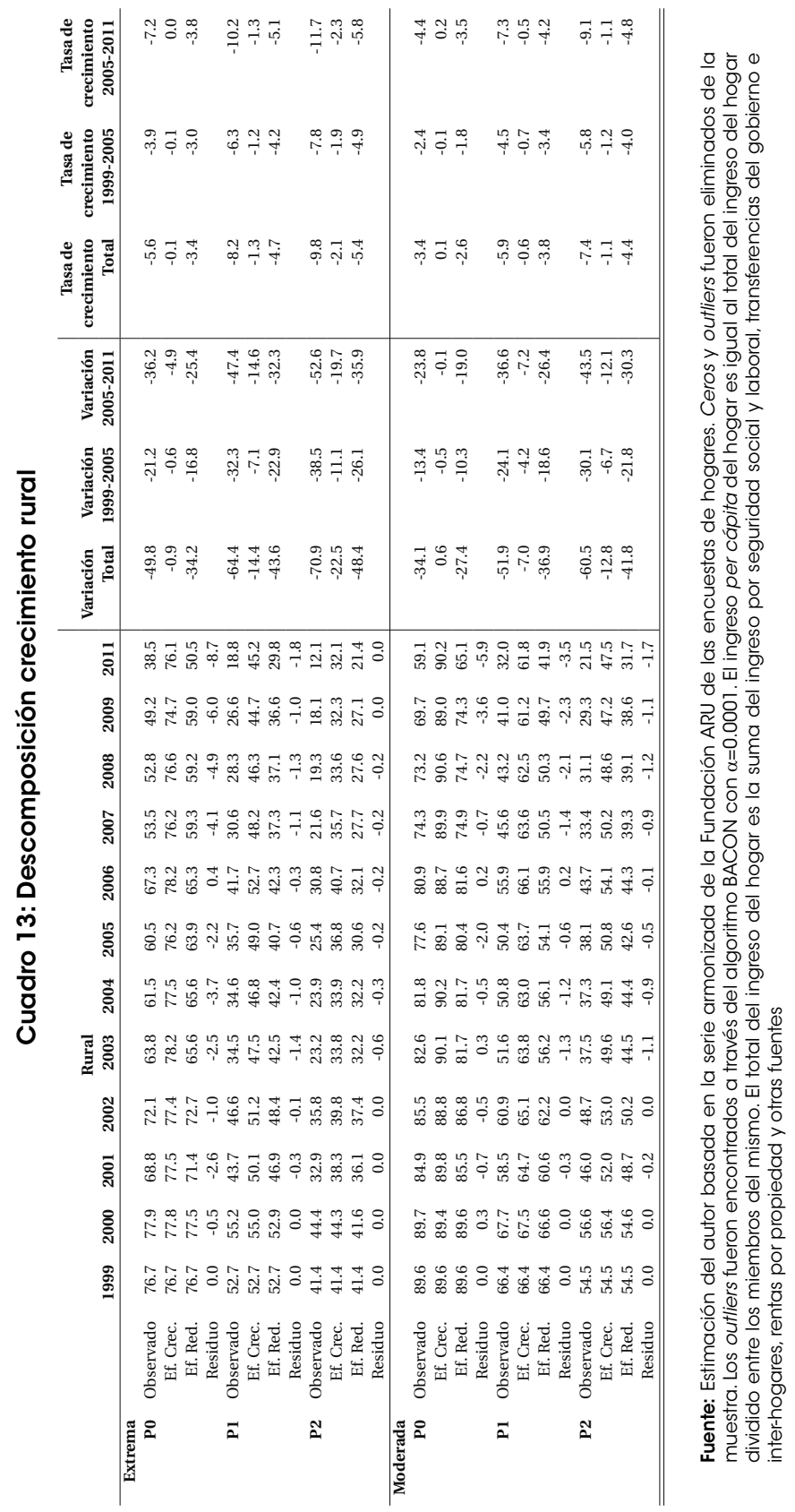




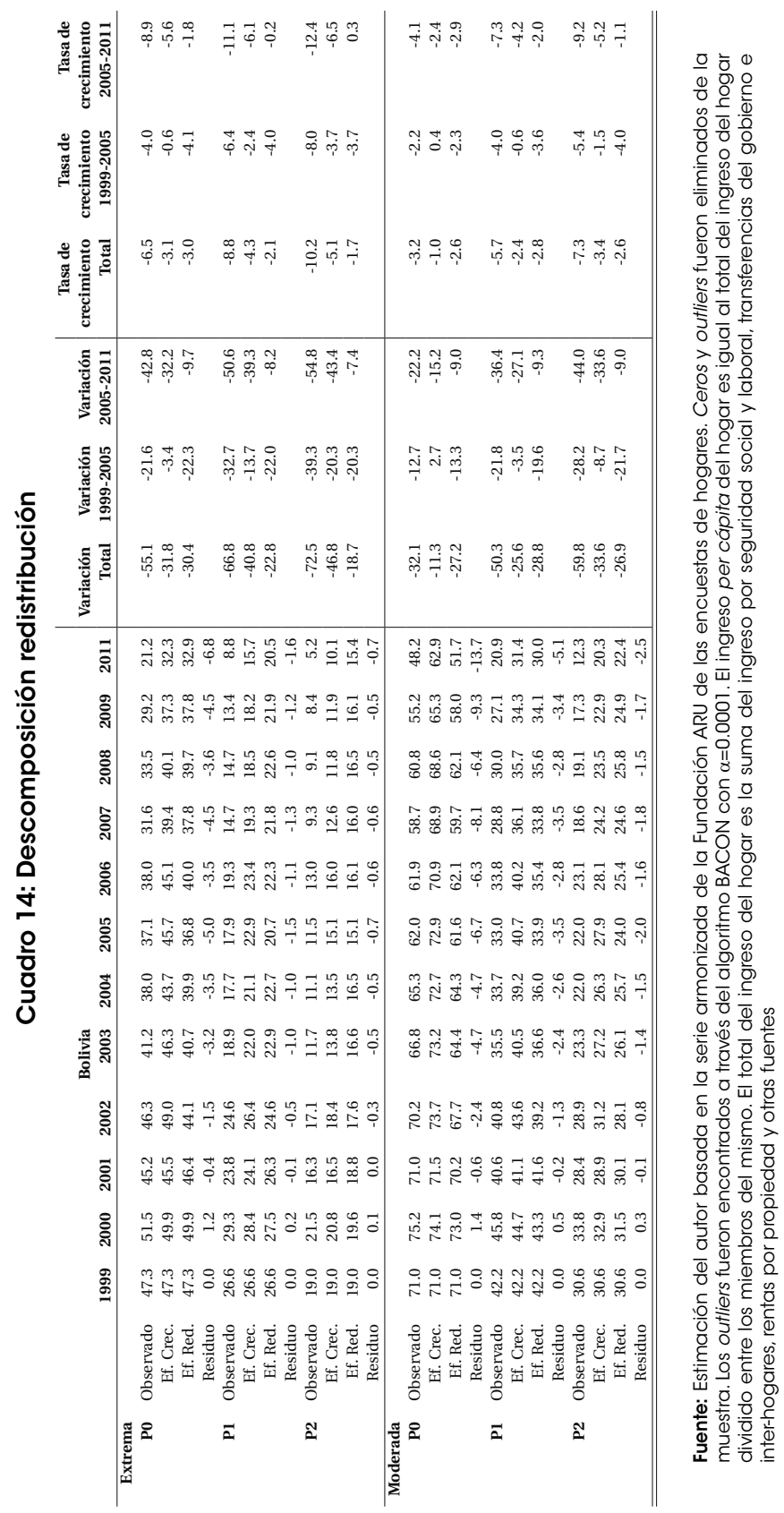




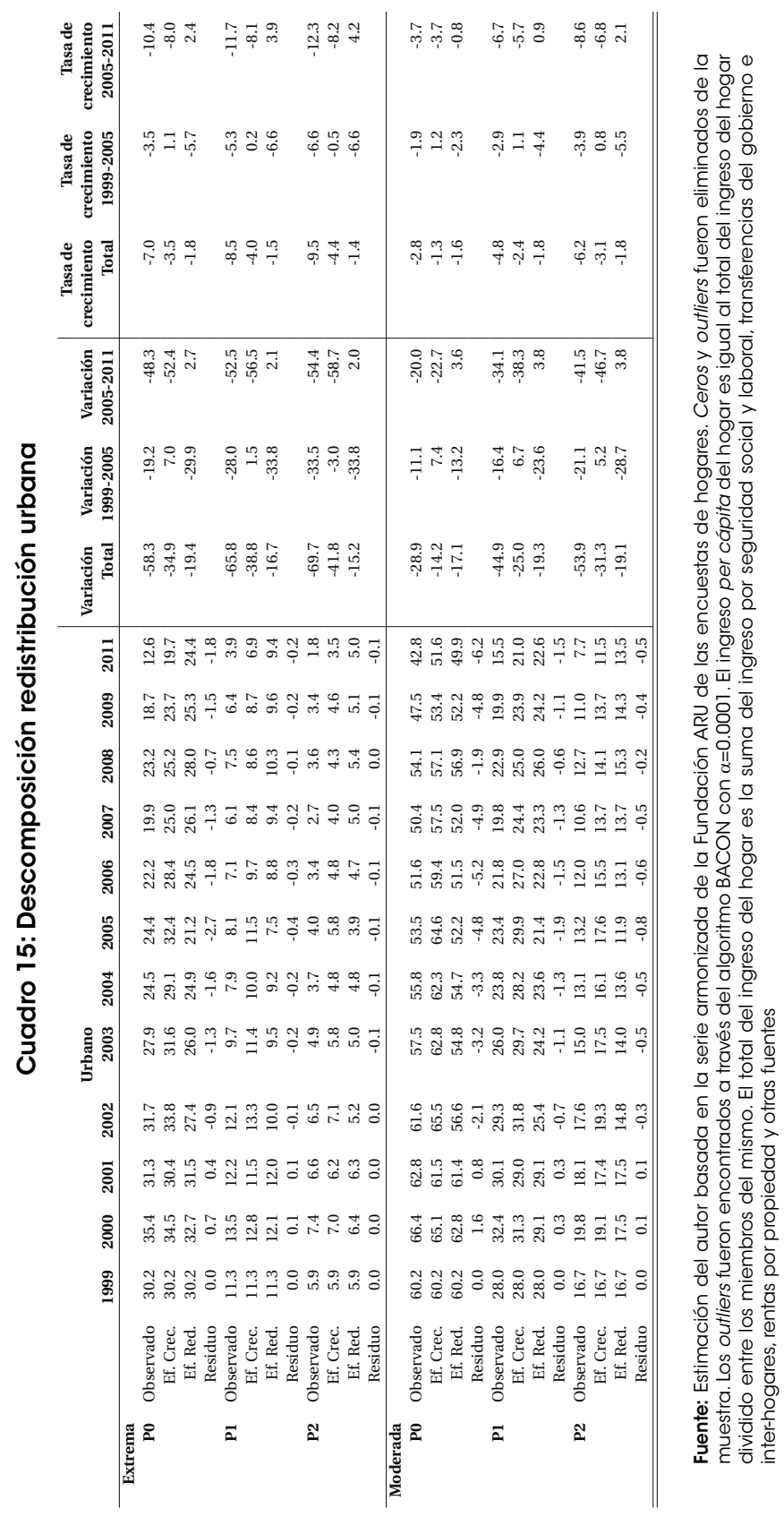




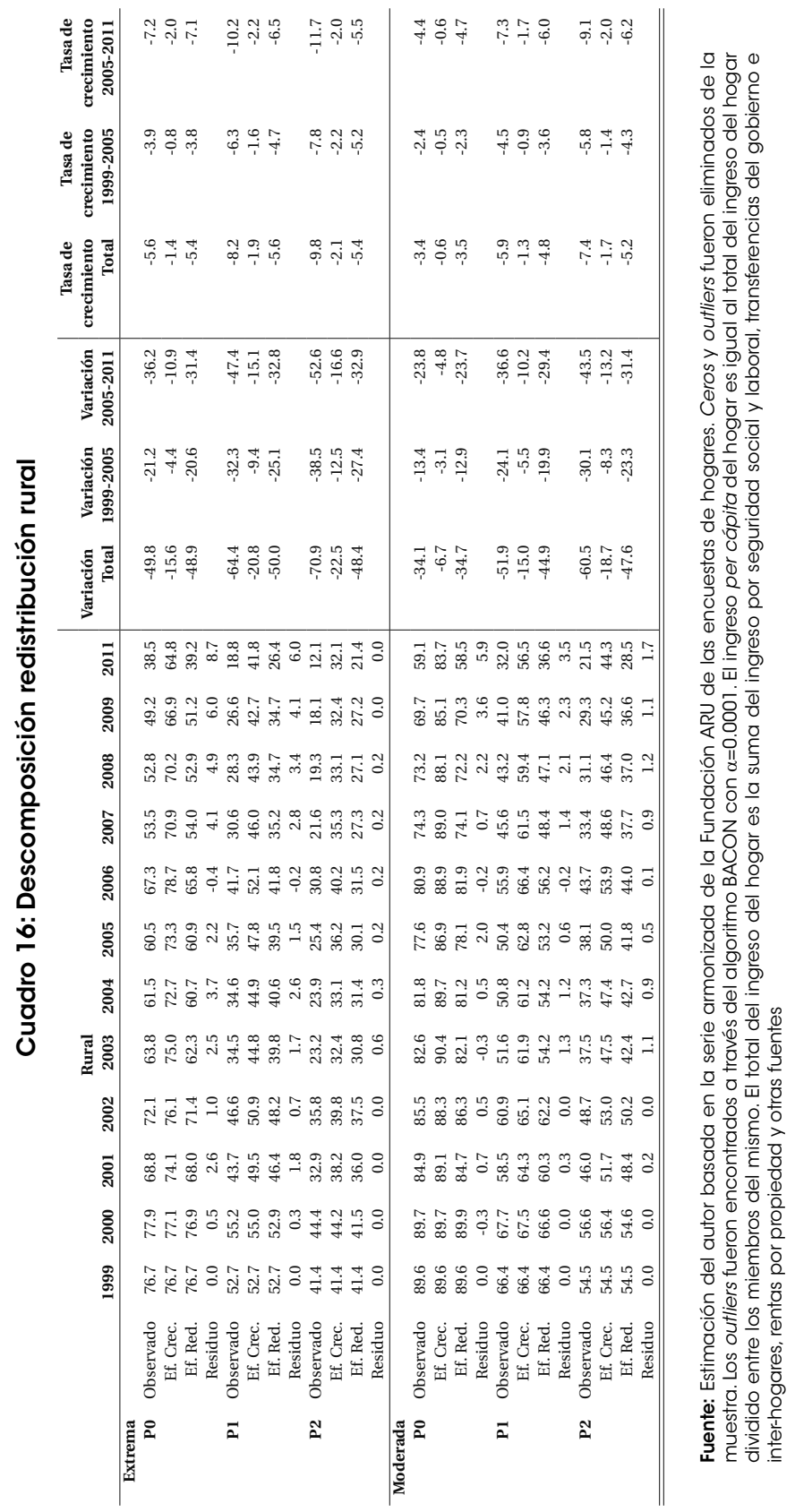




\section{Apéndice D. Gráficos}

Figura 20: Evolución de la pobreza extrema, Bolivia 1999-201 1

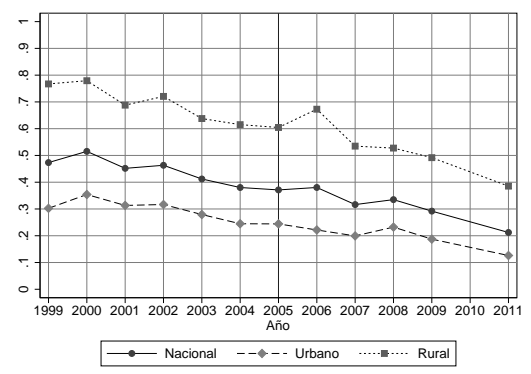

Incidencia en pabreza

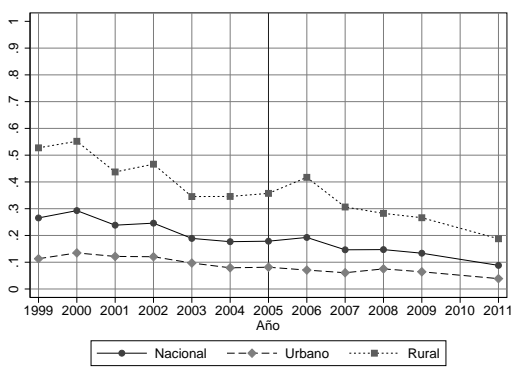

Brecha de pobreza

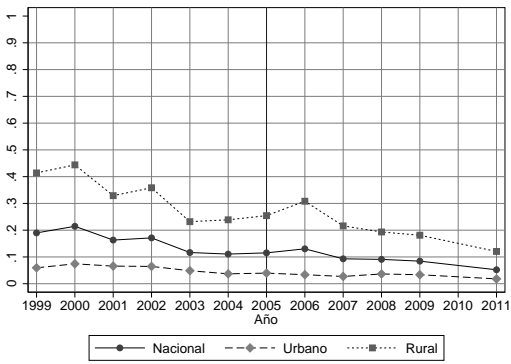

Fuente: Estimación del autor basada en la serie armonizada de la Fundación ARU de las encuestas de hogares. Ceros y outliers fueron eliminados de la muestra. Los outliers fueron encontrados a través del algoritmo $\mathrm{BACON} \operatorname{con} \alpha=0.0001$. El ingreso per cápita del hogar es igual al total del ingreso del hogar dividido entre los miembros del mismo. El total del ingreso del hogar es la suma del ingreso por seguridad social y laboral, transferencias del gobierno e inter-hogares, rentas por propiedad y otras fuentes. La incidencia en la pobreza tiene la siguiente fórmula: $P_{0}=\frac{1}{N} \int_{i=0}^{a} d y$ donde $N$ es la cantidad total de hogares $q$ es la cantidad de hogares que se encuentran por debajo de la de pobreza y y el ingreso del hogar. La brecha de pobreza se calcula mediante $P_{1}=\frac{1}{N} \int_{i=0}^{q} \frac{z-y_{i}}{Z} d y$. La severidad de la pobreza se calcula mediante $P_{2}=\frac{1}{N} \int_{i=0}^{q}\left(\frac{z-y_{i}}{Z}\right)^{2} d y$. 
Figura 21: Evolución de la pobreza moderada, Bolivia 1999-201 1
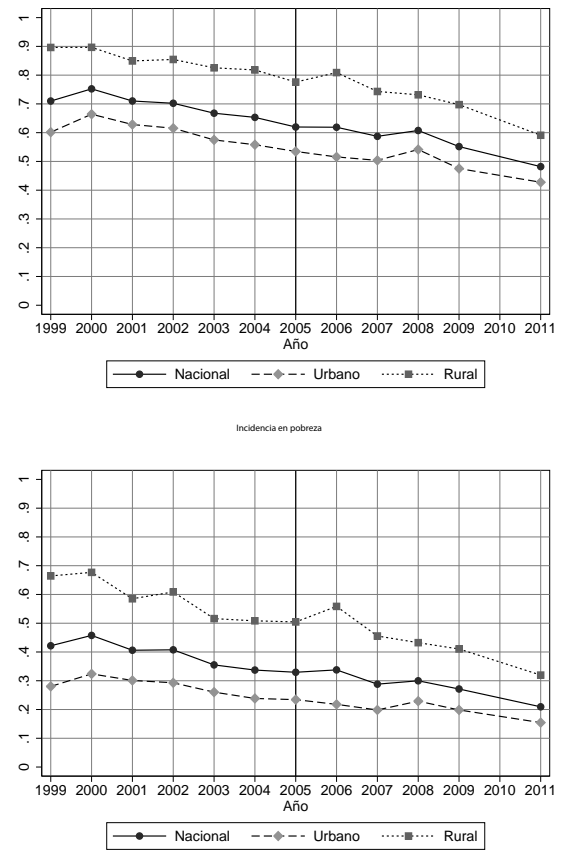

Brecha de pobreza

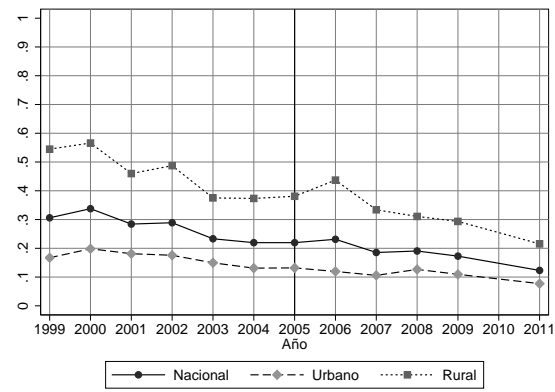

Fuente: Estimación del autor basada en la serie armonizada de la Fundación ARU de las encuestas de hogares. Ceros y outliers fueron eliminados de la muestra. Los outliers fueron encontrados a través del algoritmo BACON $\operatorname{con} \alpha=0.0001$. El ingreso per cápita del hogar es igual al total del ingreso del hogar dividido entre los miembros del mismo. El total del ingreso del hogar es la suma del ingreso por seguridad social y laboral, transferencias del gobierno e inter-hogares, rentas por propiedad y otras fuentes. La incidencia en la pobreza tiene la siguiente fórmula: $P_{0}=\frac{1}{N} \int_{i=0}^{q} d y$ donde $N$ es la cantidad total de hogares $q$ es la cantidad de hogares que se encuentran por debajo de la de pobreza y y el ingreso del hogar. La brecha de pobreza se calcula mediante $P_{1}=\frac{1}{N} \int_{i=0}^{q} \frac{z-y_{i}}{Z} d y$. La severidad de la pobreza se calcula mediante $P_{2}=\frac{1}{N} \int_{i=0}^{q}\left(\frac{z-y_{i}}{Z}\right)^{2} d y$. 
Figura 22: Pruebas de robustez, pobreza extrema. Bolivia

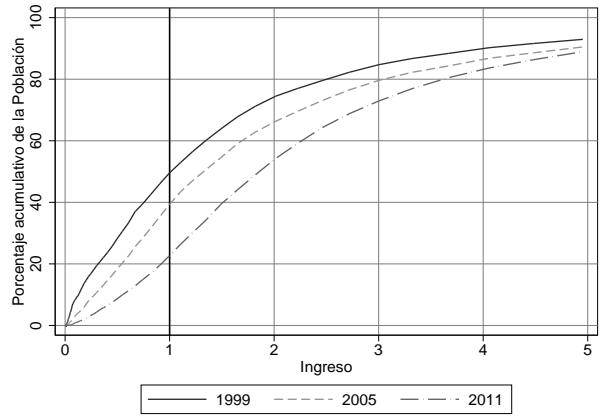

Curva de incidencia en pobreza

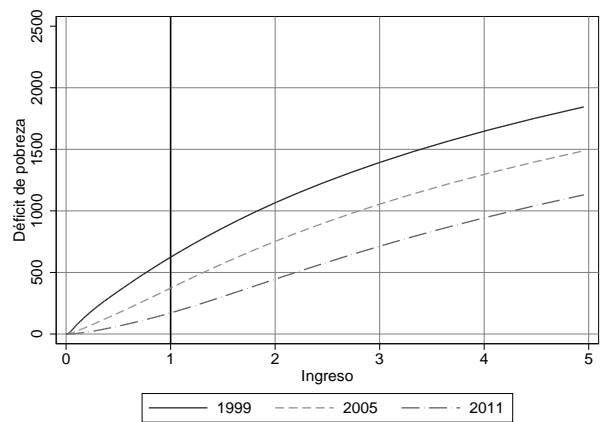

Curva de déficit de pobreza

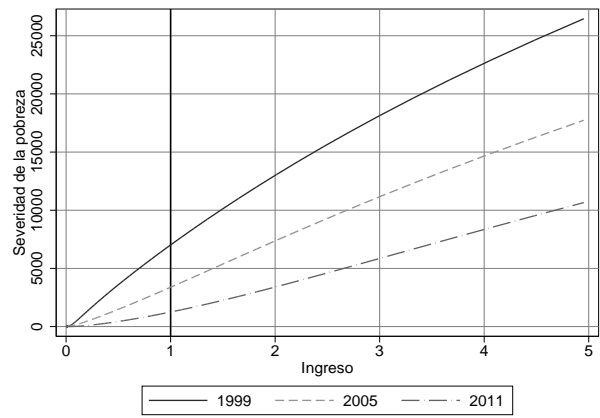

Curva de severidad de la pobreza

Fuente: Estimación del autor basada en la serie armonizada de la Fundación ARU de las encuestas de hogares. Ceros y outliers fueron eliminados de la muestra. Los outliers fueron encontrados a través del algoritmo BACON con $\alpha=0.0001$. El ingreso per cápita del hogar es igual al total del ingreso del hogar dividido entre los miembros del mismo. El total del ingreso del hogar es la suma del ingreso por seguridad social y laboral, transferencias del gobierno e inter-hogares, rentas por propiedad y otras fuentes. 
Figura 23: Pruebas de robustez, pobreza moderada. Bolivia

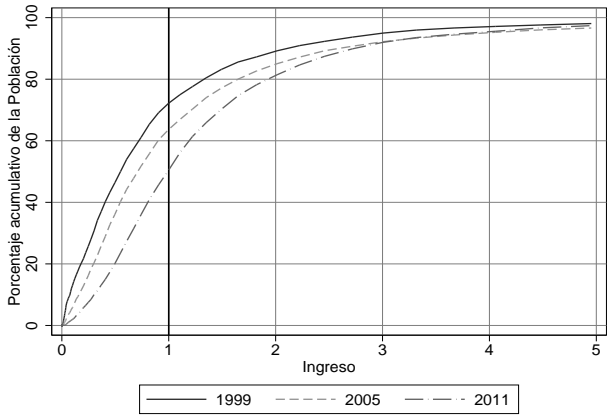

Curva de incidencia en pobreza

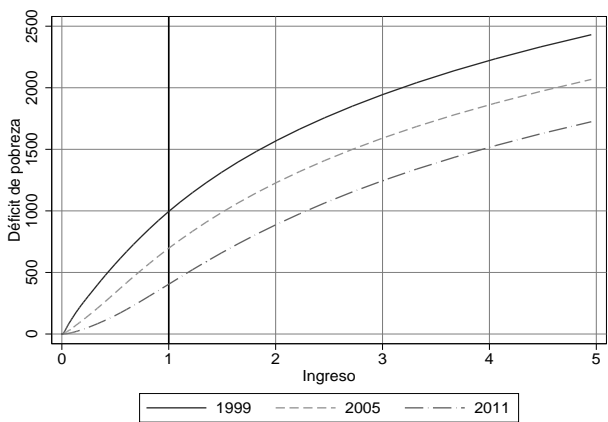

Curva de déficit de pobreza

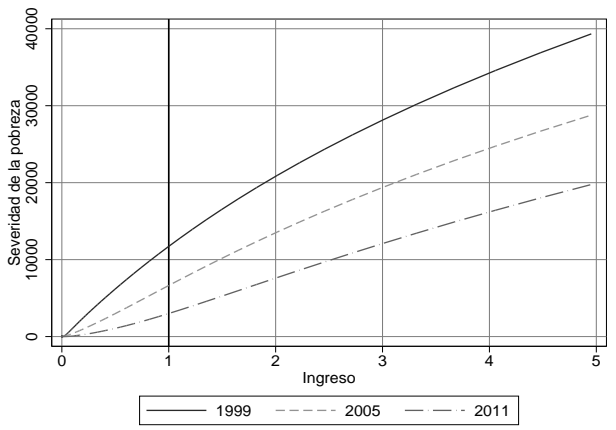

Curva de severidad de la pobreza

Fuente: Estimación del autor basada en la serie armonizada de la Fundación ARU de las encuestas de hogares. Ceros y outliers fueron eliminados de la muestra. Los outliers fueron encontrados a través del algoritmo BACON con $\alpha=0.0001$. El ingreso per cápita del hogar es igual al total del ingreso del hogar dividido entre los miembros del mismo. El total del ingreso del hogar es la suma del ingreso por seguridad social y laboral, transferencias del gobierno e inter-hogares, rentas por propiedad y otras fuentes. 
Figura 24: Pruebas de robustez, pobreza extrema urbana

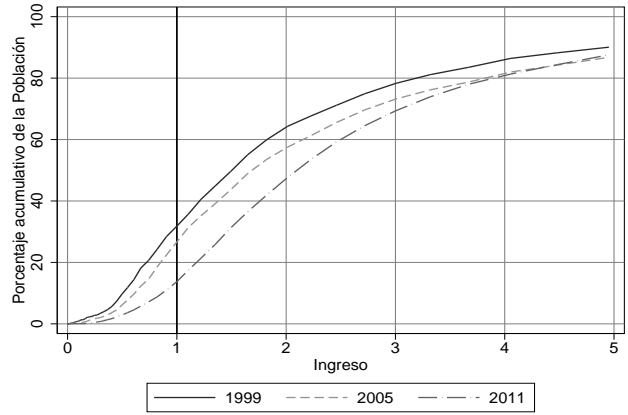

Curva de incidencia en pobreza

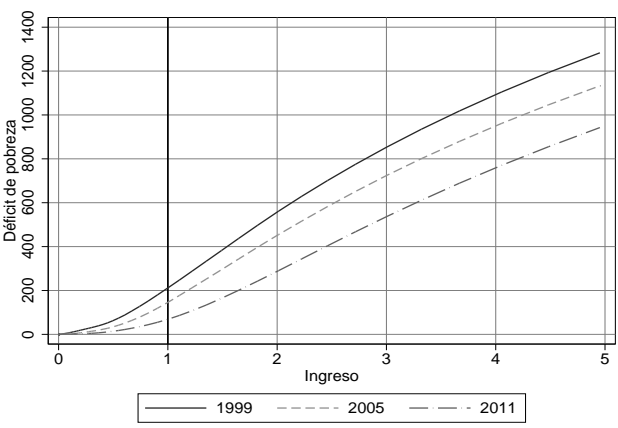

Curva de déficit de pobreza

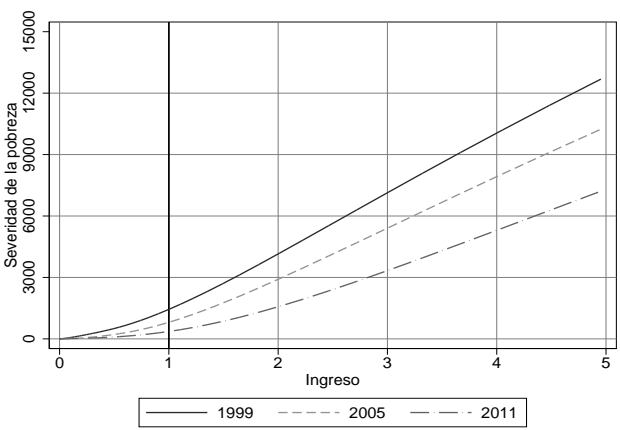

Curva de severidad de la pobreza

Fuente: Estimación del autor basada en la serie armonizada de la Fundación ARU de las encuestas de hogares. Ceros y outliers fueron eliminados de la muestra. Los outliers fueron encontrados a través del algoritmo BACON con $\alpha=0.0001$. El ingreso per cápita del hogar es igual al total del ingreso del hogar dividido entre los miembros del mismo. El total del ingreso del hogar es la suma del ingreso por seguridad social y laboral, transferencias del gobierno e inter-hogares, rentas por propiedad y otras fuentes. 


\section{Figura 25: Pruebas de robustez, pobreza moderada urbana}

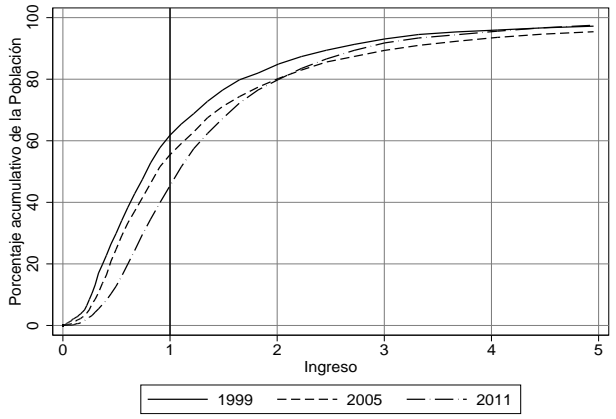

Curva de incidencia en pobreza

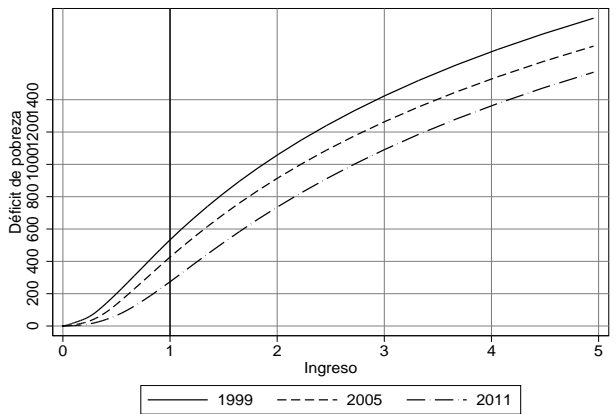

Curva de déficit de pobreza

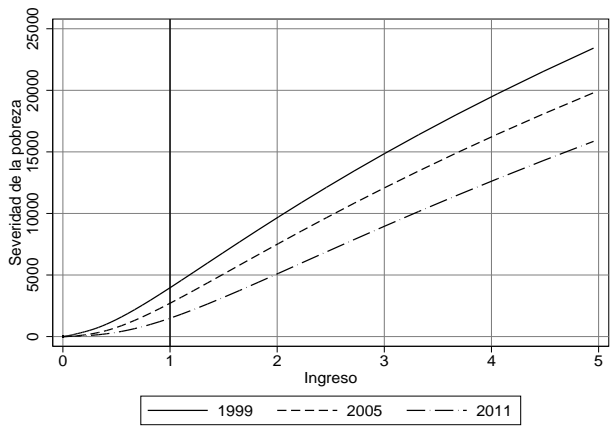

Curva de severidad de la pobreza

Fuente: Estimación del autor basada en la serie armonizada de la Fundación ARU de las encuestas de hogares. Ceros y outliers fueron eliminados de la muestra. Los outliers fueron encontrados a través del algoritmo BACON con $\alpha=0.0001$. El ingreso per cápita del hogar es igual al total del ingreso del hogar dividido entre los miembros del mismo. El total del ingreso del hogar es la suma del ingreso por seguridad social y laboral, transferencias del gobierno e inter-hogares, rentas por propiedad y otras fuentes. 
Figura 26: Pruebas de robustez, pobreza extrema rural

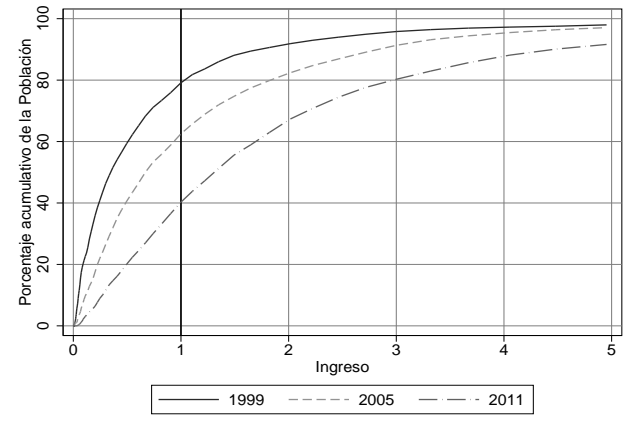

Curva de incidencia en pobreza

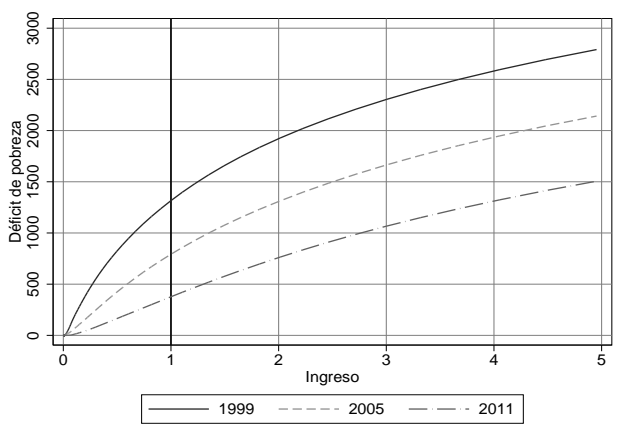

Curva de déficit de pobreza

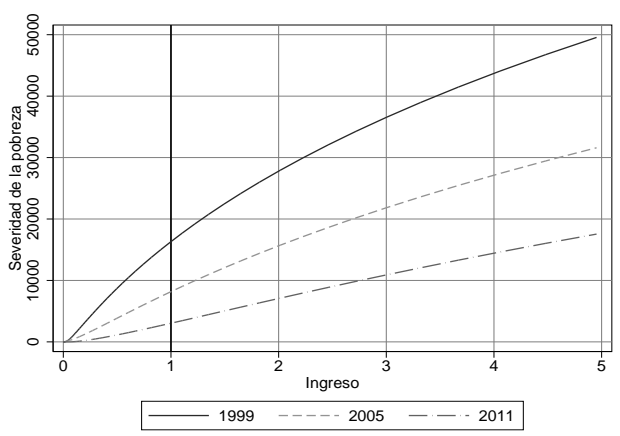

Curva de severidad de la pobreza

Fuente: Estimación del autor basada en la serie armonizada de la Fundación ARU de las encuestas de hogares. Ceros y outliers fueron eliminados de la muestra. Los outliers fueron encontrados a través del algoritmo BACON con $\alpha=0.0001$. El ingreso per cápita del hogar es igual al total del ingreso del hogar dividido entre los miembros del mismo. El total del ingreso del hogar es la suma del ingreso por seguridad social y laboral, transferencias del gobierno e inter-hogares, rentas por propiedad y otras fuentes. 
Figura 27: Pruebas de robustez, pobreza moderada rural

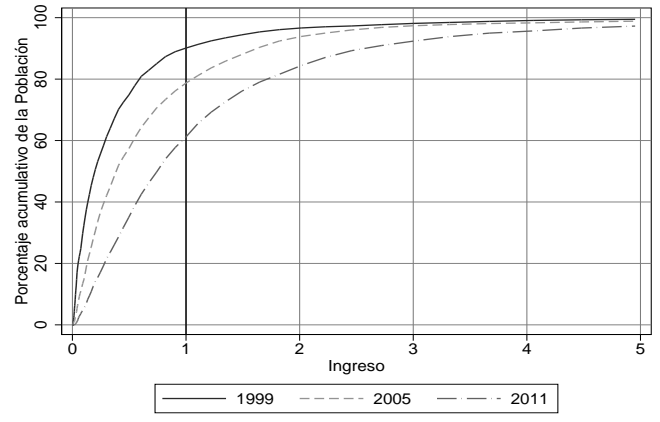

Curva de incidencia en pobreza

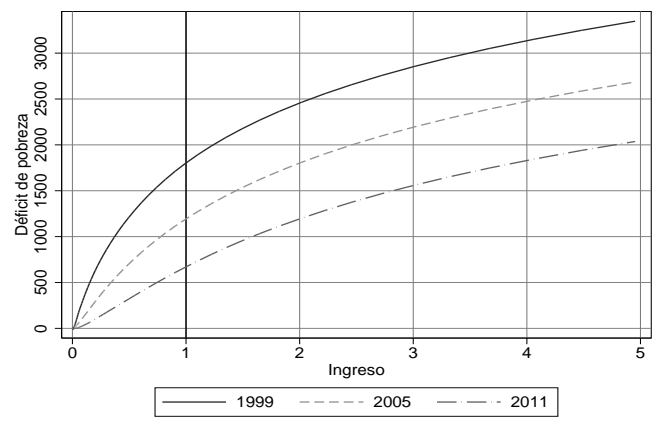

Curva de déficit de pobreza

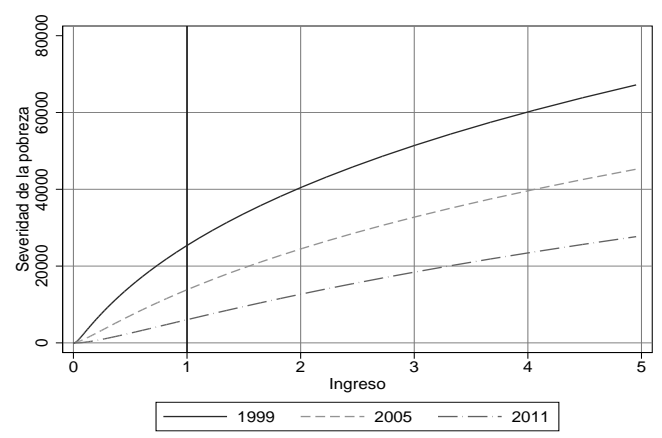

Curva de severidad de la pobreza

Fuente: Estimación del autor basada en la serie armonizada de la Fundación ARU de las encuestas de hogares. Ceros y outliers fueron eliminados de la muestra. Los outliers fueron encontrados a través del algoritmo BACON con $\alpha=0.0001$. El ingreso per cápita del hogar es igual al total del ingreso del hogar dividido entre los miembros del mismo. El total del ingreso del hogar es la suma del ingreso por seguridad social y laboral, transferencias del gobierno e inter-hogares, rentas por propiedad y otras fuentes. 


\section{Figura 28: Comparación con datos oficiales. Pobreza extrema. Bolivia}

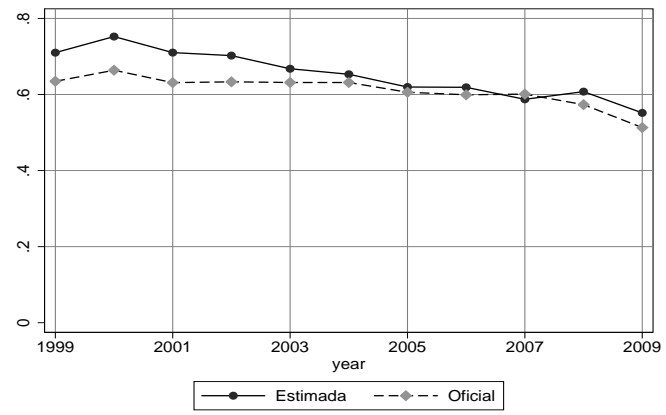

Incidencia en pobreza

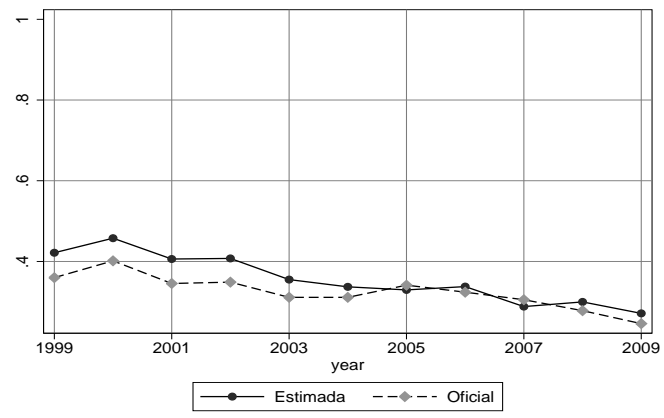

Brecha pobreza

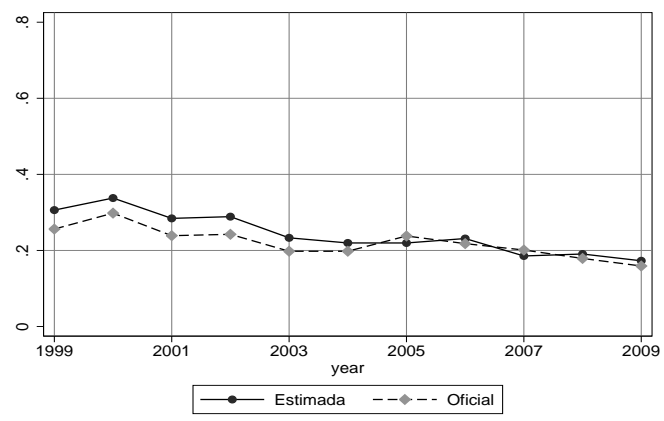

Severidad de la pobreza

Fuente: Estimación del autor basada en la serie armonizada de la Fundación ARU de las encuestas de hogares. Ceros y outliers fueron eliminados de la muestra. Los outliers fueron encontrados a través del algoritmo BACON con $\alpha=0.0001$. El ingreso per cápita del hogar es igual al total del ingreso del hogar dividido entre los miembros del mismo. El total del ingreso del hogar es la suma del ingreso por seguridad social y laboral, transferencias del gobierno e inter-hogares, rentas por propiedad y otras fuentes. Los datos oficiales fueron extraídos del Dossier de la Unidad de Análisis de Políticas Públicas y Económicas (UDAPE) 2011. 


\section{Figura 29: Comparación con datos oficiales. Pobreza moderada. Bolivia}

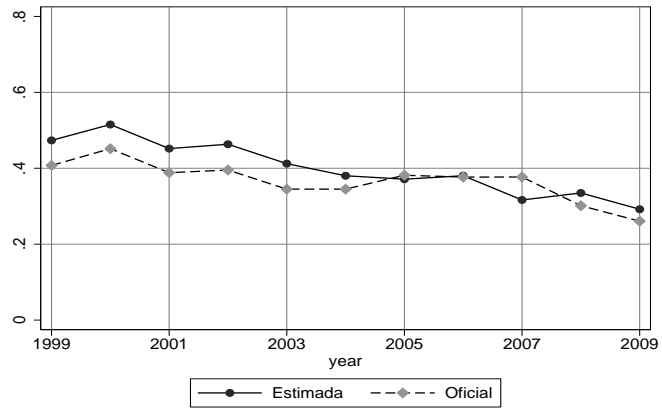

Incidencia en pobreza

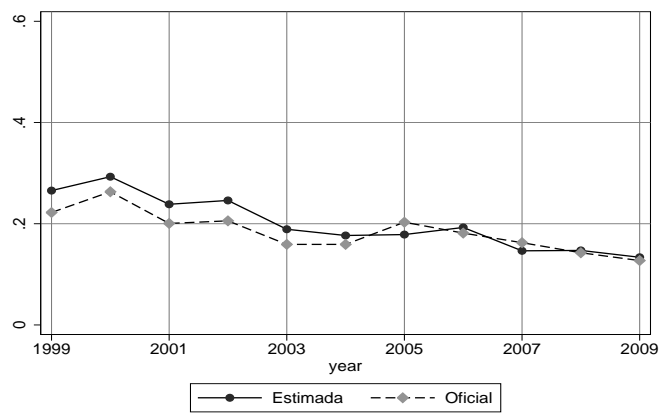

Brecha pobreza

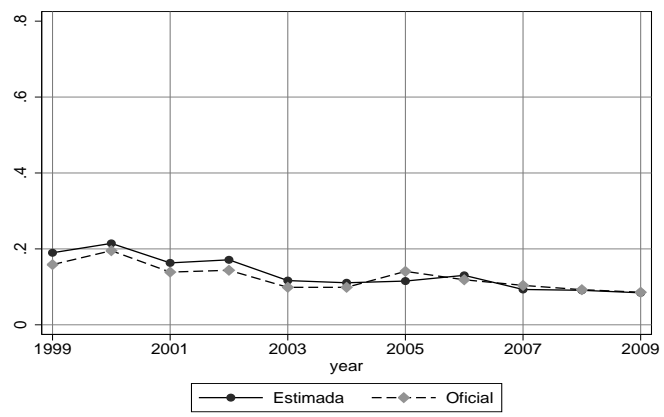

Severidad de la pobreza

Fuente: Estimación del autor basada en la serie armonizada de la Fundación ARU de las encuestas de hogares. Ceros y outliers fueron eliminados de la muestra. Los outliers fueron encontrados a través del algoritmo BACON $\operatorname{con} \alpha=0.0001$. El ingreso per cápita del hogar es igual al total del ingreso del hogar dividido entre los miembros del mismo. El total del ingreso del hogar es la suma del ingreso por seguridad social y laboral, transferencias del gobierno e inter-hogares, rentas por propiedad y otras fuentes. Los datos oficiales fueron extraídos del Dossier de la Unidad de Análisis de Políticas Públicas y Económicas (UDAPE) 2011. 


\section{Figura 30: Comparación con datos oficiales. Pobreza extrema urbana}

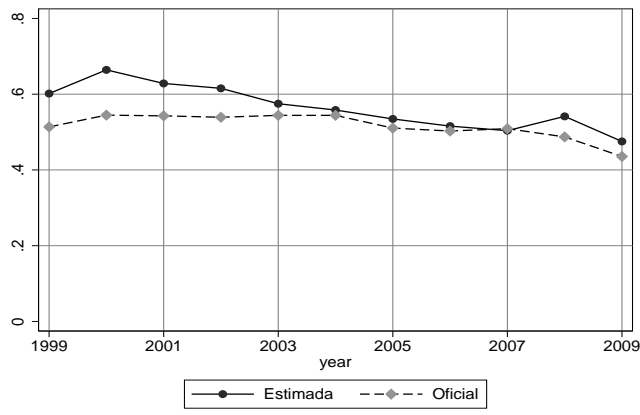

Incidencia en pobreza

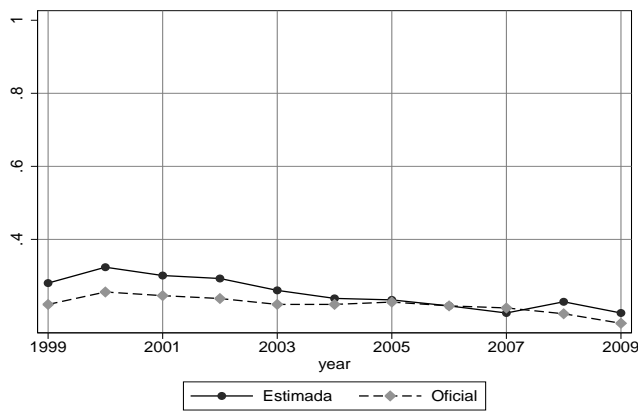

Brecha pobreza

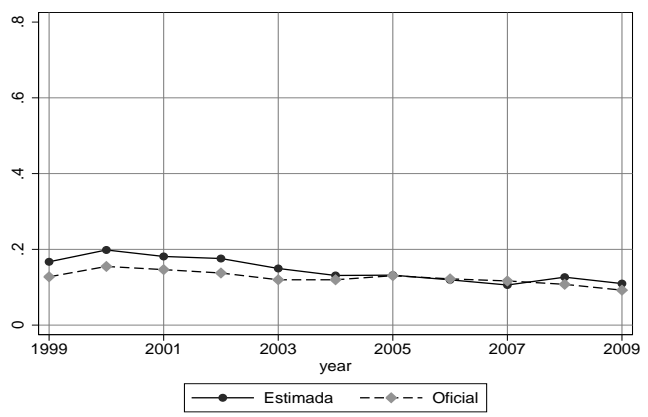

Severidad de la pobreza

Fuente: Estimación del autor basada en la serie armonizada de la Fundación ARU de las encuestas de hogares. Ceros y outliers fueron eliminados de la muestra. Los outliers fueron encontrados a través del algoritmo BACON con $\alpha=0.0001$. El ingreso per cápita del hogar es igual al total del ingreso del hogar dividido entre los miembros del mismo. El total del ingreso del hogar es la suma del ingreso por seguridad social y laboral, transferencias del gobierno e inter-hogares, rentas por propiedad y otras fuentes. Los datos oficiales fueron extraídos del Dossier de la Unidad de Análisis de Políticas Públicas y Económicas (UDAPE) 2011. 
Figura 31: Comparación con datos oficiales. Pobreza moderada urbana

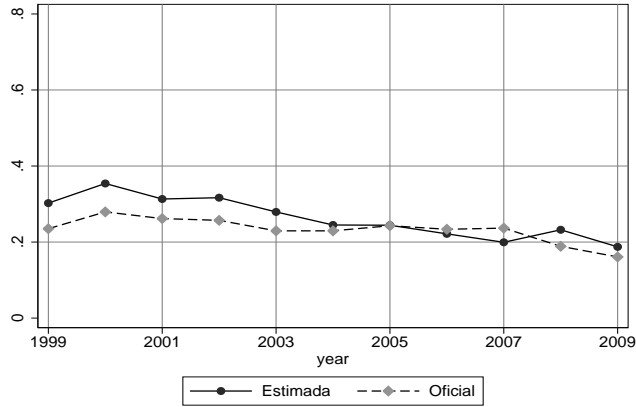

Incidencia en pobreza

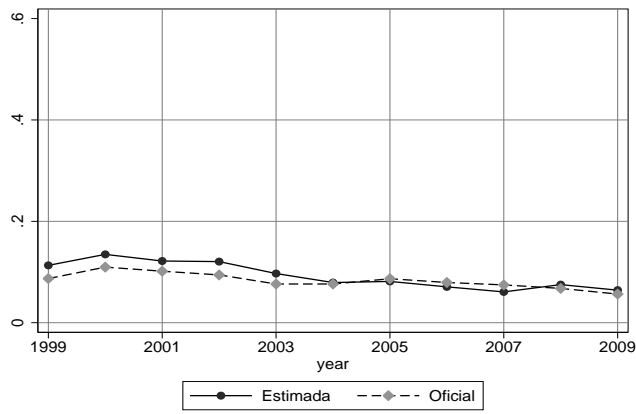

Brecha pobreza

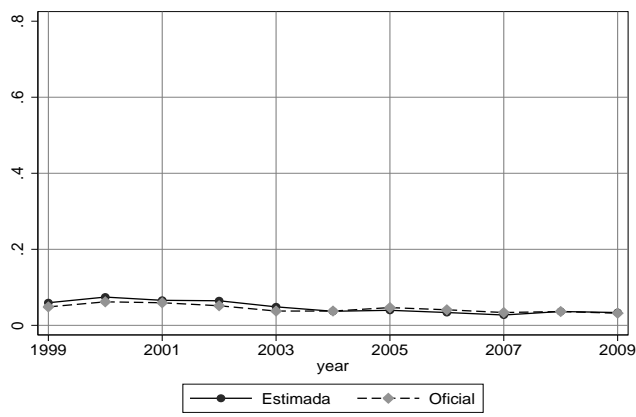

Severidad de la pobreza

Fuente: Estimación del autor basada en la serie armonizada de la Fundación ARU de las encuestas de hogares. Ceros y outliers fueron eliminados de la muestra. Los outliers fueron encontrados a través del algoritmo BACON $\operatorname{con} \alpha=0.0001$. El ingreso per cápita del hogar es igual al total del ingreso del hogar dividido entre los miembros del mismo. El total del ingreso del hogar es la suma del ingreso por seguridad social y laboral, transferencias del gobierno e inter-hogares, rentas por propiedad y otras fuentes. Los datos oficiales fueron extraídos del Dossier de la Unidad de Análisis de Políticas Públicas y Económicas (UDAPE) 2011. 
Figura 32: Comparación con datos oficiales. Pobreza extrema rural

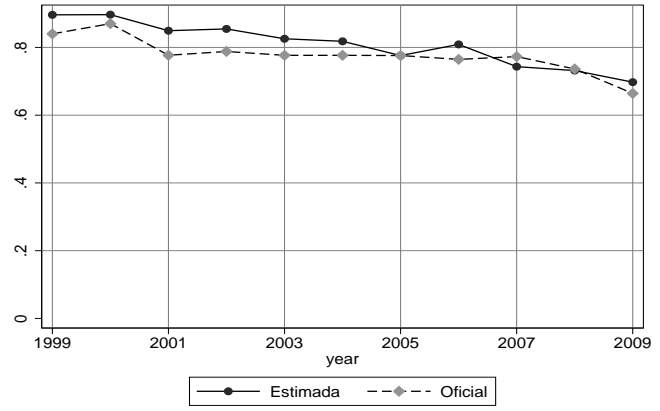

Incidencia en pobreza

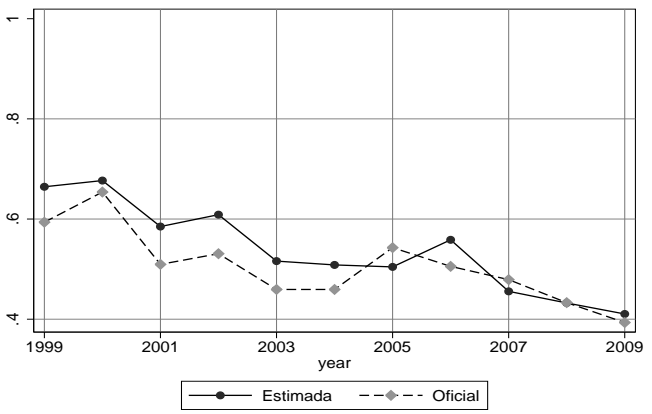

Brecha pobreza

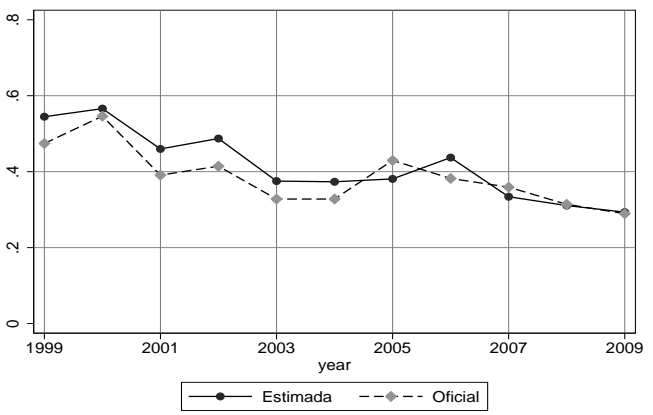

Severidad de la pobreza

Fuente: Estimación del autor basada en la serie armonizada de la Fundación ARU de las encuestas de hogares. Ceros y outliers fueron eliminados de la muestra. Los outliers fueron encontrados a través del algoritmo BACON con $\alpha=0.0001$. El ingreso per cápita del hogar es igual al total del ingreso del hogar dividido entre los miembros del mismo. El total del ingreso del hogar es la suma del ingreso por seguridad social y laboral, transferencias del gobierno e inter-hogares, rentas por propiedad y otras fuentes. Los datos oficiales fueron extraídos del Dossier de la Unidad de Análisis de Políticas Públicas y Económicas (UDAPE) 2011. 
Figura 33: Comparación con datos oficiales. Pobreza moderada rural

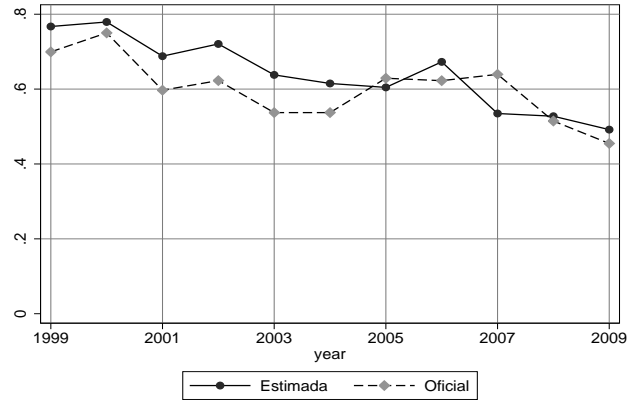

Incidencia en pobreza

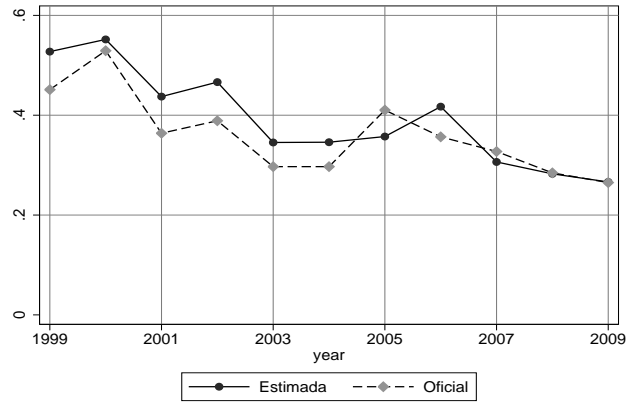

Brecha pobreza

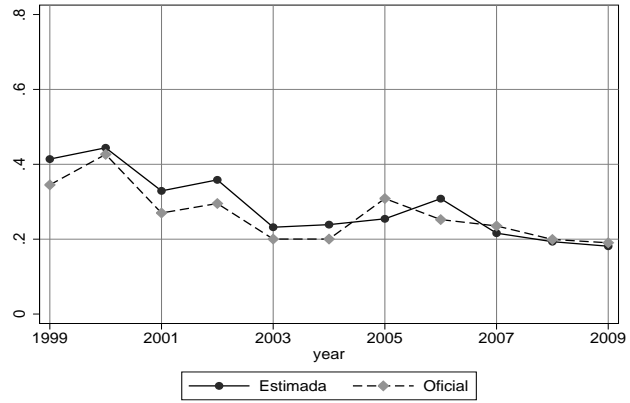

Severidad de la pobreza

Fuente: Estimación del autor basada en la serie armonizada de la Fundación ARU de las encuestas de hogares. Ceros y outliers fueron eliminados de la muestra. Los outliers fueron encontrados a través del algoritmo BACON con $\alpha=0.0001$. El ingreso per cápita del hogar es igual al total del ingreso del hogar dividido entre los miembros del mismo. El total del ingreso del hogar es la suma del ingreso por seguridad social y laboral, transferencias del gobierno e inter-hogares, rentas por propiedad y otras fuentes. Los datos oficiales fueron extraídos del Dossier de la Unidad de Análisis de Políticas Públicas y Económicas (UDAPE) 2011. 
Figura 34: Simulaciones. Pobreza extrema. Bolivia

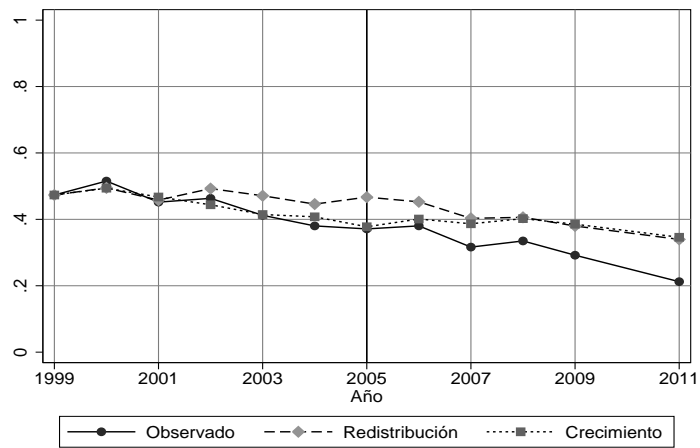

Incidencia en pobreza

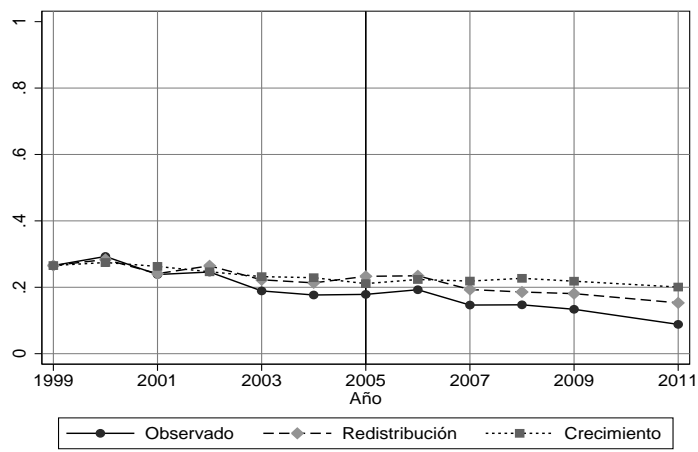

Brecha pobreza

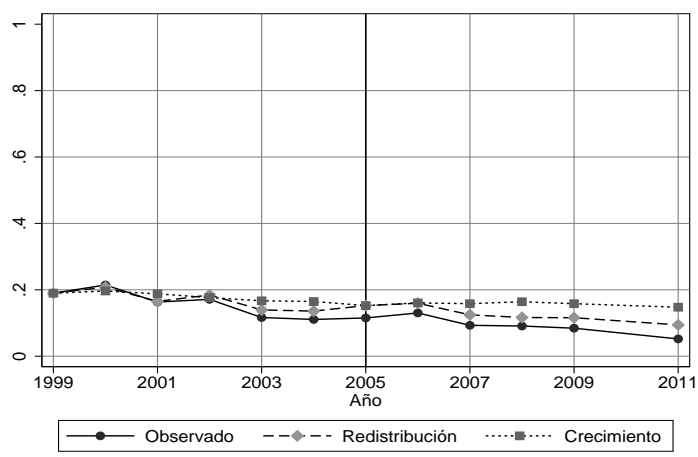

Severidad de la pobreza 
Figura 35: Simulaciones. Pobreza moderada. Bolivia

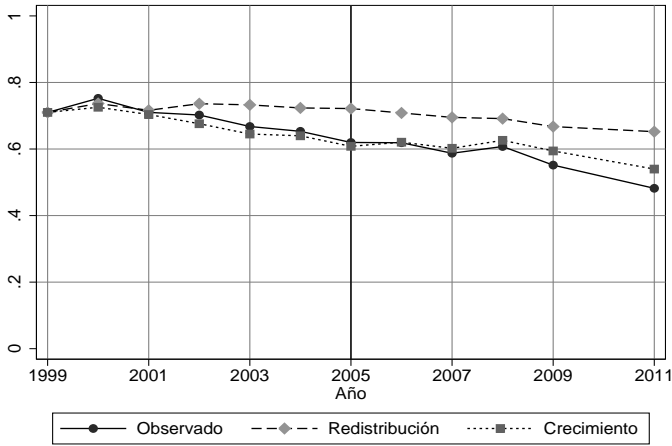

Incidencia en pobreza

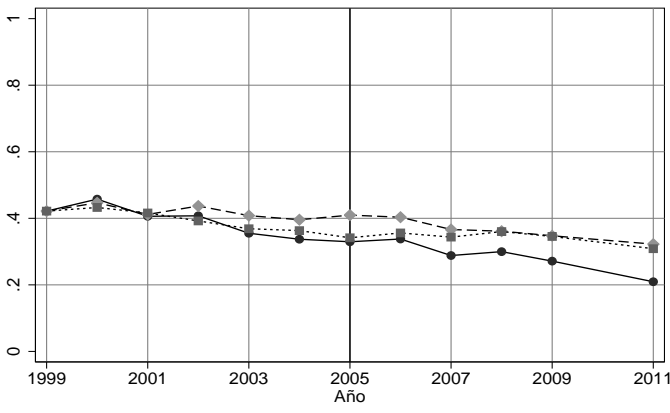

$\longrightarrow$ Observado $\quad--\downarrow-$ Redistribución $\quad \cdots \cdots \cdot \cdots \cdot$ Crecimiento

Brecha pobreza

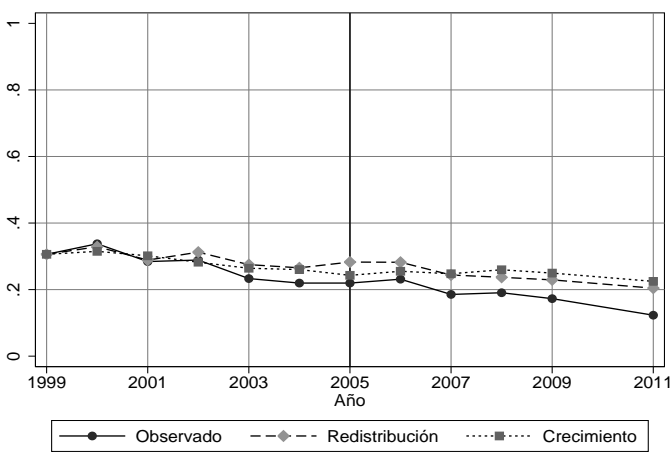

Severidad de la pobreza 
Figura 36: Simulaciones. Pobreza extrema urbana

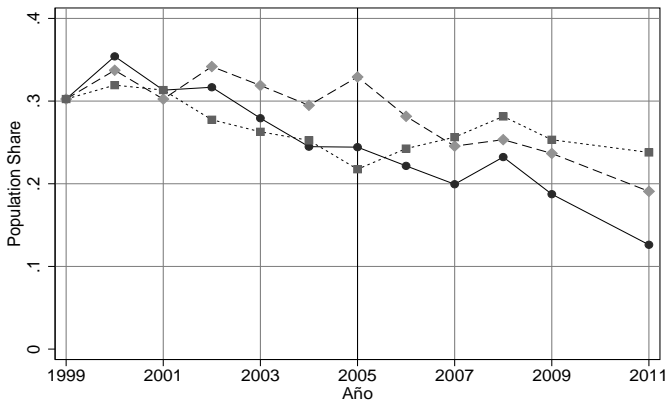

$\longrightarrow$ Observado $\quad--\downarrow--$ Redistribución $\quad \cdots \cdots \cdot \cdots \cdot \cdots$ Crecimiento

Incidencia en pobreza

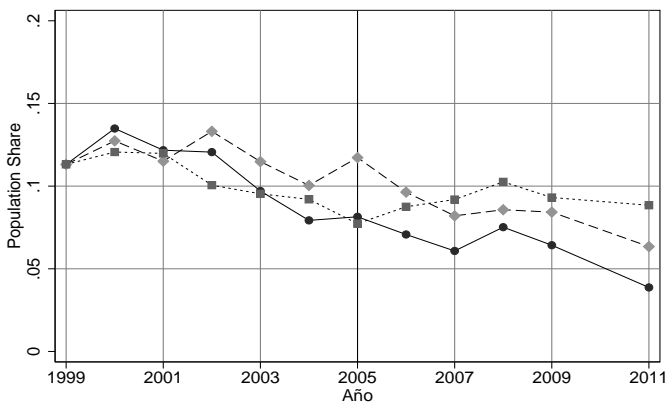

$\longrightarrow$ Observado $\quad--\downarrow--$ Redistribución $\quad \cdots \cdot \cdots \cdot \cdots \cdot$ Crecimiento

Brecha pobreza

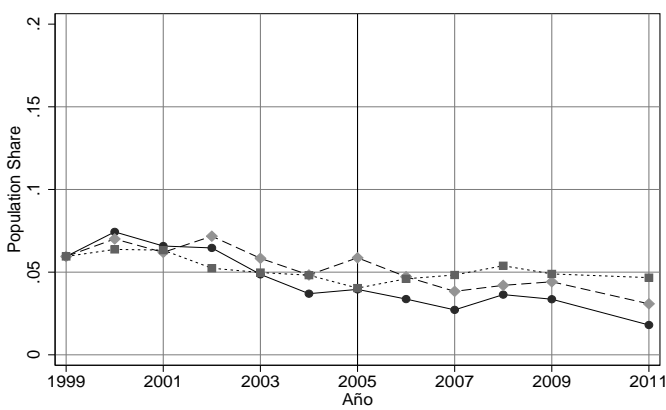

bservado _- - - Redistribución …........ Crecimiento

Severidad de la pobreza 
Figura 37: Simulaciones. Pobreza moderada urbana

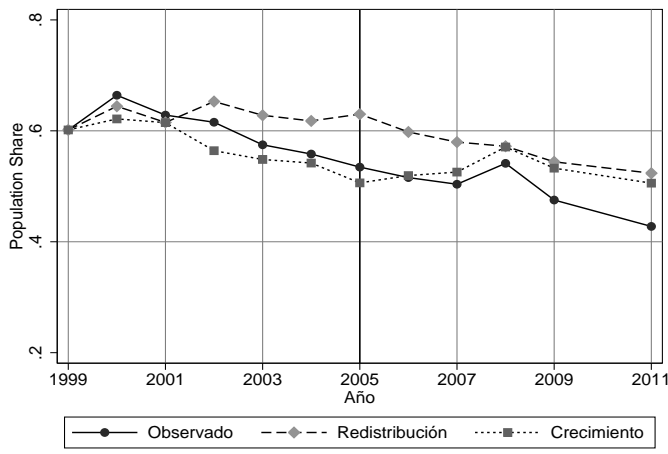

Incidencia en pobreza

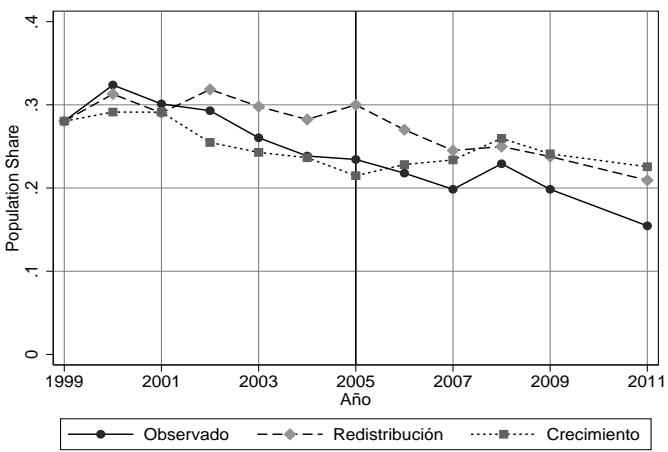

Brecha pobreza

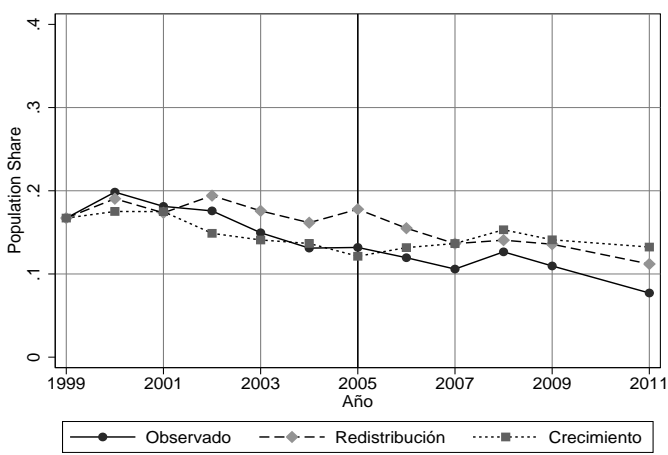

Severidad de la pobreza 
Figura 38: Simulaciones. Pobreza extrema rural

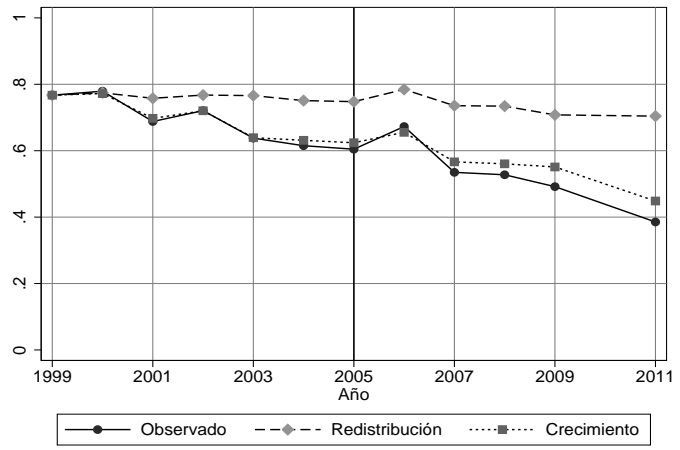

Incidencia en pobreza

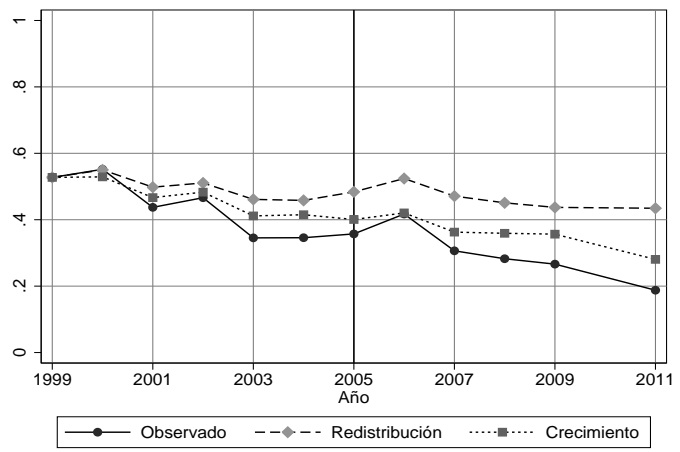

Brecha pobreza

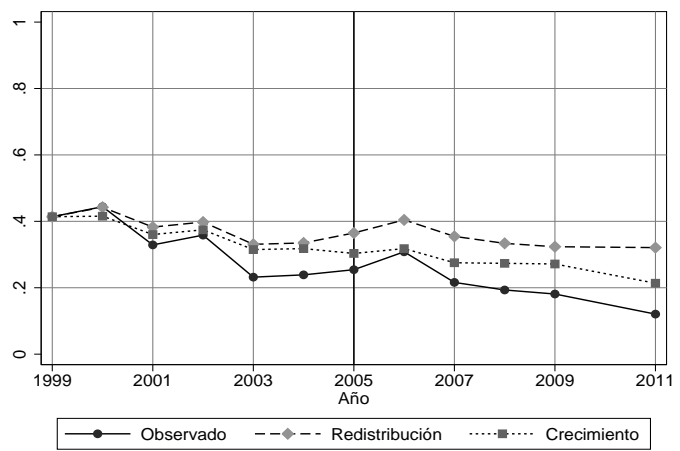

Severidad de la pobreza 
Figura 39: Simulaciones. Pobreza moderada rural

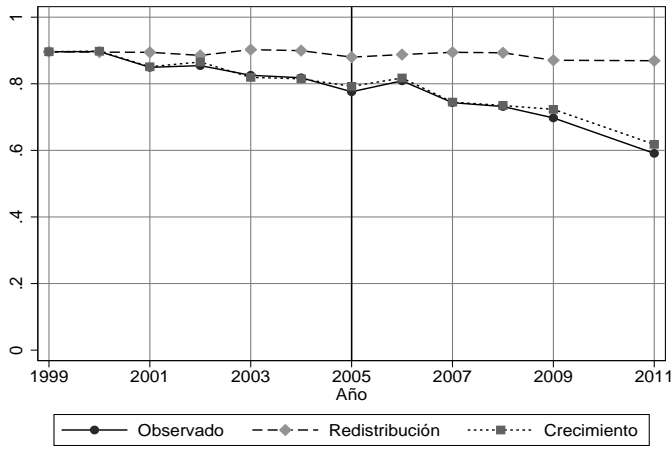

Incidencia en pobreza

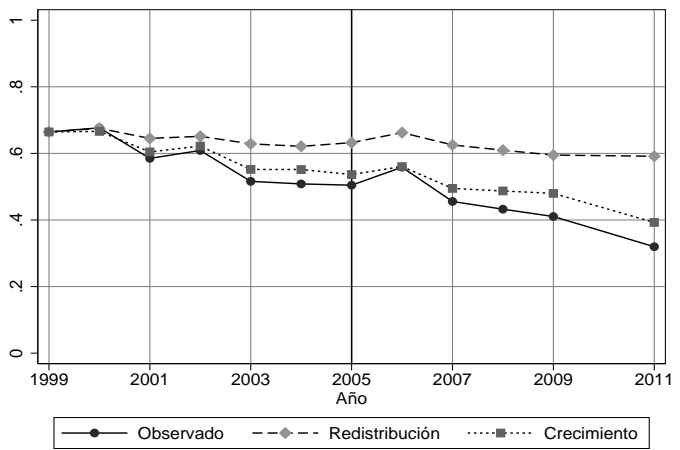

Brecha pobreza

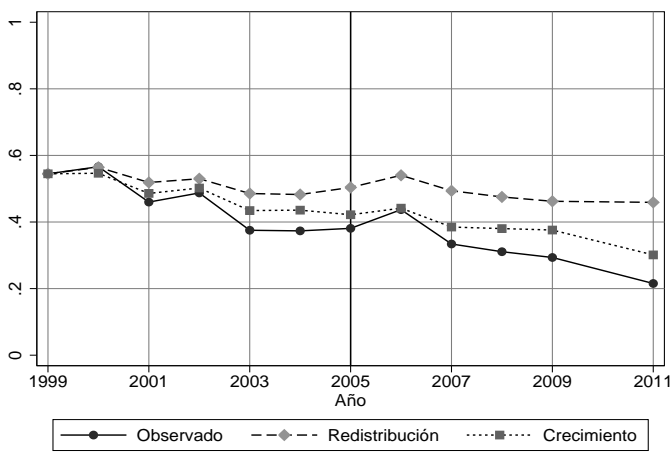

Severidad de la pobreza 
Figura 40: Cambio en dos periodos. Pobreza extrema. Bolivia
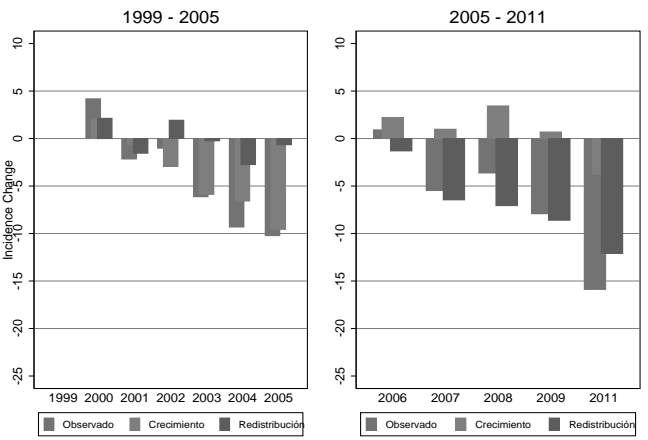

Incidencia en pobreza
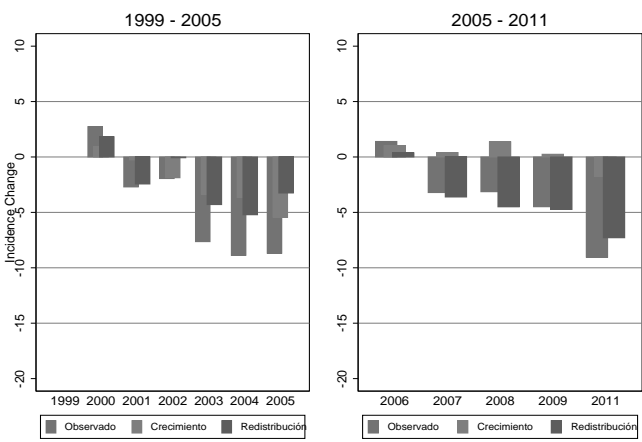

Brecha pobreza
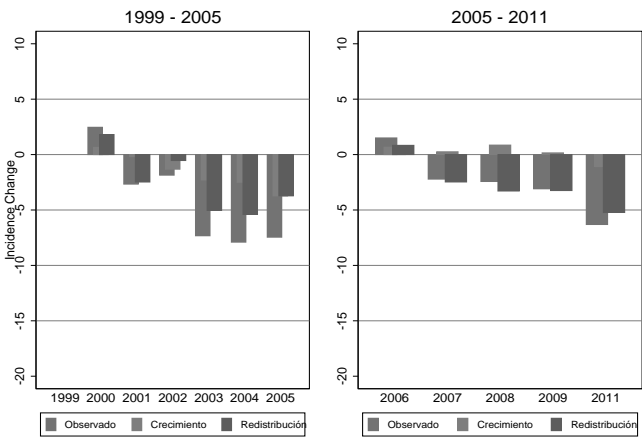

Severidad de la pobreza 
Figura 41: Cambio en dos periodos. Pobreza moderada. Bolivia
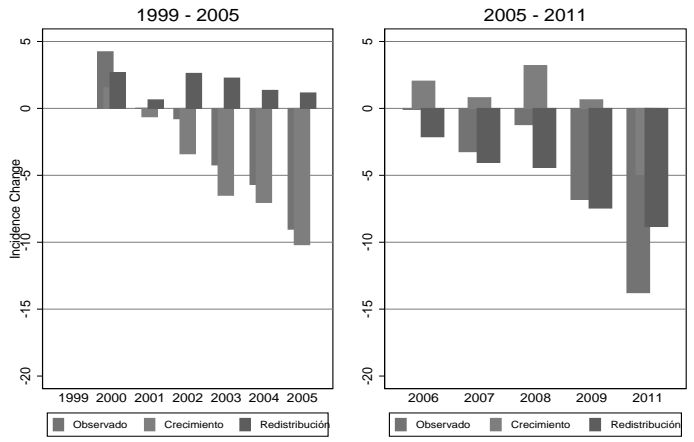

Incidencia en pobreza
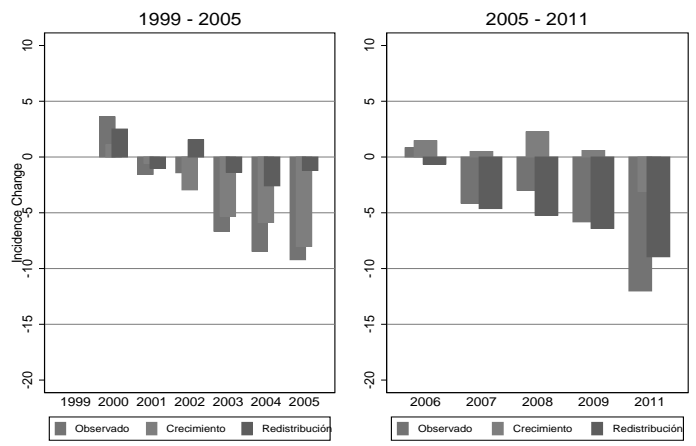

Brecha pobreza

$1999-2005$

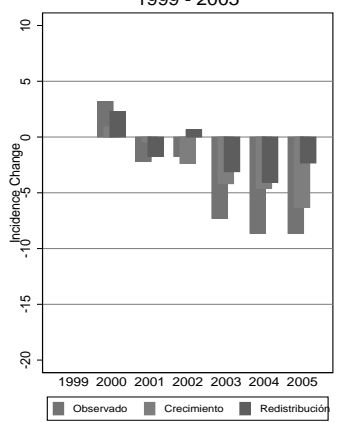

$2005-2011$

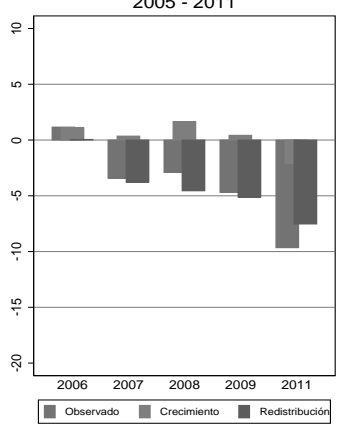

Severidad de la pobreza 
Figura 42: Cambio en dos periodos. Pobreza extrema urbana
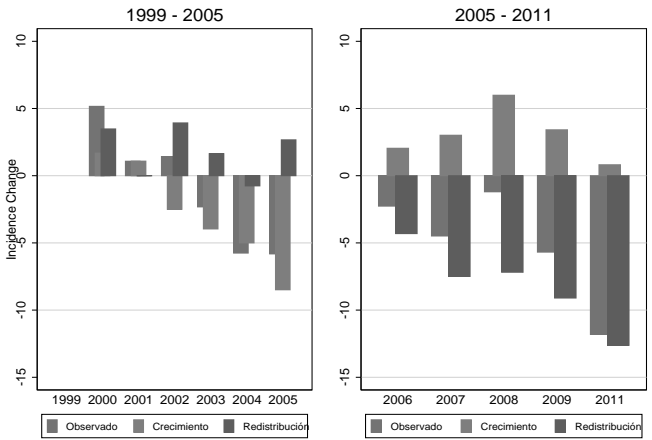

Incidencia en pobreza
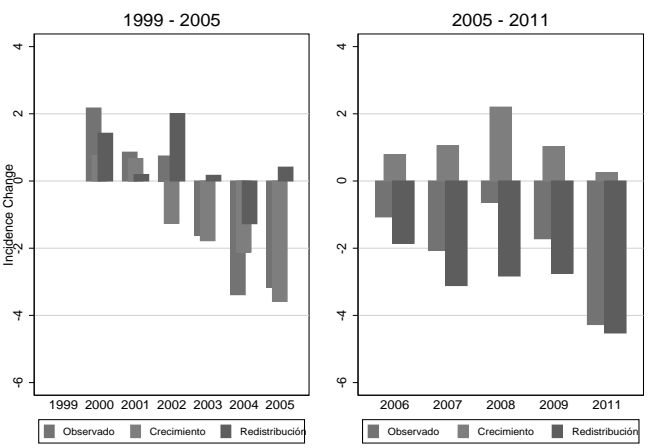

Brecha pobreza
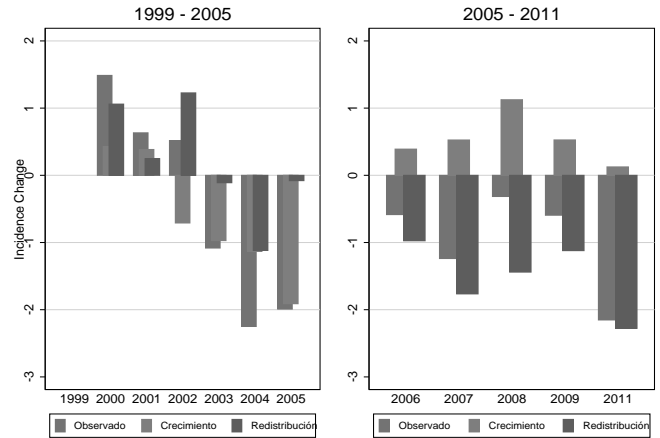

Severidad de la pobreza 
Figura 43: Cambio en dos periodos. Pobreza moderada urbana
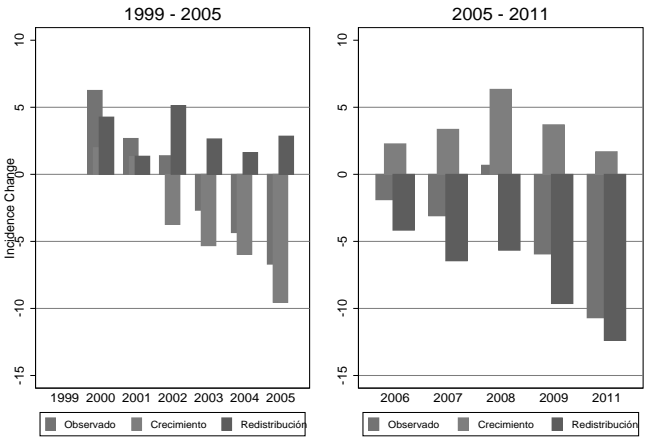

Incidencia en pobreza
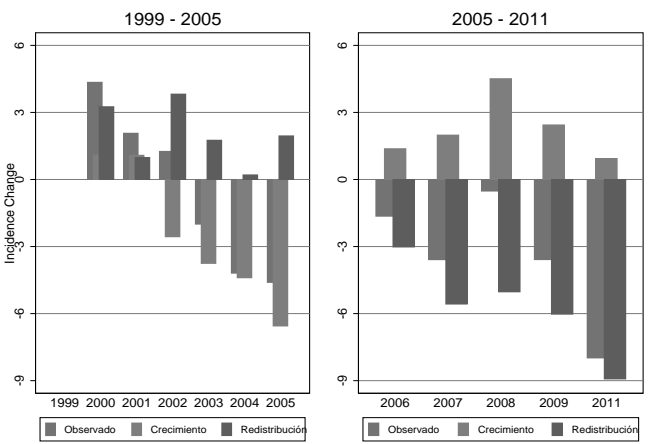

Brecha pobreza

$1999-2005$

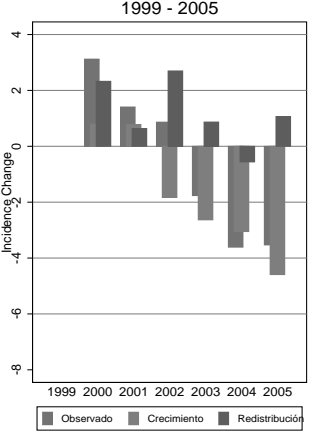

$2005-2011$

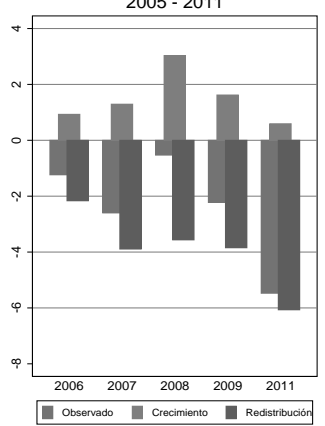

Severidad de la pobreza 
Figura 44: Cambio en dos periodos. Pobreza extrema rural
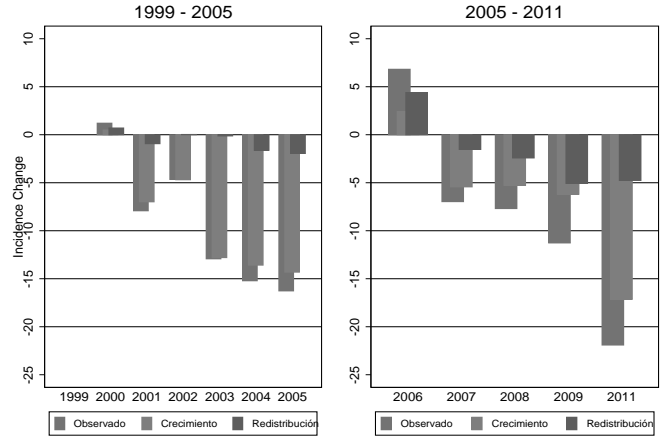

Incidencia en pobreza
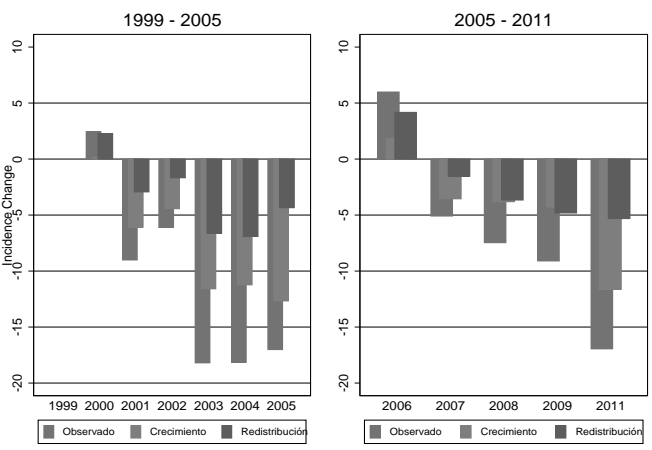

Brecha pobreza

$1999-2005$

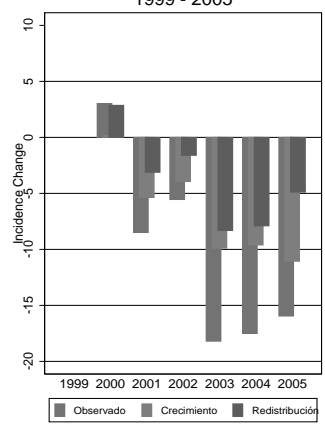

$2005-2011$

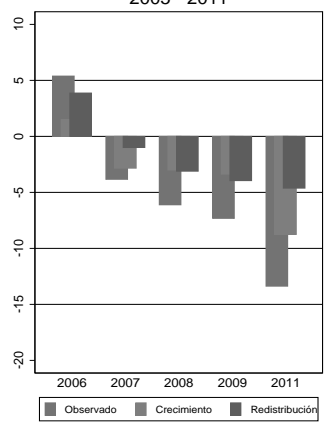

Severidad de la pobreza 
Figura 45: Cambio en dos periodos. Pobreza moderada rural
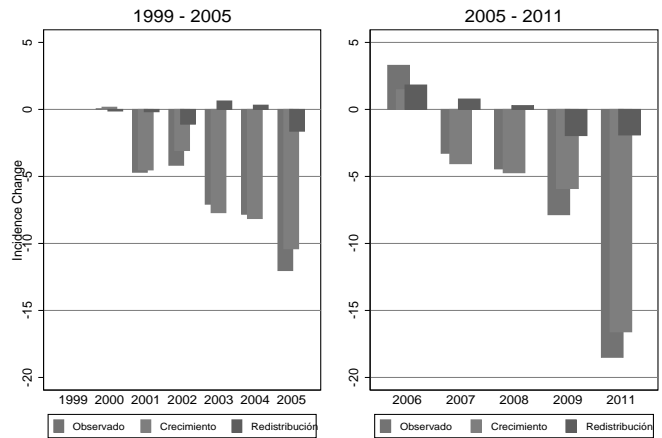

Incidencia en pobreza
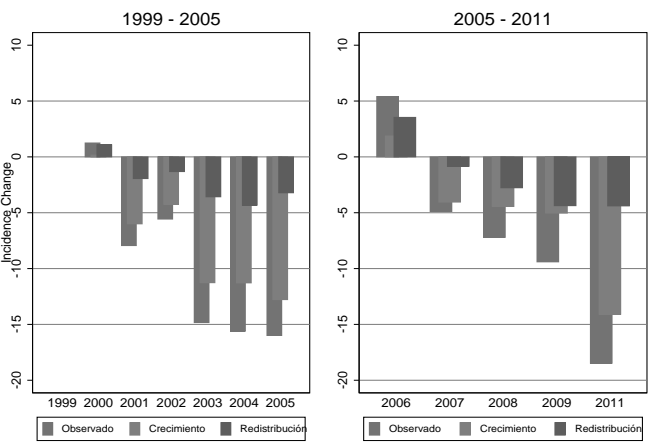

Brecha pobreza
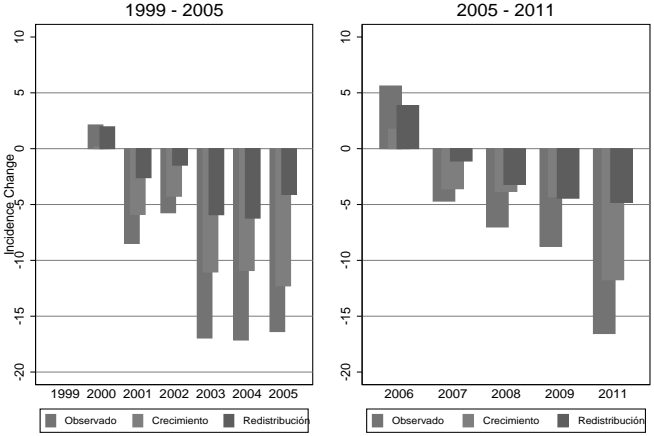

Severidad de la pobreza 